\title{
NIST Interlaboratory Study on the Glycosylation of NISTmAb, a Monoclonal Antibody Reference Material June 2015 to February 2016
}

Maria Lorna A. De Leoz

David L. Duewer

Stephen E. Stein

This publication is available free of charge from: https://doi.org/10.6028/NIST.IR.8186
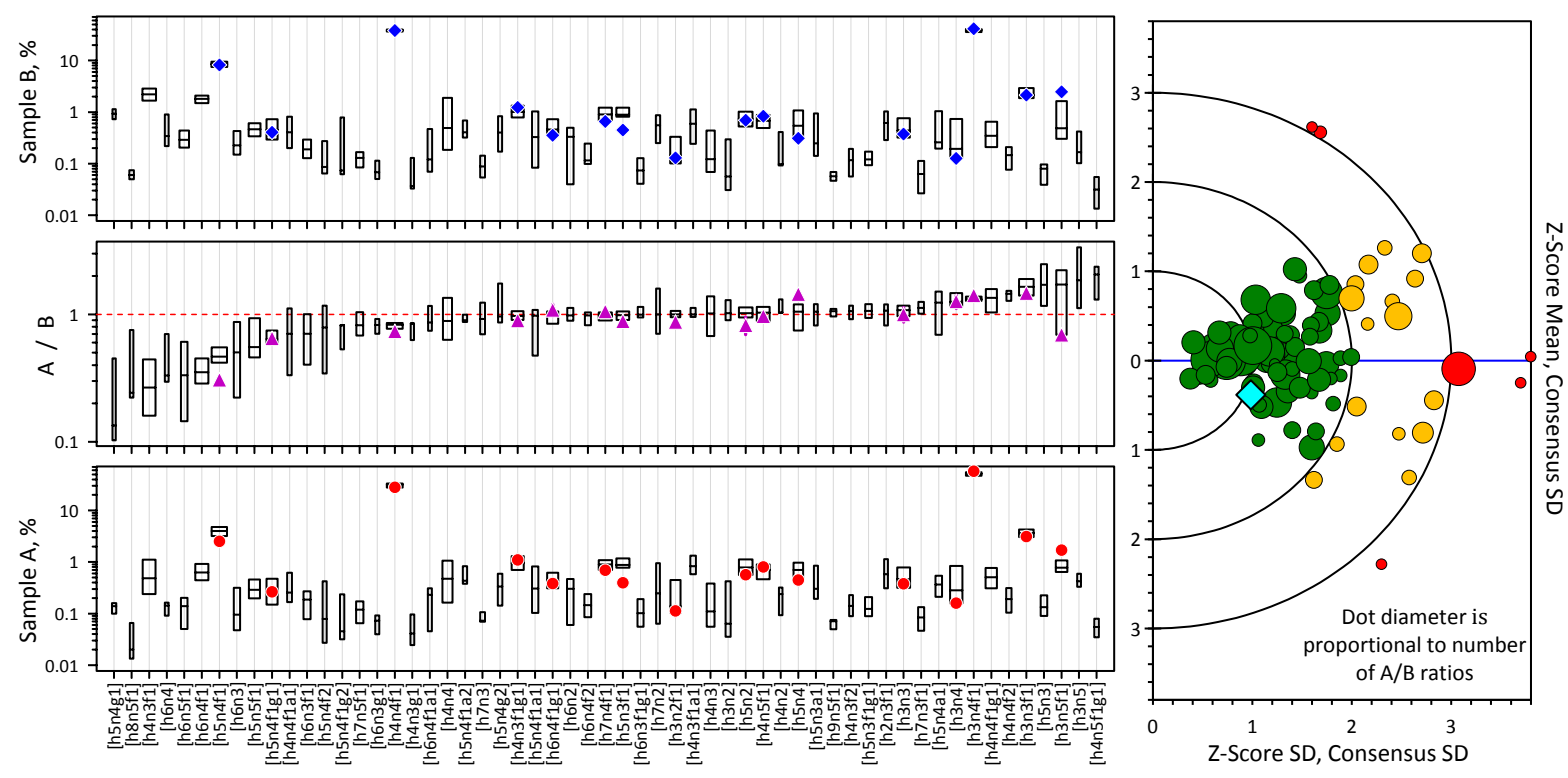

i B, your Mean $\pm S D$

A $\mathrm{A} / \mathrm{B}$, your Mean $\pm \mathrm{SD}$

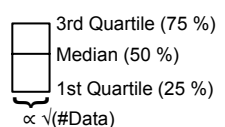

Sample A: modified NISTmAb Sample B: NISTmAb

* Data as reported in 103 reports from 76 laboratories
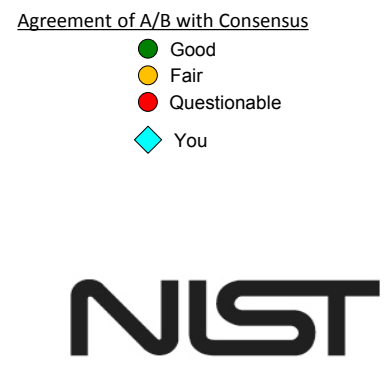

National Institute of Standards and Technology U.S. Department of Commerce 



\section{NIST Interlaboratory Study on the Glycosylation of NISTmAb, a Monoclonal Antibody Reference Material June 2015 to February 2016}

Maria Lorna A. De Leoz Biomolecular Measurement Division Material Measurement Laboratory

David L. Duewer Chemical Sciences Division Material Measurement Laboratory

Stephen E. Stein

Biomolecular Measurement Division Material Measurement Laboratory

This publication is available free of charge from: https://doi.org/10.6028/NIST.IR.8186

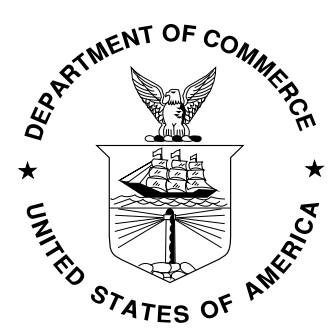

U.S. Department of Commerce Wilbur L. Ross, Jr., Secretary 
(This page intentionally blank) 


\begin{abstract}
The National Institute of Standards and Technology coordinated an interlaboratory study for laboratories that measure glycosylation in monoclonal antibodies. This report describes the design of and results for the NIST Interlaboratory Study on the Glycosylation of NISTmAb, a Monoclonal Antibody Reference Material from 103 reports submitted by 76 laboratories. Two materials were used in the study, 1) the Primary Standard (PS) for NIST Reference Material 8671, NISTmAb, Humanized IgG1 $\kappa$ Monoclonal Antibody, and 2) a material derived from the PS by treatment with galactosidase. The study was conducted in two stages: Stage 1 involved nine selected laboratories who volunteered to assist in final study design; Stage 2 was widely advertised and open to all laboratories. The materials for the study were shipped to participants in two batches: June 2015 and August to September 2015 for Stage 1 and Stage 2, respectively. Participants were requested to provide measurement results by July 30, 2015 (Stage 1) and November 6, 2015 (Stage 2).
\end{abstract}

\title{
Key words
}

Glycan, Glycopeptide, Glycosylation, Glycoform, Glycomics, IgG, Monoclonal Antibody, NISTmAb, RM 8671

\section{Disclaimer}

Certain commercial entities, equipment, or materials may be identified in this document in order to describe an experimental procedure or concept adequately. Such identification is not intended to imply recommendation or endorsement by the National Institute of Standards and Technology, nor is it intended to imply that the entities, materials, or equipment are necessarily the best available for the purpose. 


\section{Table of Contents}

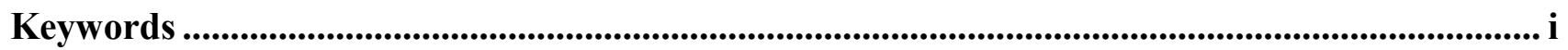

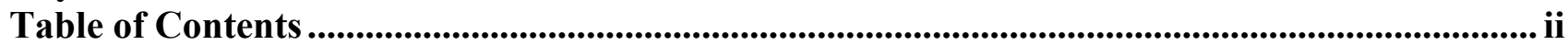

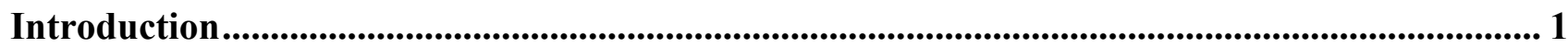

Interlaboratory Study: Glycosylation of Monoclonal Antibodies ................................................ 1

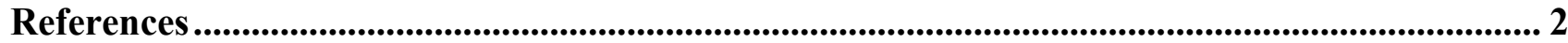

Appendix A. Shipping Package Inserts for the Interlaboratory Study ............................ A-1

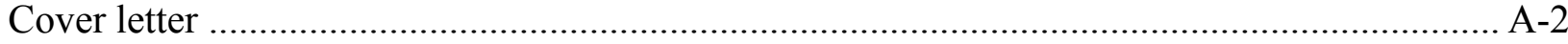

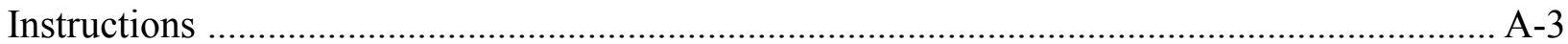

Packing List and Shipment Receipt Confirmation Form ................................................. A-4

Data Reporting Template .................................................................................. A-5

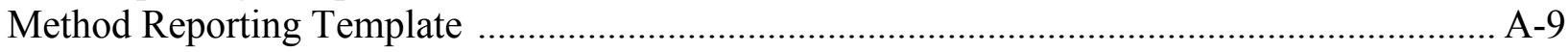

Comments and Suggestions Template .......................................................................... A-12

Appendix B. Final Report for the Interlaboratory Study ............................................ B-1

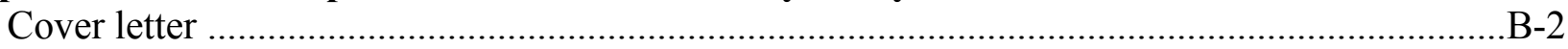

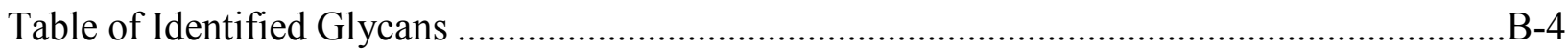

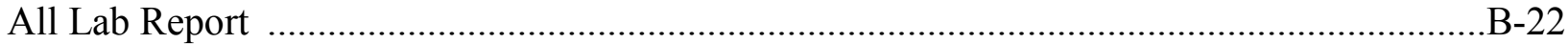

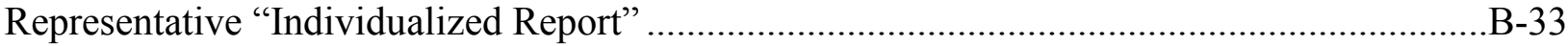




\section{Introduction}

Glycosylation is a critical post-translational modification in monoclonal antibodies [1]. It can impact the safety and efficacy of the drug, including its clearance rates, effector functions, folding, immunogenicity, and solubility. However, glycosylation is inherently heterogeneous and challenging to analyze, leading to a proliferation of analysis methods [2-15]. With the advent of biosimilars and other protein-based drugs, it is important to compare the glycosylation of biologics in an accurate and precise manner [16].

The National Institute of Standards and Technology (NIST) coordinated this interlaboratory study for measurement of glycosylation in monoclonal antibodies. The goals of this study are two-fold:

- to determine measurement variability in identifying and quantifying N-glycans across the glycan measurement community and

- to aid in assigning consensus values for the glycosylation of the recombinant NIST

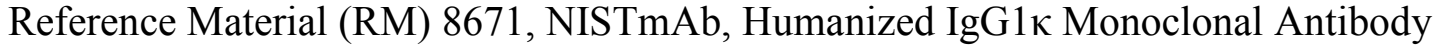
produced in murine-derived cells [17].

Participants used their method of choice to determine glycan content in the control and study materials. Some participants submitted more than one report; each report was assigned a confidential laboratory number. Participants provided their data to NIST, where it was compiled and evaluated for consensus values, within-laboratory precision, and concordance within the glycomics community. NIST provided the participants with a technical summary of reported and derived values from all laboratories, a table of all identified glycans, and an individualized graphical analysis of their performance for the exercise. Participants who have concerns regarding their laboratory's performance were encouraged to consult with the interlaboratory coordinators.

\section{Interlaboratory Study: Glycosylation of Monoclonal Antibodies}

This interlaboratory study was done in two stages: Stage 1 was open to nine selected laboratories that helped fine-tune the study; Stage 2 was open to all laboratories.

Individual units of batch-prepared samples were distributed to each participant: two 0.5-mg (Stage 1) or 0.4-mg (Stage 2) liquid-frozen monoclonal antibody samples for analysis and one 1-mL $25 \mathrm{mmol} / \mathrm{L} \mathrm{L-Histidine} \mathrm{pH} 6.0$ solution for use in reconstituting the two samples. The antibody samples were the Primary Standard (PS) for NIST RM 8671 NISTmAb and a material derived from the PS. The derived material was prepared as a 70:30 by mass mixture of unmodified PS with PS treated with $\beta 1-4$ Galactosidase S (8,000 units/mL, New England Biolabs, Ipswich, MA).

Unless multiple vials were requested, participants received one vial of each sample. These samples were shipped on dry ice to 90 laboratories in June 2015 (Stage 1) or August-September 2015 (Stage 2). Participants were requested to provide measurement results by July 30, 2015 and November 6, 2015 for Stage 1 and Stage 2, respectively. However, 32 laboratories asked to delay their submission of reports. The last report was received on September 2, 2015 for Stage 1 and February 1, 2016 for Stage 2. A total of 103 reports were submitted by 76 laboratories. The communication materials included in the sample shipment and emailed to participants are provided in Appendix A.

Participants were requested to report methods and percent abundance values for all glycans found in the two samples using method and data reporting templates provided along with the samples. The 
method reporting template contained drop down boxes of common methods and parameters for identification and quantification, and spaces to list other techniques or parameters. The data reporting template listed 16 glycans in Stage 1 and 54 glycans in Stage 2 and space to report other glycans not listed in the template. Not all participants reported values for all the target glycans, and many participants reported values for non-target glycans.

The final report delivered to every participant in the interlaboratory study consists of four documents, as shown in Appendix B:

- A cover letter containing a brief description of the samples and other three documents.

- An "All-Lab Report" that summarizes reported and derived values for Samples A and B, and the $\mathrm{A} / \mathrm{B}$ ratio.

- A "Table of Identified Glycans" showing identifiers, compositions, and structures for all glycans reported in any data set.

- An "Individualized Report" that graphically analyzes each participant's results for all analytes reported by at least six participants. It contains boxplots of Samples A and B, and the $\mathrm{A} / \mathrm{B}$ ratio, and a target plot summary for the $\mathrm{A} / \mathrm{B}$ ratio. This report also provides a graphical summary of each participant's measurement comparability, including glycan composition counts and sums, repeatability, limits of reporting, minimum reported values, and consensus values.

\section{References}

[1] Prien, JM, et al. (2015) Orthogonal Technologies for NISTmAb N-Glycan Structure Elucidation and Quantitation. State-of-the-Art and Emerging Technologies for Therapeutic Monoclonal Antibody Characterization, Vol 2: Biopharmaceutical Characterization: The Nistmab Case Study, 1201: 185-235.

[2] Ruhaak, LR, Zauner, G, Huhn, C, Bruggink, C, Deelder, AM, Wuhrer, M (2010) Glycan labeling strategies and their use in identification and quantification. Anal Bioanal Chem, 397(8): 3457-81. https://doi.org/10.1007/s00216-010-3532-z.

[3] Rosati, S, Yang, Y, Barendregt, A, Heck, AJ (2014) Detailed mass analysis of structural heterogeneity in monoclonal antibodies using native mass spectrometry. Nat Protoc, 9(4): 96776. https://doi.org/10.1038/nprot.2014.057.

[4] Song, T, Ozcan, S, Becker, A, Lebrilla, CB (2014) In-Depth Method for the Characterization of Glycosylation in Manufactured Recombinant Monoclonal Antibody Drugs. Analytical Chemistry, 86(12): 5661-5666. https://doi.org/10.1021/ac501102t.

[5] Mechref, Y, Hu, YL, Desantos-Garcia, JL, Hussein, A, Tang, HX (2013) Quantitative Glycomics Strategies. Molecular \& Cellular Proteomics, 12(4): 874-884. https://doi.org/10.1074/mcp.R112.026310.

[6] Zhang, H, Ashline, DJ, Reinhold, VN (2014) Tools to MSn Sequence and Document the Structures of Glycan Epitopes. Discov Subtleties Sugars (2013), 2013: 117-131.

[7] Beck, A, Wagner-Rousset, E, Ayoub, D, Van Dorsselaer, A, Sanglier-Cianferani, S (2013) Characterization of therapeutic antibodies and related products. Anal Chem, 85(2): 715-36. https://doi.org/10.1021/ac3032355.

[8] Hong, Q, Lebrilla, CB, Miyamoto, S, Ruhaak, LR (2013) Absolute quantitation of immunoglobulin $G$ and its glycoforms using multiple reaction monitoring. Anal Chem, 85(18): 8585-93. https://doi.org/10.1021/ac4009995. 
[9] Triguero, A, Cabrera, G, Royle, L, Harvey, DJ, Rudd, PM, Dwek, RA, Bardor, M, Lerouge, P, Cremata, JA (2010) Chemical and enzymatic $N$-glycan release comparison for $N$-glycan profiling of monoclonal antibodies expressed in plants. Anal Biochem, 400(2): 173-83. https://doi.org/10.1016/j.ab.2010.01.027.

[10] Stadlmann, J, Pabst, M, Kolarich, D, Kunert, R, Altmann, F (2008) Analysis of immunoglobulin glycosylation by LC-ESI-MS of glycopeptides and oligosaccharides. Proteomics, 8(14): 2858-71. https://doi.org/10.1002/pmic.200700968.

[11] Wagner-Rousset, E, Fekete, S, Morel-Chevillet, L, Colas, O, Corvaia, N, Cianferani, S, Guillarme, D, Beck, A (2017) Development of a fast workflow to screen the charge variants of therapeutic antibodies. J Chromatogr A, 1498: 147-154. https://doi.org/10.1016/j.chroma.2017.02.065.

[12] Stoll, D, Danforth, J, Zhang, K, Beck, A (2016) Characterization of therapeutic antibodies and related products by two-dimensional liquid chromatography coupled with UV absorbance and mass spectrometric detection. J Chromatogr B Analyt Technol Biomed Life Sci, 1032: 51-60. https://doi.org/10.1016/j.jchromb.2016.05.029.

[13] Shubhakar, A, Kozak, RP, Reiding, KR, Royle, L, Spencer, DI, Fernandes, DL, Wuhrer, M (2016) Automated High-Throughput Permethylation for Glycosylation Analysis of Biologics Using MALDI-TOF-MS. Anal Chem, 88(17): 8562-9. https://doi.org/10.1021/acs.analchem.6b01639.

[14] Reusch, D, Haberger M, Maier B, Maier M, Kloseck R, Zimmermann B, Hook M, Szabo Z, Tep S, Wegstein J, Alt N, Bulau P Wuhrer M. (2015) Comparison of methods for the analysis of therapeutic immunoglobulin G Fc-glycosylation profiles--part 1: separation-based methods. MAbs, 7(1): 167-79. https://doi.org/10.4161/19420862.2014.986000.

[15] Reusch, D, Haberger M, Maier B, Gassner J, Hook M, Wagner K, Bonnington L, Bulau P, Wuhrer M (2015) Comparison of methods for the analysis of therapeutic immunoglobulin $G$ Fc-glycosylation profiles-Part 2: Mass spectrometric methods. MAbs, 7(4): 732-42. https://doi.org/10.1080/19420862.2015.1045173.

[16] Huhn, C, Selman, MH, Ruhaak, LR, Deelder, AM, Wuhrer, M (2009) IgG glycosylation analysis. Proteomics, 9(4): 882-913. https://doi.org/10.1002/pmic.200800715.

[17] National Institute of Standards and Technology Standard Reference Materials Program (2016) Report of Investigation: Reference Material 8671 NISTmAb, Humanized IgG1 $\kappa$ Monoclonal Antibody. NIST, Gaithersburg, MD, USA. https://www-s.nist.gov/srmors/view_cert.cfm?srm=8671 


\section{Appendix A. Shipping Package Inserts for the Interlaboratory Study}

The following six items were included in each package shipped to each participant:

- Cover letter

- Instructions

- Packing List and Shipment Receipt Confirmation Form

- Data Reporting Template

- Method Reporting Template

- Comments Template

A cover letter describing the interlaboratory study, instructions, packing list, method, data and comment reporting sheets were enclosed in a sealed waterproof bag placed at the top of the shipping box, between the cardboard covering and the foam insulation. All the shipping package inserts were also sent by email as one Microsoft Excel file with multiple tabs to each participant. 


\section{Cover Letter}

\section{NIST Interlaboratory Study on Glycosylation Analysis Welcome Packet}

August 27, 2015

Name

Address

Lab \#:

Dear Colleague,

Welcome to the NIST Interlaboratory Study on Glycosylation Analysis. Thank you for agreeing to participate in this endeavor. Alteration in glycosylation may significantly modify the biological activity of monoclonal antibodies. Thus, analysis of their glycoforms is essential, whether it is a batch-to-batch analysis of a drug candidate, comparison of the glycan profile of a biosimilar, or a complete glycomics profiling of a new drug. There are several published methods to quantify and identify glycoforms in proteins, but only a handful of multi-lab studies to assess the performance of these various approaches. The goals of this study are two-fold: 1) to determine measurement variability in identifying and quantifying $\mathrm{N}$-glycans across laboratories and 2) to aid in assigning consensus values for the glycosylation of the NISTmAb reference material, a soon-to-be-released well-characterized monoclonal antibody reference material.

Each laboratory is assigned a laboratory number so that study results may be viewed and discussed openly in anonymity. Your lab number is shown above. Please use this number on the forms for submission of results. Your lab number remains confidential.

Sample shipment will occur on August 31,2015. We request that the resulting data be returned on or before November 6, 2015. Your laboratory will receive two frozen monoclonal antibody samples, Sample A (white) and Sample B (blue), for glycosylation analysis using your own method. Both samples are humanized IgG1k expressed in murine suspension culture. The samples are "drug-like substances" not for human use. The samples are $0.4 \mathrm{mg}$ each, with a concentration of $100 \mathrm{mg} / \mathrm{mL}$. You will also receive a vial containing $25 \mathrm{mmol} / \mathrm{L}$ L-Histidine $\mathrm{pH} 6.0$ solution (yellow) that you may use (optional) to reconstitute the two samples.

We ask you to perform a glycosylation analysis in triplicate using your own method for each of the two samples. The Excel file provided has two tabs called "Data Reporting" and "Method Reporting" to report your data and method, respectively. If you choose to use more than one method, we ask that you create a separate file for each. Results should be attached in an email to lorna.deleoz@nist.gov with the subject "NIST Interlab Results."

Please feel free to contact Lorna at (301) 975-6731 or lorna.deleoz@nist.gov if you have questions.

Again, many thanks for your participation.

Sincerely,

M. Lorna A. De Leoz, Ph.D.

Principal Investigator

NIST Interlaboratory Study on Glycosylation Analysis

Biomolecular Measurement Division

National Institute of Standards and Technology

Gaithersburg, Maryland, USA 20899-8362
Stephen E. Stein, Ph.D.

Group Leader

Biomolecular Measurement Division

National Institute of Standards and Technology

Gaithersburg, Maryland, USA 20899-8362 


\section{Instructions}

\section{NIST Interlaboratory Study on Glycosylation Analysis Instructions}

August 27, 2015

Dear Colleague,

Enclosed are samples for the NIST Interlaboratory Study on Glycosylation Analysis. Sample details are provided below:

Sample A: white label, frozen liquid, $0.4 \mathrm{mg}, 100 \mathrm{mg} / \mathrm{mL} \mathrm{mAb}$

Sample B: blue label, frozen liquid, $0.4 \mathrm{mg}, 100 \mathrm{mg} / \mathrm{mL} \mathrm{mAb}$

Buffer: yellow label, frozen liquid, $1 \mathrm{~mL}, 25 \mathrm{mmol} / \mathrm{L}$ L-Histidine, $\mathrm{pH} 6.0$

The package for this study consists of two vials of monoclonal antibody samples, Sample A (white) and Sample B (blue), one vial of L-Histidine solution (yellow) which you may use to reconstitute the samples, and a welcome packet consisting of a letter, instructions, packing list/shipment receipt confirmation form, and data, method, and comment forms to report your results. As soon as you receive the samples, please return the filled shipment receipt confirmation form (third tab) to us.

Please perform a glycosylation analysis in triplicate using your own method for Sample A and Sample B. After completing your analysis, please enter the percent abundances of the glycans and their standard deviations in the "Data Reporting" tab. Also include the percent abundances for each replicate. If a value obtained is below your limit of detection or quantification, please indicate this result on the form as "ND" (not detected) or "NQ" (not quantified), respectively.

Please describe your method in the "Method Reporting" tab by filling in as much information as you can. The last tab, "Comments," is for your feedback on all the stages of the interlab study, including shipping, samples, data reporting, and analysis. Your input, expertise, and feedback is extremely valuable for future studies.

We request that the filled Excel sheets be returned to us as an email attachment to lorna.deleoz@nist.gov (Subject: NIST Interlab Results) on or before November 6, 2015. Please let me know if this schedule would pose problems for your laboratory.

Please feel free to contact Lorna at (301) 975-6731 or lorna.deleoz@nist.gov if you have questions.

Again, many thanks for your participation.

Sincerely,

M. Lorna A. De Leoz, Ph.D.

Principal Investigator

NIST Interlaboratory Study on Glycosylation Analysis

Biomolecular Measurement Division

National Institute of Standards and Technology

Gaithersburg, Maryland, USA 20899-8362
Stephen E. Stein, Ph.D.

Group Leader

Biomolecular Measurement Division

National Institute of Standards and Technology

Gaithersburg, Maryland, USA 20899-8362 


\section{Packing List and Shipment Receipt Confirmation Form}

\section{NIST Interlaboratory Study on Glycosylation Analysis \\ Packing List and Shipment Receipt Confirmation Form}

This box contains: one vial each of the following:
Please fill in only the green boxes and return to lorna.deleoz@nist.gov upon receipt of samples.
Vial

Sample A Sample B

Buffer
Form

Liquid frozen

Liquid frozen

Liquid frozen
Amount

$0.4 \mathrm{mg}$

$0.4 \mathrm{mg}$

$1 \mathrm{~mL}$
Label Color

White

Blue

Yellow

\section{Description}

$100 \mathrm{mg} / \mathrm{mL} \mathrm{mAb}$

$100 \mathrm{mg} / \mathrm{mL} \mathrm{mAb}$

Please:

1) Open the pack immediately.

2) Check that the box contains all of the above vials.

3) Check if the vials are intact.

4) Store the samples at $-20^{\circ} \mathrm{C}$ or below until analysis.

5) Email lorna.deleoz@nist.gov the following information (Subject: NIST Interlab Shipment Receipt):
A) Lab \#
B) Date this shipment arrived:
C) Are all 3 vials intact? Yes / No
If "No," which one(s) were damaged?
D) Was there any dry ice left in cooler? Yes/No
E) Did the samples arrive frozen? Yes/No
F) At what temperature are you storing the samples?
G) When do you anticipate analyzing these samples?

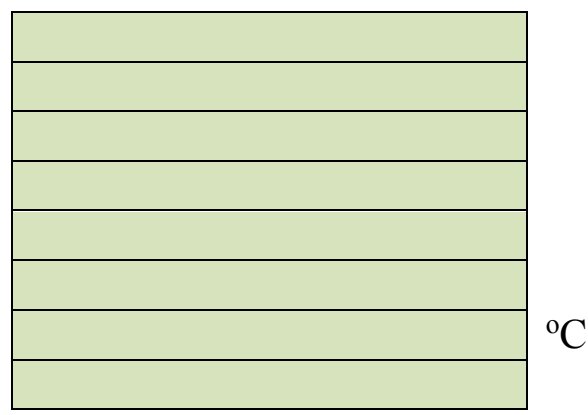

Your prompt return of this information to lorna.deleoz@nist.gov is appreciated.

Please contact Dr. M. Lorna De Leoz at (301) 975-6731 or lorna.deleoz@nist.gov if you have questions or concerns.

Thank you. 


\section{Data Reporting Template}

NIST Interlaboratory Study on Glycosylation Analysis

Data Reporting Template, page 1 of 4

Lab \#:

Report \#:

Total \# of Reports Submitted:

Please refer to the instructions before entering any data. Fill in as much of the green boxes to report your results. NOT ALL GLYCANS MAY BE PRESENT IN THE SAMPLE. Please do not reorder, edit, or delete any of the 54 glycans. If you found glycans not listed in the table, please add them below the line "List other glycans below."

Please use the glycan analysis method you normally use. If you obtained data from more than one method, please save the data and methods for each additional method in a new, renamed Excel file. If you acquired more than three replicates, you may add columns in the raw data section. If a value obtained is below your limit of detection or quantification, please indicate this result on the form as "ND" (not detected) or "NQ" (not quantified), respectively. Further guidance is shown when you hover your mouse on cells with red triangles on the upper right corner. Note that many cells are annotated.

Please double check entries into this table! It is useful to have a second person confirm data entry. If you have questions on any of the boxes, please contact Dr. M. Lorna De Leoz (lorna.deleoz@nist.gov or (301) 975-6731) for clarification. 


\section{NIST Interlaboratory Study on Glycosylation Analysis}

Data Reporting Template, page 2 of 4

\begin{tabular}{|c|c|c|c|c|c|c|c|c|c|c|c|c|c|c|c|c|c|}
\hline & \multicolumn{4}{|c|}{ DESCRIPTION: GLYCAN IDENTITY } & \multicolumn{4}{|c|}{ RESULTS: GLYCAN QUANTIFICATION } & \multicolumn{6}{|c|}{ RAW DATA: GLYCAN QUANTIFICATION } & \multicolumn{3}{|c|}{ COMMENTS: } \\
\hline & \multicolumn{3}{|c|}{ Glycan Identity } & \multirow[b]{2}{*}{ Other Info } & \multicolumn{2}{|l|}{ Sample A } & \multicolumn{2}{|c|}{ Sample B } & \multicolumn{3}{|c|}{ Sample A, \% Abundance } & \multicolumn{3}{|c|}{ Sample B, \% Abundance } & \multirow[b]{2}{*}{$\begin{array}{c}\text { Uncertainty } \\
\text { in Identity }\end{array}$} & \multirow{2}{*}{$\begin{array}{c}\text { Uncertainty } \\
\text { in } \\
\text { Abundance }\end{array}$} & \multirow[b]{2}{*}{$\begin{array}{c}\text { Other } \\
\text { Comments }\end{array}$} \\
\hline & $\begin{array}{l}\text { Common Names } \\
\text { [Composition] }\end{array}$ & $\begin{array}{c}\text { CFG } \\
\text { Structure }\end{array}$ & $\begin{array}{c}\text { Oxford } \\
\text { Structure }\end{array}$ & & $\begin{array}{c}\% \\
\text { Abundance }\end{array}$ & SD & $\begin{array}{c}\% \\
\text { Abundance }\end{array}$ & SD & $\begin{array}{c}\text { Replicate } \\
1\end{array}$ & $\begin{array}{c}\text { Replicate } \\
2\end{array}$ & $\begin{array}{c}\text { Replicate } \\
3\end{array} \mid$ & $\begin{array}{c}\text { Replicate } \\
1\end{array}$ & $\begin{array}{c}\text { Replicate } \\
2\end{array}$ & Replicate & & & \\
\hline 1 & $\begin{array}{l}\text { 1. GOF / FA2 } \\
{[\mathrm{h} 3 \mathrm{n} 4 \mathrm{f} 1]}\end{array}$ & $=\infty .1$ & $=-\infty$ & $\begin{array}{l}\text { NGA2F;(GICNAc) } \\
\text { 2Man3(Fuc)(Glc } \\
\text { NAc)2:Mannotri }\end{array}$ & & & & & & & & & & & & & \\
\hline 2 & $\begin{array}{l}\text { 2. G1F/ FA2G1 } \\
\text { [h4n4f1] }\end{array}$ & 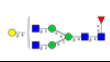 & $\therefore$ & \begin{tabular}{|l} 
NA2G1F;Gal(Glc \\
NAc)2(Man)3(GI \\
CNAc)2Fuc;Asial
\end{tabular} & & & & & & & & & & & & & \\
\hline & $\begin{array}{l}\text { 2a. G1F(1,6)/F(6)A2[6]G(4)1 } \\
\text { [h4n4f1] }\end{array}$ & $=0$ &.. & $\begin{array}{l}\text { NA2G1F;Gal(GIc } \\
\text { NAc)2(Man)3(GI } \\
\text { CNAc)2Fuc;Asial }\end{array}$ & & & & & & & & & & & & & \\
\hline & $\begin{array}{l}\text { 2b. G1F(1,3) or } F(6) A 2[3] G(4) 1 \\
\text { [h4n4f1] }\end{array}$ & $\because$ & $\therefore$ & $\begin{array}{l}\text { NA2G1F;Gal(Glc } \\
\text { NAc)2(Man)3(GI } \\
\text { cNAc)2Fuc;Asial }\end{array}$ & & & & & & & & & & & & & \\
\hline 3 & $\begin{array}{l}\text { 3. G2F / FA2G2 or G1F+1aGal } \\
\text { [h5n4f1] }\end{array}$ & & $\therefore$ & $\begin{array}{l}\text { NA2F;(Gal)2(Glc } \\
\text { NAc)2(Man)3(GI } \\
\text { CNAc)2Fuc;Mann }\end{array}$ & & & & & & & & & & & & & \\
\hline & $\begin{array}{l}\text { 3a. G2F / F(6)A2G(4)2 } \\
\text { [h5n4f1] }\end{array}$ & $\ldots$ & $\because \cdots$ & $\begin{array}{l}\text { NA2F;(Gal)2(Glc } \\
\text { NAc)2(Man)3(GI } \\
\text { cNAc)2Fuc;Mann }\end{array}$ & & & & & & & & & & & & & \\
\hline & $\begin{array}{l}\text { 3b. G1F+1aGal / F(G)A2G1Ga1 } \\
\text { [h5n4f1] }\end{array}$ & & $: \cdots$ & $\begin{array}{l}\text { NA2F;(Gal)2(Glc } \\
\text { NAc)2(Man)3(GI } \\
\text { cNAc)2Fuc;Mann }\end{array}$ & & & & & & & & & & & & & \\
\hline 4 & $\begin{array}{l}\text { 4. GOF-N/ FA1 } \\
\text { [h3n3f1] }\end{array}$ & & $\therefore$ & & & & & & & & & & & & & & \\
\hline & $\begin{array}{l}\text { 4a. GOF-N(1,6)/F(6)A(6)1 } \\
\text { [h3n3f1] }\end{array}$ & & 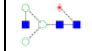 & & & & & & & & & & & & & & \\
\hline & $\begin{array}{l}\text { 4b. GOF-N(1,3) / F(6)A(3)1 } \\
\text { [h3n3f1] }\end{array}$ & & $\cdots$ & & & & & & & & & & & & & & \\
\hline 5 & $\begin{array}{l}\text { 5. G1F-N / FA1G1 } \\
\text { [h4n3f1] }\end{array}$ & & $\because$ & \begin{tabular}{|c|} 
Core fucosylated \\
mono antennary \\
monogalactosyla
\end{tabular} & & & & & & & & & & & & & \\
\hline$\frac{\sqrt{2}}{\frac{2}{2}}$ & $\begin{array}{l}\text { 5a. G1F-N(1,6) / FA1[6]G1 } \\
\text { [h4n3f1] }\end{array}$ & & $=1$ & \begin{tabular}{|c|} 
Core fucosylated \\
mono antennary \\
monogalactosyla
\end{tabular} & & & & & & & & & & & & & \\
\hline$\frac{9}{2}$ & $\begin{array}{l}\text { 5b. G1F-N(1,3) / FA1[3]G1 } \\
\text { [h4n3f1] }\end{array}$ & & $\therefore$ & \begin{tabular}{|l|} 
Core fucosylated \\
mono antennary \\
monogalactosyla
\end{tabular} & & & & & & & & & & & & & \\
\hline 6 & $\begin{array}{l}\text { 6. G1F-N+1aGal / FA1G1Ga1 } \\
{[\mathrm{h} 5 \mathrm{n} 3 \mathrm{f} 1]}\end{array}$ & & $\therefore$ & & & & & & & & & & & & & & \\
\hline 7 & $\begin{array}{l}\text { 7. G1F2-N+1aGal / FA1F1G1Ga1 } \\
\text { [h5n3f2] }\end{array}$ & & $\therefore$ & & & & & & & & & & & & & & \\
\hline 8 & $\begin{array}{l}\text { 8. GOFB / FA2B } \\
\text { [h3n5f1] }\end{array}$ & & $::$ & & & & & & & & & & & & & & \\
\hline 9 & $\begin{array}{l}\text { 9. G1FB / FA2BG1 } \\
\text { [h4n5f1] }\end{array}$ & $=$ & $: \therefore$ & & & & & & & & & & & & & & \\
\hline 10 & $\begin{array}{l}\text { 10. G2FB / FA2BG2 } \\
\text { [h5n5f1] }\end{array}$ & $\therefore$ & $::$ & & & & & & & & & & & & & & \\
\hline 11 & $\begin{array}{l}\text { 11. G1F2 / FA2F1G1 } \\
\text { [h4n4f2] }\end{array}$ & & $\because \cdots$ & & & & & & & & & & & & & & \\
\hline 12 & $\begin{array}{l}\text { 12. G2F2 / FA2F1G2 } \\
\text { [h5n4f2] }\end{array}$ & $\therefore=$. & $\because \cdots$ & & & & & & & & & & & & & & \\
\hline 13 & $\begin{array}{l}\text { 13. G2F+1aGal / FA2G2Ga1 } \\
\text { [h6n4f1] }\end{array}$ & 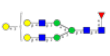 & 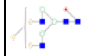 & & & & & & & & & & & & & & \\
\hline 14 & $\begin{array}{l}\text { 14. G2F2+1aGal / FA2F1G2Ga1 } \\
\text { [h6n4f2] }\end{array}$ & & 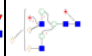 & & & & & & & & & & & & & & \\
\hline 15 & $\begin{array}{l}\text { 15. G2FB+1aGal / FA2BG2Ga1 } \\
\text { [h6n5f1] }\end{array}$ & & $: \therefore$ & & & & & & & & & & & & & & \\
\hline 16 & $\begin{array}{l}\text { 16. G2F+2aGal / FA2G2Ga2 } \\
{[\mathrm{h} 7 \mathrm{n} 4 \mathrm{f} 1]}\end{array}$ & $\infty_{0}$ & $\because \cdots$ & & & & & & & & & & & & & & \\
\hline 17 & $\begin{array}{l}\text { 17. G2FB+2aGal / FA2BG2Ga2 } \\
{[\text { [h7n5f1] }}\end{array}$ & $=0$. & $:$. & & & & & & & & & & & & & & \\
\hline
\end{tabular}


NIST Interlaboratory Study on Glycosylation Analysis

Data Reporting Template, page 3 of 4

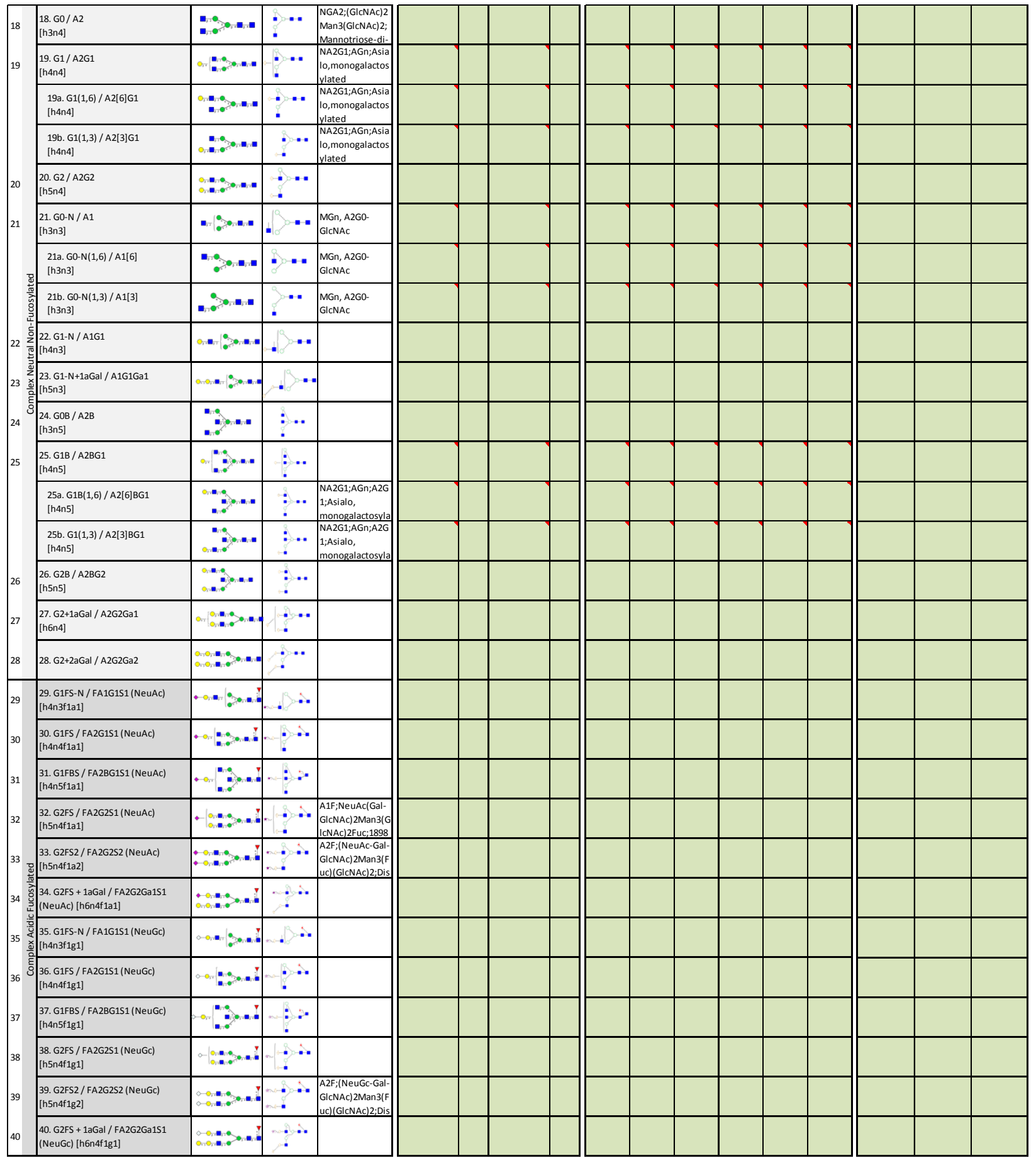


NIST Interlaboratory Study on Glycosylation Analysis

Data Reporting Template, page 4 of 4
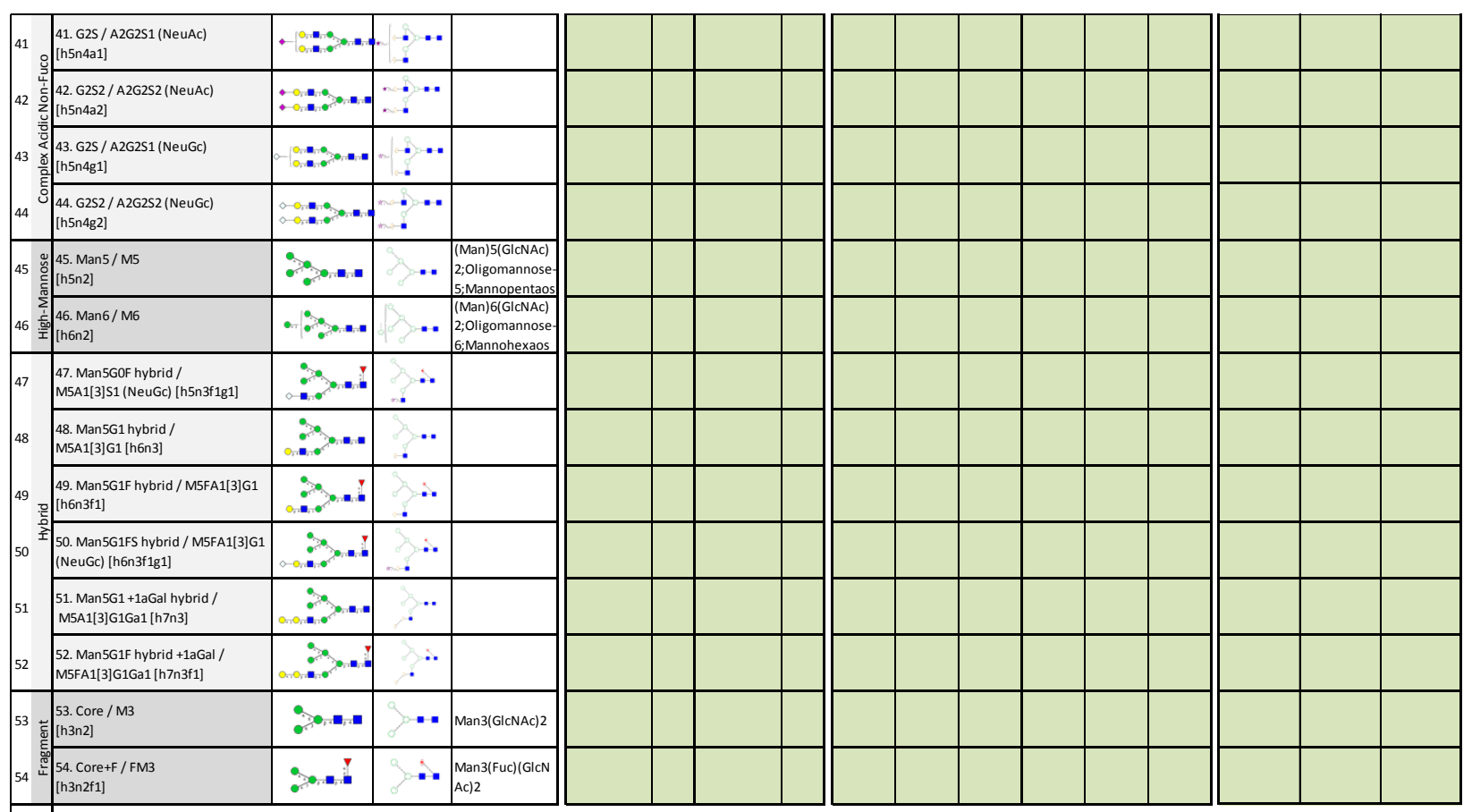

List other glycans below
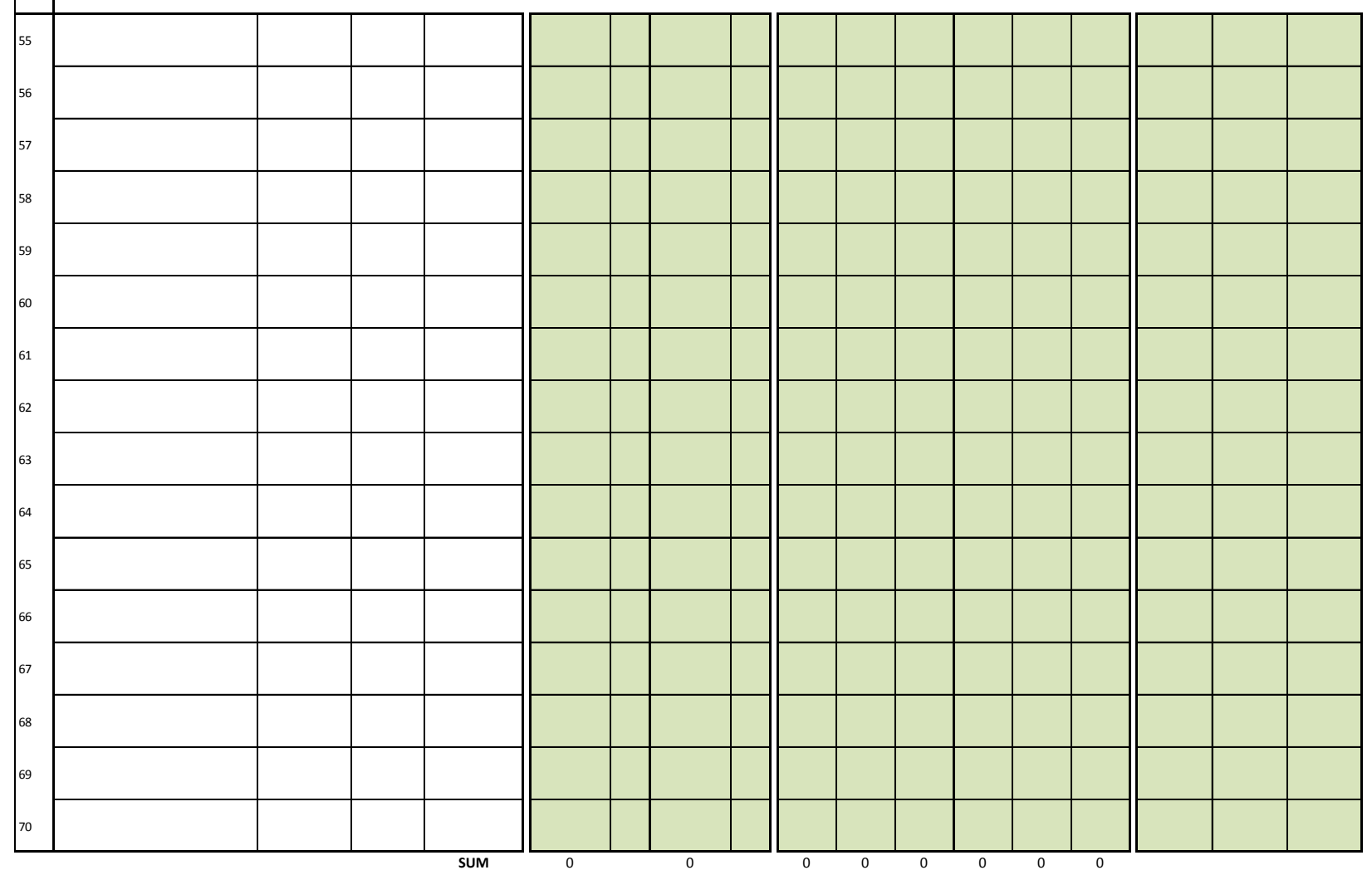


\section{Method Reporting Template}

\section{NIST Interlaboratory Study on Glycosylation Analysis}

Method Reporting Template, page 1 of 3

Please describe the methods used in this reported results.

\section{Identification of Data}

\begin{tabular}{|l|l|}
\hline Lab \# & \\
\hline Lab Classification & Select one \\
\hline Country & Select one \\
\hline Report \# & \\
\hline Total \# of Reports Submitted & \\
\hline
\end{tabular}

\section{Description of Measurement Method}

\section{Sample Preparation}

\begin{tabular}{|l|l|}
\hline Dates of measurements for Sample A & \\
\hline Dates of measurements for Sample B & \\
\hline
\end{tabular}

Number of replicate measurements for Sample A Number of replicate measurements for Sample B

\begin{tabular}{|c|}
\hline Mass (ug) of Sample A used per run \\
\hline Mass (ug) of Sample B used per run \\
\hline
\end{tabular}

\begin{tabular}{|l|l|}
\hline Dilution factor (if any) & \\
\hline Dilution media & \\
\hline
\end{tabular}

\begin{tabular}{|l|l|}
\hline Type and number of replicates for Sample A & \\
\hline Type and number of replicates for Sample B & \\
\hline
\end{tabular}

\section{Other/Comment:} - Other/Comment:

Please refer to the instructions before acquiring any data.

On this form, fill in as much of the green boxes as you can. If you have obtained another set of data using another method, please use a new sheet. You may expand the columns and rows to document additional information. Further guidance is shown when you hover your mouse on cells with red triangles on the upper right side. If you have questions on any of the boxes, please feel free to contact Dr. M. Lorna De Leoz at lorna.deleoz@nist.gov or(301) 975-6731 for clarification.

Please double check entries! It is useful to have a second person confirm data entry. Thanks!

\begin{tabular}{|l|l|l|l|}
\hline Proteolytic enzyme used & Select one & $\boldsymbol{\nabla}$ & Other/Comment: \\
\hline Derivatization used & Select one & $\boldsymbol{\nabla}$ & Other/Comment: \\
\hline
\end{tabular}

Describe pre-treatment of samples (e.g. immobilization), if any

Describe the digestion conditions (enzyme: IgG ratio, buffer (including additives), $\mathrm{pH}$, digestion time, temperature)

Describe purification/cleanup methods (e.g. SPE or ziptip, type, vacuum or gravity) 
NIST Interlaboratory Study on Glycosylation Analysis

Method Reporting Template, page 2 of 3

\section{Analysis}

\begin{tabular}{|l|l|}
\hline General Strategy (If other, please specify) \\
\hline Other/Comment:
\end{tabular}

Describe identification method (parameters, type(s) of instrument(s) used (manufacturer, model \#))

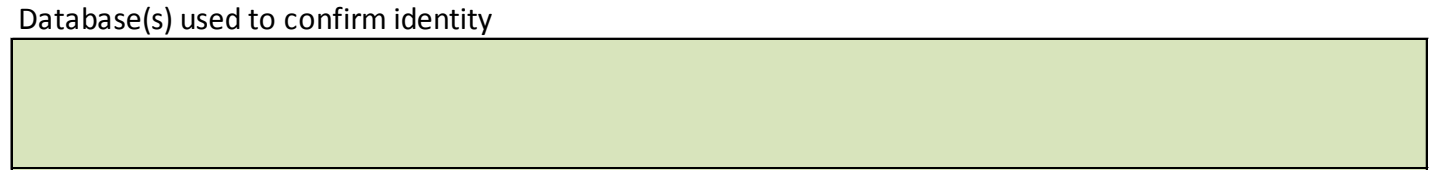

Describe quantification method, type(s) of instrument(s) used (manufacturer, model \#)

Describe separation/chromatography method (gradient, parameters, type(s) of instrument(s) used (manufacturer, model \#))

Describe how the percent abundances of glycans were extracted from the data 
NIST Interlaboratory Study on Glycosylation Analysis

Method Reporting Template, page 3 of 3

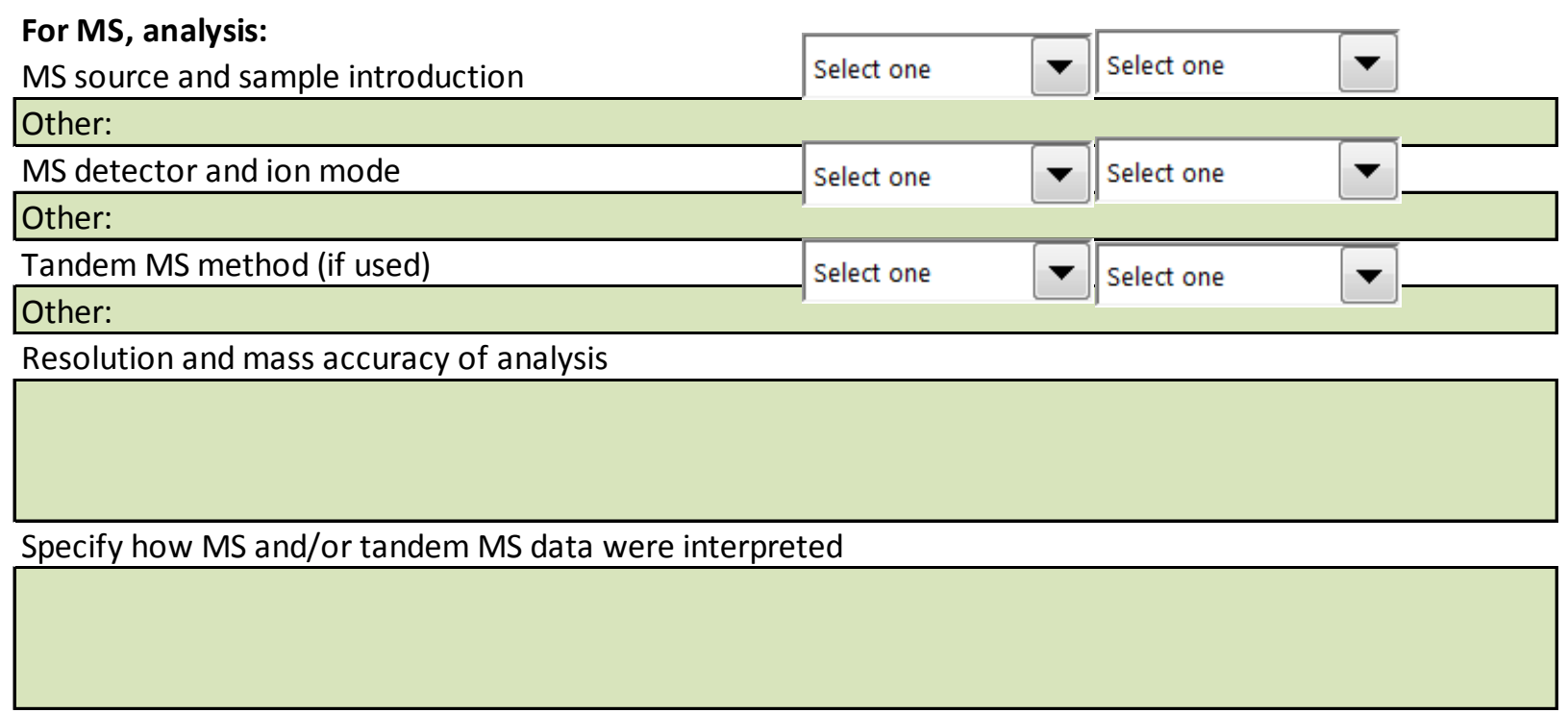

For glycopeptide analysis, specify the sequence(s) of the peptide(s) used to quantify the mAb glycans

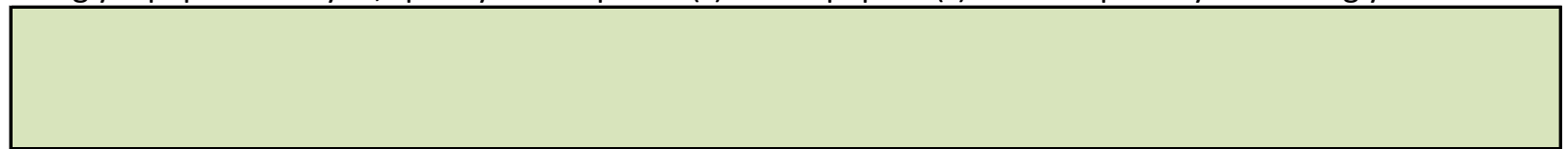

For ESI, specify how charge states were analyzed

Other information 


\section{Comments and Suggestions}

\section{NIST Interlaboratory Study on Glycosylation Analysis}

\section{Comments and Suggestions}

Your input, expertise, and feedback is extremely valuable for future studies. Please write any comments and suggestions that may be relevant to the interlab study. Feel free to expand columns and rows if you need more space.

Address any questions to Dr. M. Lorna De Leoz at lorna.deleoz@nist.gov or (301) 9756731. Thanks!

Overall:

Shipping:

Glycan Identification (current methods for describing identity of glycans):

Data Reporting:

Samples (e.g. concentration, amount, container, label...):

Sample Analysis:

Other: 


\section{Appendix B. Final Report for the Interlaboratory Study}

The final report delivered to every participant in the interlaboratory study consists of four files:

- Cover letter: contains a brief description of the samples and the other three documents

- Table of Identified Glycans: list of identifiers, compositions, and structures for all glycans reported in any data set

- All-Lab Report: summarizes reported and derived values for Samples A and B, and the $\mathrm{A} / \mathrm{B}$ ratio

- Individualized Report: graphically analysis of each participant's results for all glycan compositions. It contains boxplots of Samples $\mathrm{A}$ and $\mathrm{B}$, and the $\mathrm{A} / \mathrm{B}$ ratio, and a target plot summary for the $\mathrm{A} / \mathrm{B}$ ratio for compositions reported by at least six participants . This report also provides a graphical summary of each participant's measurement comparability, including glycan composition counts and sums, repeatability, limits of reporting, minimum reported values, and consensus values. 


\section{Cover Letter}

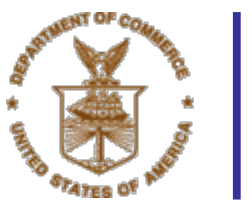

UNITED STATES DEPARTMENT OF COMMERCE National Institute of Standards and Technology Gaithersburg, Maryland 20899

Material Measurement Laboratory

June 2, 2017

Dear Colleague:

Thank you for participating in the NIST interlaboratory study of NISTmAb Glycosylation. Enclosed is the preliminary report of the results. Included in this report are: 1) a summary of reported and derived values for Samples A and B, and A/B ratio from all laboratories, 2) a detailed graphical analysis of your results; and 3) summary tables of the results you reported.

The NISTmAb Glycosylation study consisted of two vials of liquid-frozen monoclonal antibody samples, NISTmAb and a glycan-modified NISTmAb, and one $25 \mathrm{mmol} / \mathrm{L} \mathrm{L}$-Histidine $\mathrm{pH} 6.0$ solution that was intended for use in reconstituting the two samples. Your overall measurement comparability is summarized in the boxplot and targetplot summaries found in page 1 of your report; this summary reflects only results for glycan compositions. We intend to follow this report with a summary of results for the unique glycoforms and glycoform isomers at a later date.

If you have concerns or questions regarding your laboratory's performance, please contact $\mathrm{M}$. Lorna De Leoz at lorna.deleoz@nist.gov or +1-(301) 975-6731.

Again, many thanks for joining us in this endeavor.

Sincerely,

M. Lorna A. De Leoz, Ph.D. Research Chemist

Biomolecular Measurement

Division
Stephen E. Stein, Ph.D. NIST Fellow

Biomolecular Measurement Division
David L. Duewer, Ph.D. Chemometrician Chemical Sciences Division

\section{NLT}


The complete report for this study consists of three files:

Table of Identified Glycans

\#Pages

Identifiers and structures for all glycans reported in any data set

17

All-Lab Report

\#Pages

Summary of reported and derived values for Samples A and B, and the A/B ratio

9

Legend for the summary

1

Individualized Report

\#Pages

Boxplots of Samples A and B, and the A/B ratio, and targetplot for the $\mathrm{A} / \mathrm{B}$ ratio

Legend for the boxplots and targetplot

Plots summarizing measurement performance, including glycan composition

counts and sums, repeatability, limits of reporting, minimum reported values, and consensus

Legend for measurement performance plots

Table of measurement summary

Variable

Legend for table of measurement summary

Table of derived glycan attribute quantities

Legend for table of derived glycan attribute quantities 


\section{Table of Identified Glycans}

Glycans reported by at least one participant arranged in increasing monosaccharide composition. Entries highlighted in orange are unique glycan compositions; glycans having the same monosaccharide compositions are shown beneath the highlighted entry. 
Table of Identified Glycans

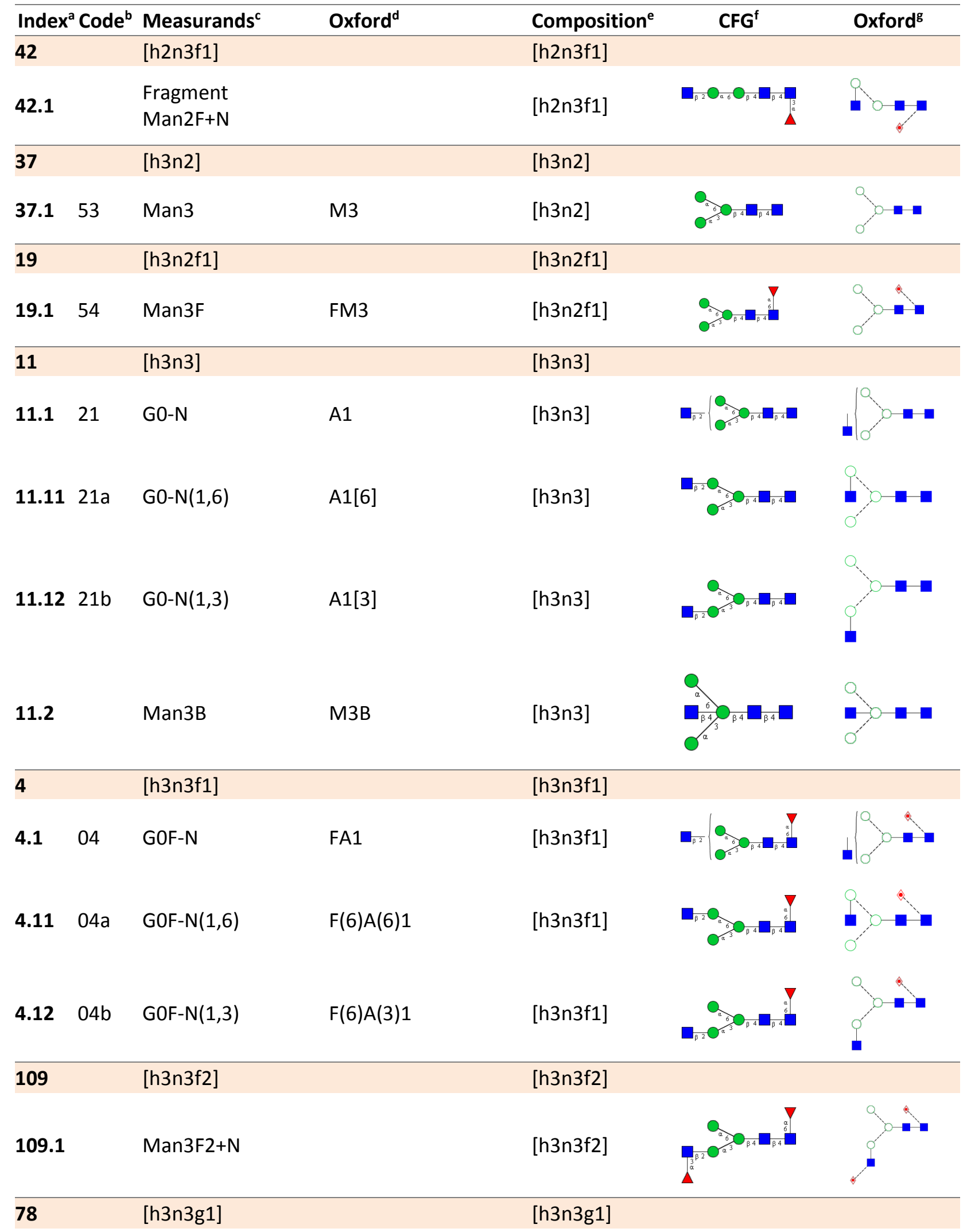




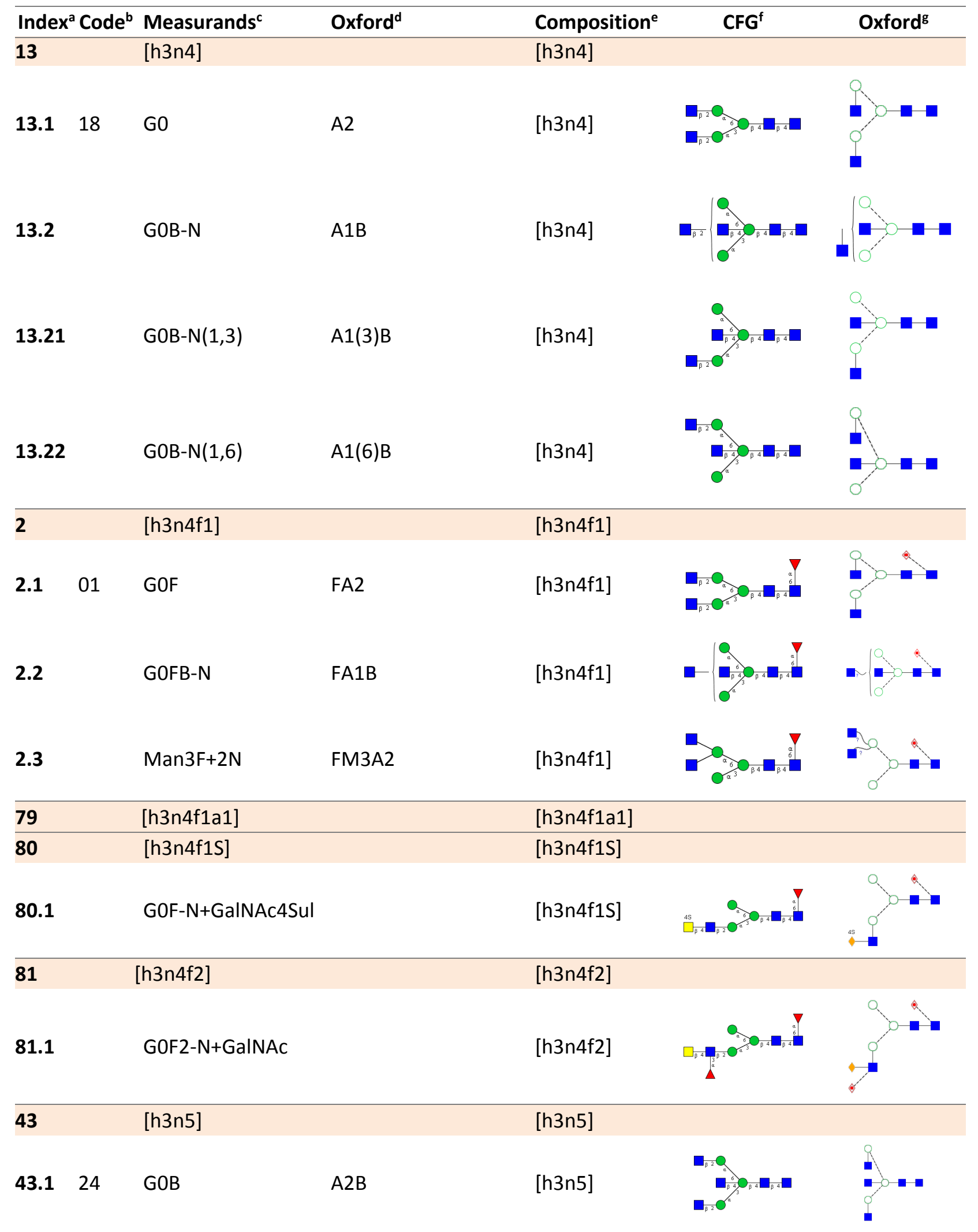




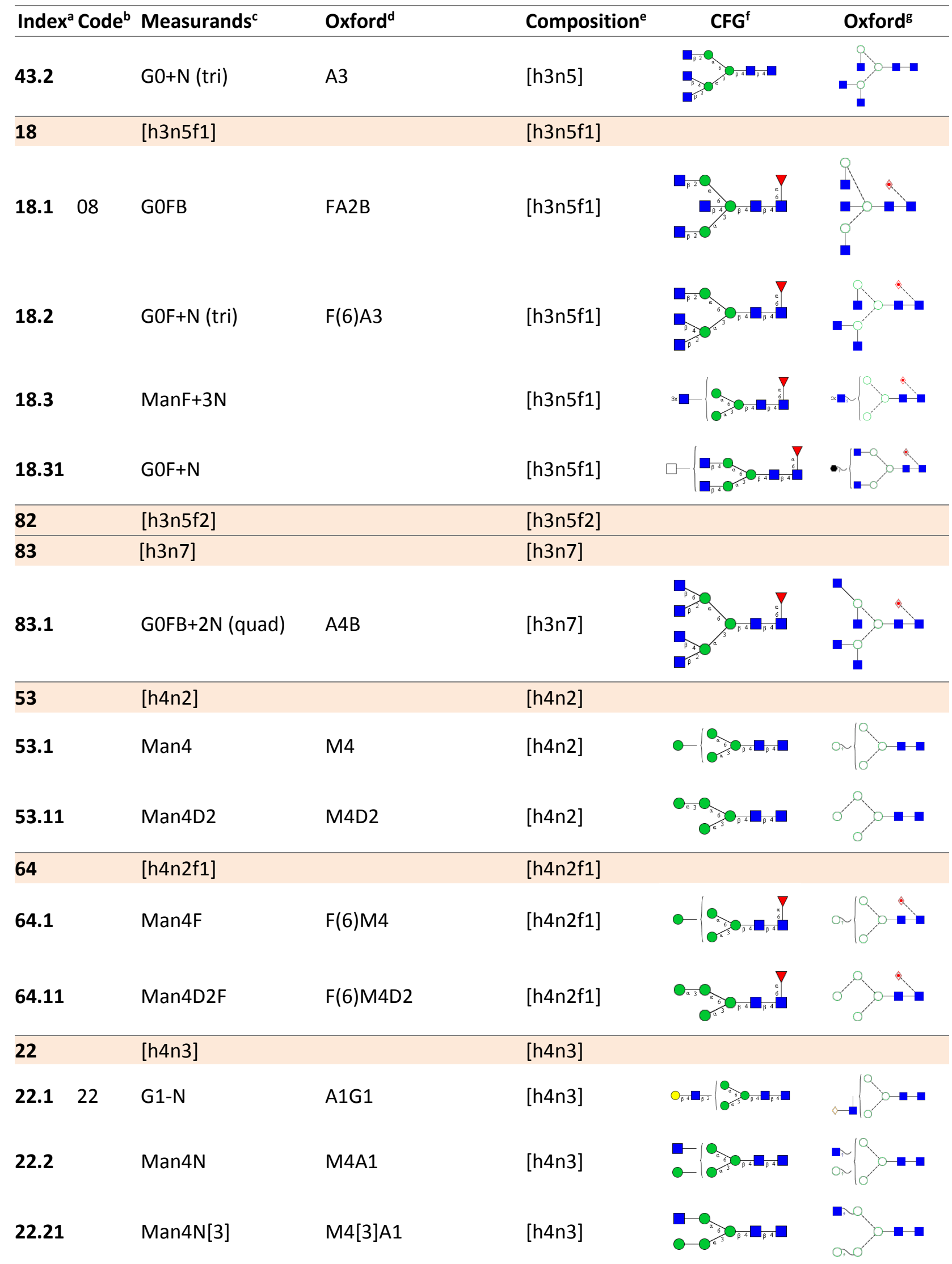




\begin{tabular}{|c|c|c|c|c|c|}
\hline Index ${ }^{a}$ Code $^{b}$ & Measurands ${ }^{c}$ & Oxford $^{d}$ & Composition $^{\mathrm{e}}$ & CFG $^{f}$ & Oxfordg \\
\hline 84 & [h4n3a1] & & [h4n3a1] & & \\
\hline 84.1 & G1S-N (NeuAc) & A1G1S1 (NeuAc) & [h4n3a1] & $-0-b_{0,4}$ & \\
\hline 10 & [h4n3f1] & & [h4n3f1] & & \\
\hline 10.105 & G1F-N & FA1G1 & [h4n3f1] & 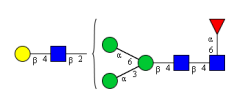 & \\
\hline $10.1105 a$ & G1F-N $(1,6)$ & FA1[6]G1 & [h4n3f1] & 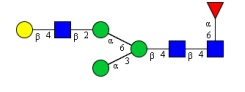 & \\
\hline $10.1205 b$ & G1F-N $(1,3)$ & FA1[3]G1 & [h4n3f1] & 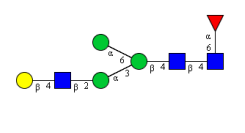 & . \\
\hline 10.2 & Man4FN & $\mathrm{F}(6) \mathrm{M} 4 \mathrm{~A} 1$ & [h4n3f1] & 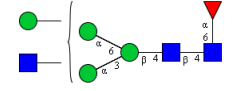 & \\
\hline 36 & [h4n3f1a1] & & [h4n3f1a1] & & \\
\hline $36.1 \quad 29$ & G1FS-N & FA1G1S1 (NeuAc) & [h4n3f1a1] & $\log _{1}$ & \\
\hline 12 & [h4n3f1g1] & & [h4n3f1g1] & & \\
\hline 12.135 & G1FS-N & FA1G1S1 (NeuGc) & [h4n3f1g1] & 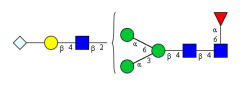 & \\
\hline 44 & [h4n3f2] & & [h4n3f2] & & \\
\hline 44.1 & $\mathrm{G} 1 \mathrm{~F}-\mathrm{N}+\mathrm{AF}$ & FA1F1G1 & [h4n3f2] & $I \operatorname{lom}_{0} 0_{F+1}$ & \\
\hline 54 & [h4n3g1] & & [h4n3g1] & & \\
\hline 54.1 & G1S (NeuGc) & A1G1S1 (NeuGc) & [h4n3g1] & $\diamond 0 \cdot \mid b_{0,4}$ & 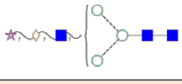 \\
\hline 20 & [h4n4] & & [h4n4] & & \\
\hline 20.119 & G1 & $\mathrm{A} 2 \mathrm{G} 1$ & [h4n4] & 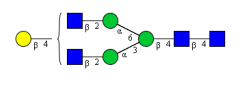 & \\
\hline $20.1119 a$ & $\mathrm{G} 1(1,6)$ & $\mathrm{A} 2[6] \mathrm{G} 1$ & [h4n4] & 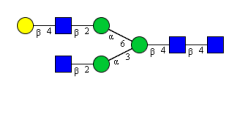 & 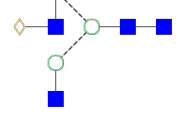 \\
\hline $20.1219 b$ & $\mathrm{G} 1(1,3)$ & $\mathrm{A} 2[3] \mathrm{G} 1$ & [h4n4] & 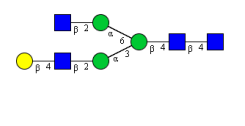 & 0 \\
\hline 20.2 & G1B-N & & [h4n4] & 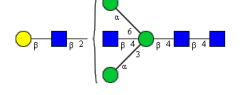 & n. \\
\hline 65 & [h4n4a1] & & [h4n4a1] & & \\
\hline
\end{tabular}




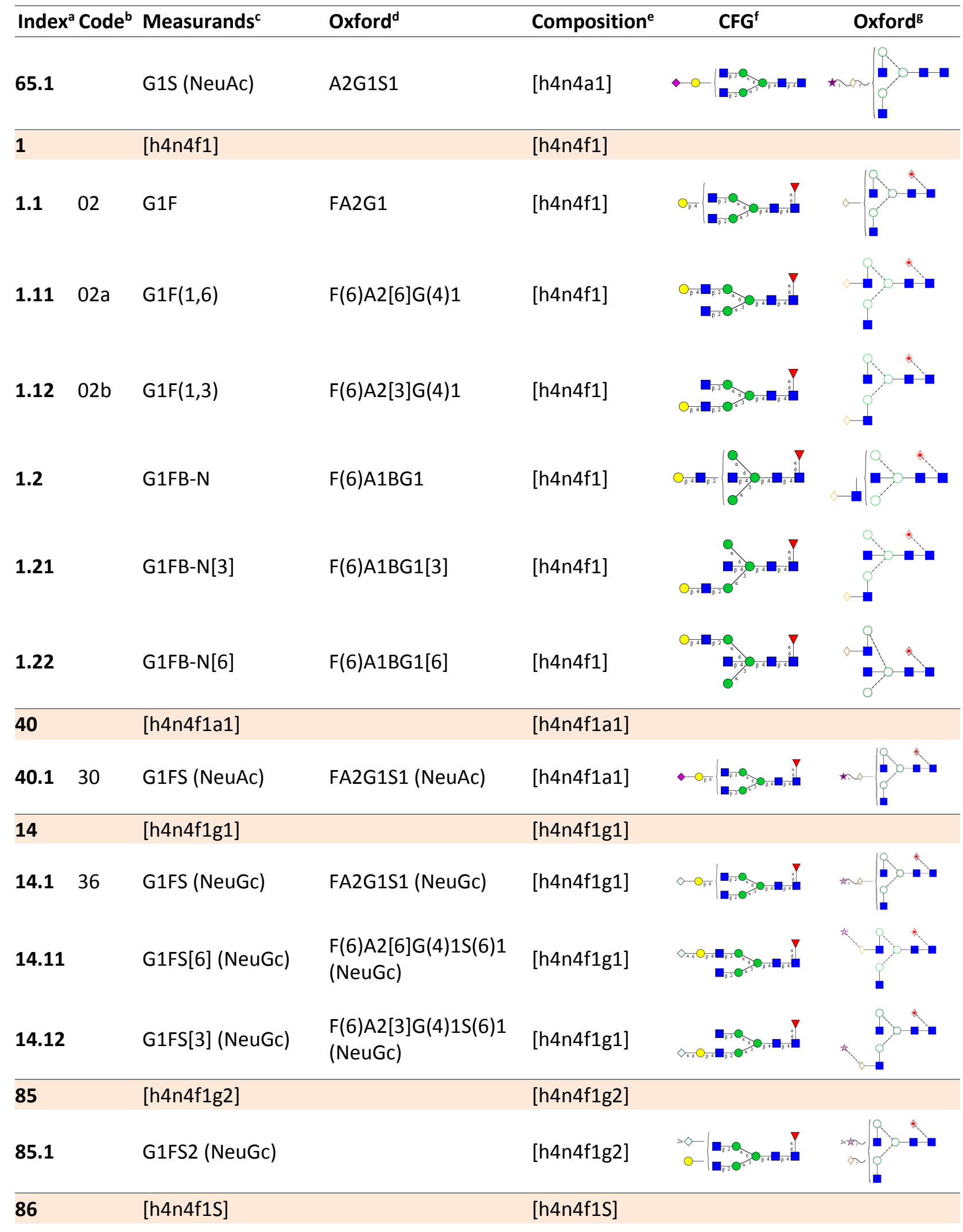




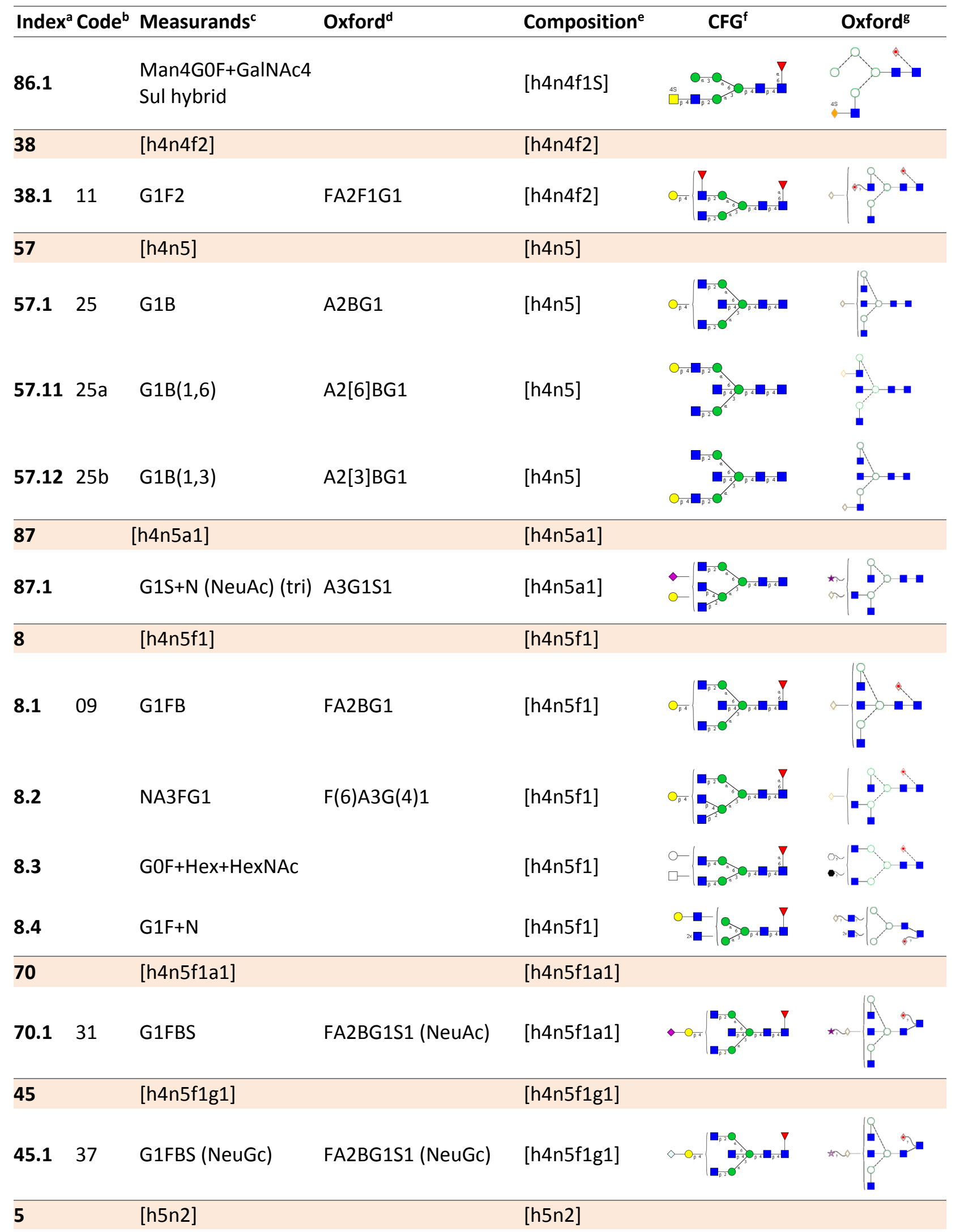




\begin{tabular}{|c|c|c|c|c|c|c|}
\hline Inde & ${ }^{a}$ Code $^{b}$ & Measurands ${ }^{c}$ & Oxford $^{d}$ & Composition $^{\mathrm{e}}$ & CFG $^{f}$ & Oxfordg \\
\hline 5.1 & 45 & Man5 & M5 & {$[\mathrm{h} 5 \mathrm{n} 2]$} & & \\
\hline 88 & & [h5n2f1] & & [h5n2f1] & & \\
\hline 88.1 & & Man5F & FM5 & [h5n2f1] & & \\
\hline 29 & & [h5n3] & & [h5n3] & & \\
\hline 29.1 & 23 & G1-N+1aGal & A1G1Ga1 & [h5n3] & $=0$ & \\
\hline 46 & & [h5n3a1] & & [h5n3a1] & & \\
\hline 46.1 & & Man4G1S hybrid & M4A1G(4)1S(6)1 & [h5n3a1] & 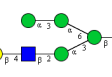 & \\
\hline 46.2 & & $\begin{array}{l}\text { Fragment G2S- } \\
\text { CoreN (NeuAc) }\end{array}$ & $\mathrm{A} 2 \mathrm{G}(4) 2 \mathrm{~S}(6) 1$ & [h5n3a1] & - & \\
\hline 9 & & [h5n3f1] & & [h5n3f1] & & \\
\hline 9.1 & 06 & G1F-N+1aGal & FA1G1Ga1 & [h5n3f1] & $a$ & \\
\hline
\end{tabular}

9.2 Man5G0F hybrid FM5A1[3] [h5n3f1]

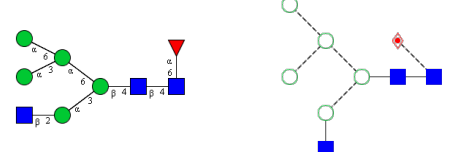

$9.3 \quad$ G1F+Man $(6) M 4 A 1 G(4) 1 \quad[h 5 n 3 f 1] \quad$

$9.31 \quad \mathrm{G} 1 \mathrm{~F}+\mathrm{Man}(1,3) \quad \mathrm{F}(6) \mathrm{M} 4 \mathrm{~A} 1[3] \mathrm{G}(4) 1 \quad[\mathrm{~h} 5 \mathrm{n} 3 \mathrm{f} 1]$

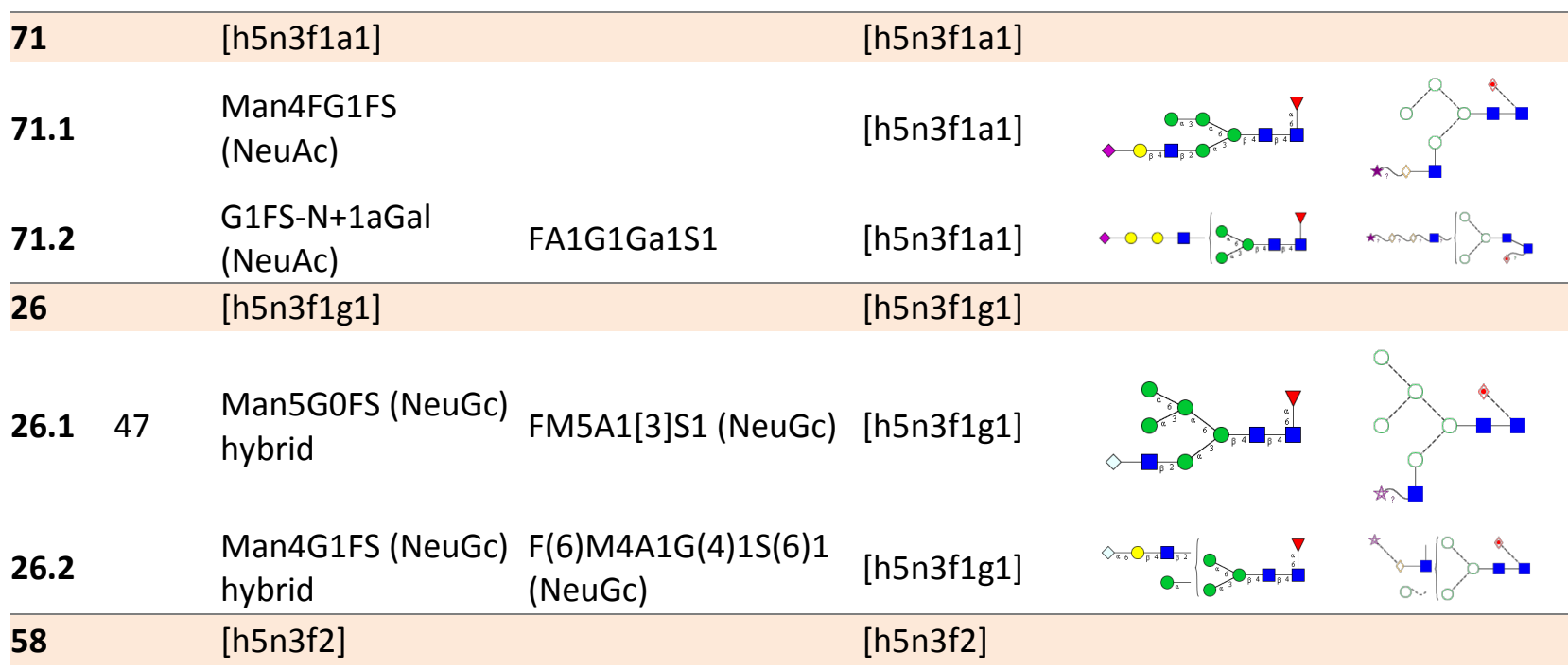




\begin{tabular}{|c|c|c|c|c|c|c|}
\hline Index & ${ }^{a}$ Code $^{b}$ & Measurands ${ }^{c}$ & Oxford $^{d}$ & Composition $^{\mathrm{e}}$ & CFG $^{f}$ & Oxford ${ }^{\mathrm{g}}$ \\
\hline 58.1 & 07 & G1F2-N+1aGal & FA1F1G1Ga1 & [h5n3f2] & 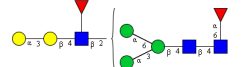 & \\
\hline 66 & & [h5n3g1] & & [h5n3g1] & & \\
\hline 66.1 & & $\begin{array}{l}\text { Man4G1S1 (NeuGc) } \\
\text { hybrid }\end{array}$ & & [h5n3g1] & $\diamond-\left.\right|_{0}, \pm$ & \\
\hline 21 & & [h5n4] & & [h5n4] & & \\
\hline 21.1 & 20 & $\mathrm{G} 2$ & $\mathrm{~A} 2 \mathrm{G} 2$ & [h5n4] & 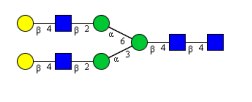 & \\
\hline 21.2 & & $\mathrm{G} 1+1 \mathrm{aGal}$ & A2G1Ga1 & [h5n4] & $O_{n=0} O_{B=}$ & \\
\hline 27 & & [h5n4a1] & & [h5n4a1] & & \\
\hline 27.1 & 41 & G2S (NeuAc) & A2G2S1 (NeuAc) & [h5n4a1] & $-\mid a_{0}^{0}$ & \\
\hline 59 & & [h5n4a2] & & [h5n4a2] & & \\
\hline 59.1 & 42 & G2S2 (NeuAc) & A2G2S2 (NeuAc) & [h5n4a2] & 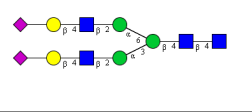 & \\
\hline 3 & & [h5n4f1] & & [h5n4f1] & & \\
\hline 3.1 & 03a & $\mathrm{G} 2 \mathrm{~F}$ & $F(6) A 2 G(4) 2$ & [h5n4f1] & 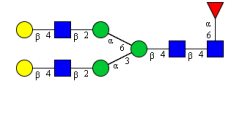 & \\
\hline 3.2 & $03 b$ & $\mathrm{G} 1 \mathrm{~F}+1 \mathrm{aGal}$ & $F(6) A 2 G 1 G a 1$ & [h5n4f1] & 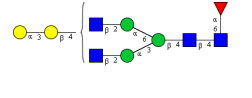 & \\
\hline 3.21 & & $\mathrm{G} 1 \mathrm{~F}(1,3)+1 \mathrm{aGal}$ & $\mathrm{F}(6) \mathrm{A} 2[3] \mathrm{G}(4) 1 \mathrm{Ga}(3) 1$ & [h5n4f1] & 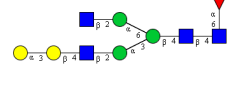 & \\
\hline 3.22 & & $\mathrm{G} 1 \mathrm{~F}(1,6)+1 \mathrm{aGal}$ & $\mathrm{F}(6) \mathrm{A} 2[6] \mathrm{G}(4) 1 \mathrm{Ga}(3) 1$ & [h5n4f1] & 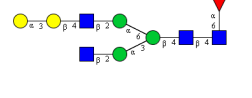 & \\
\hline 3.3 & & G1FB-N+1aGal & FA1G1BGa(2)1 & [h5n4f1] & 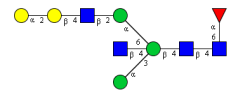 & 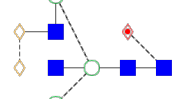 \\
\hline 35 & & [h5n4f1a1] & & [h5n4f1a1] & & \\
\hline 35.1 & 32 & G2FS (NeuAc) & FA2G2S1 (NeuAc) & [h5n4f1a1] & 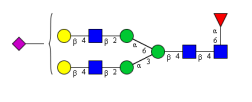 & $9-1$ \\
\hline 41 & & [h5n4f1a2] & & [h5n4f1a2] & & \\
\hline
\end{tabular}




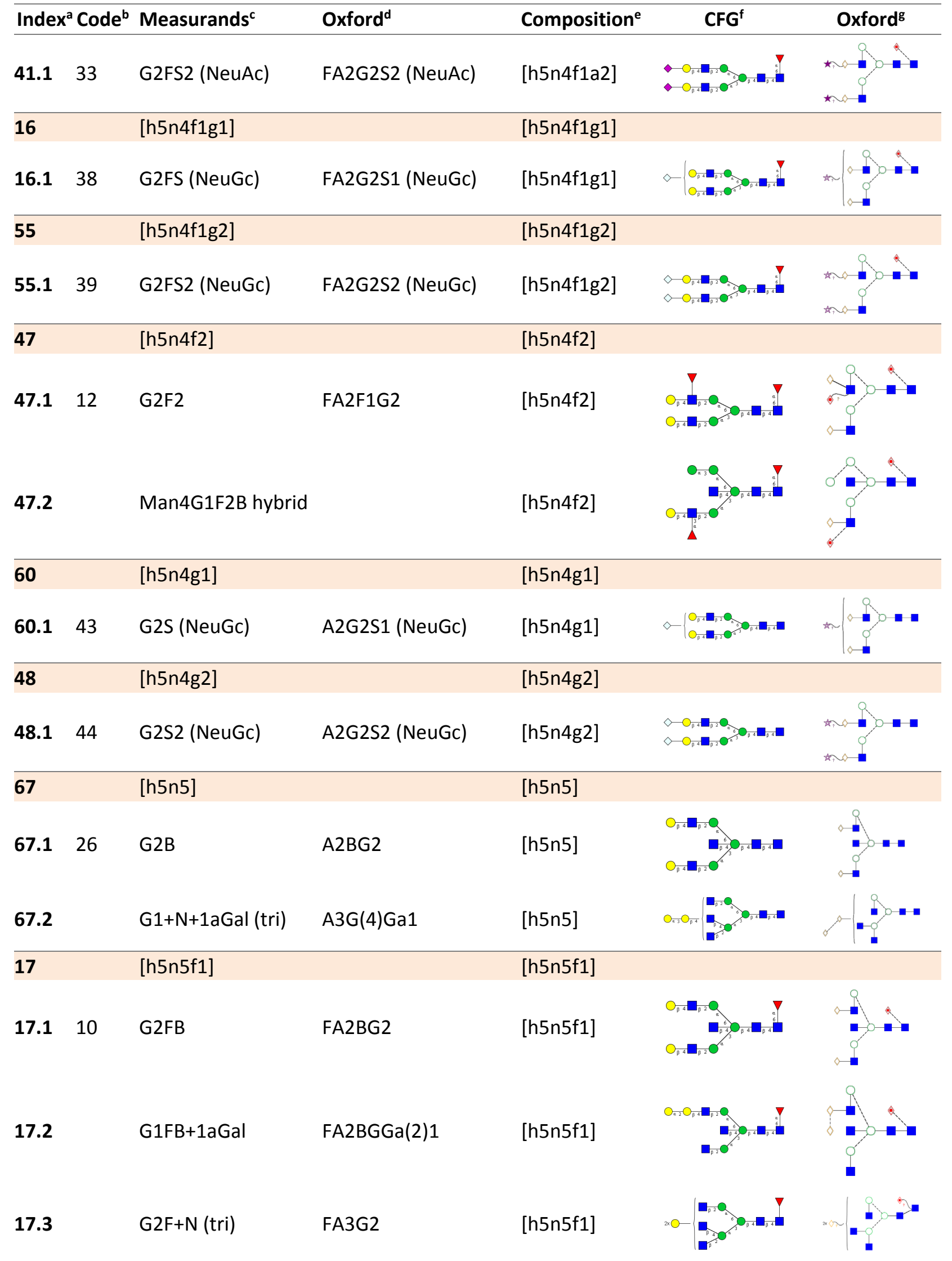




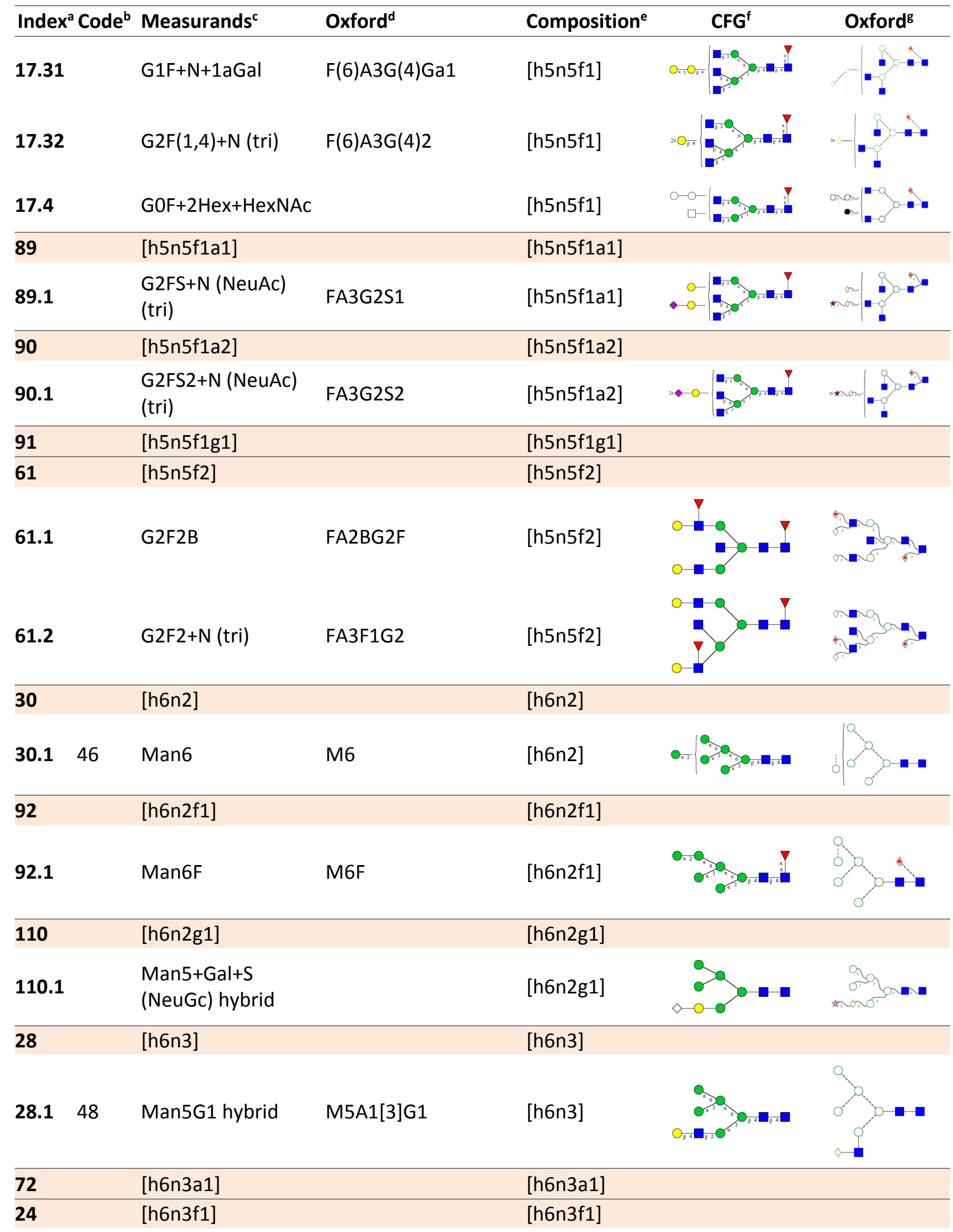




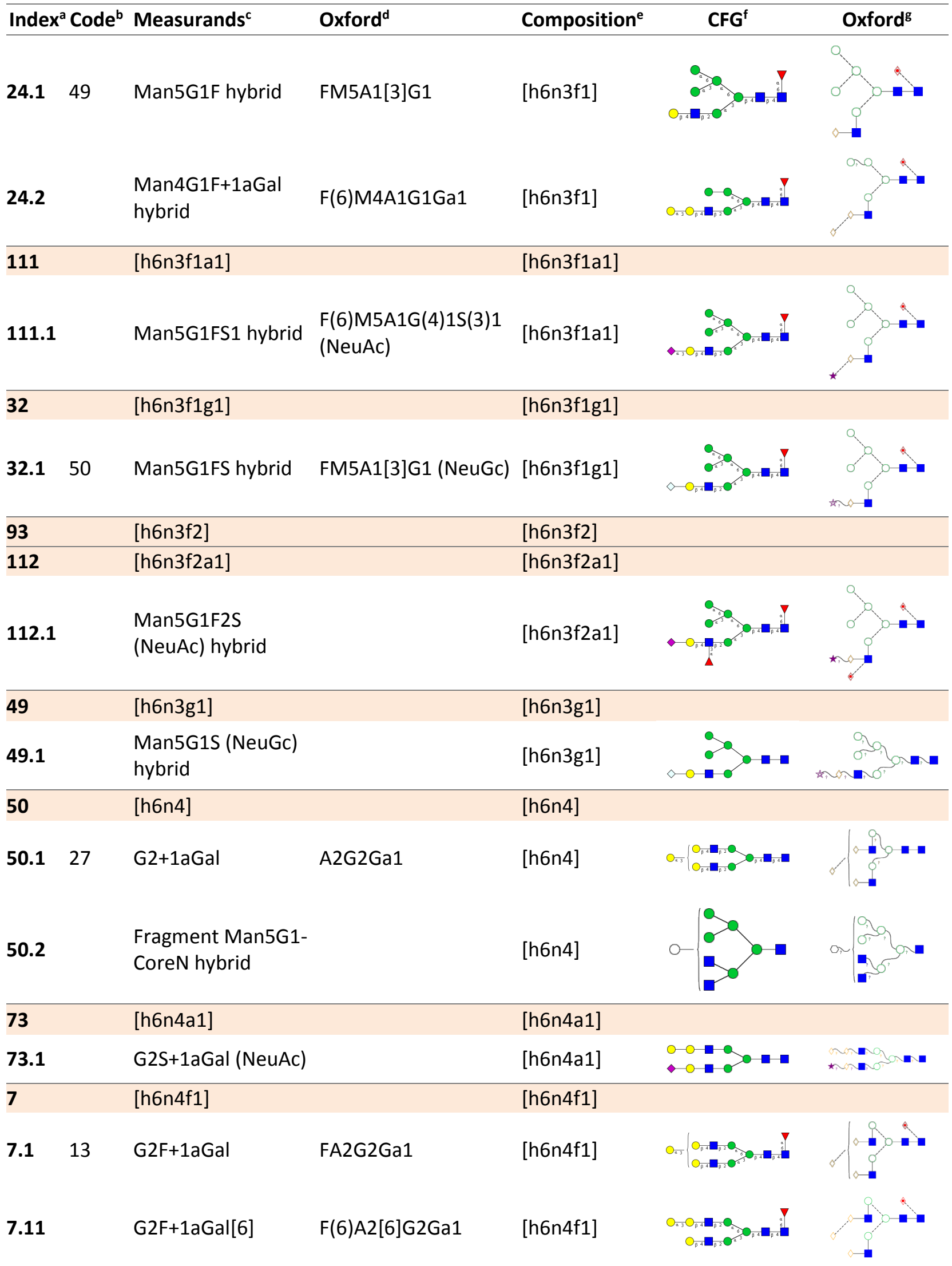




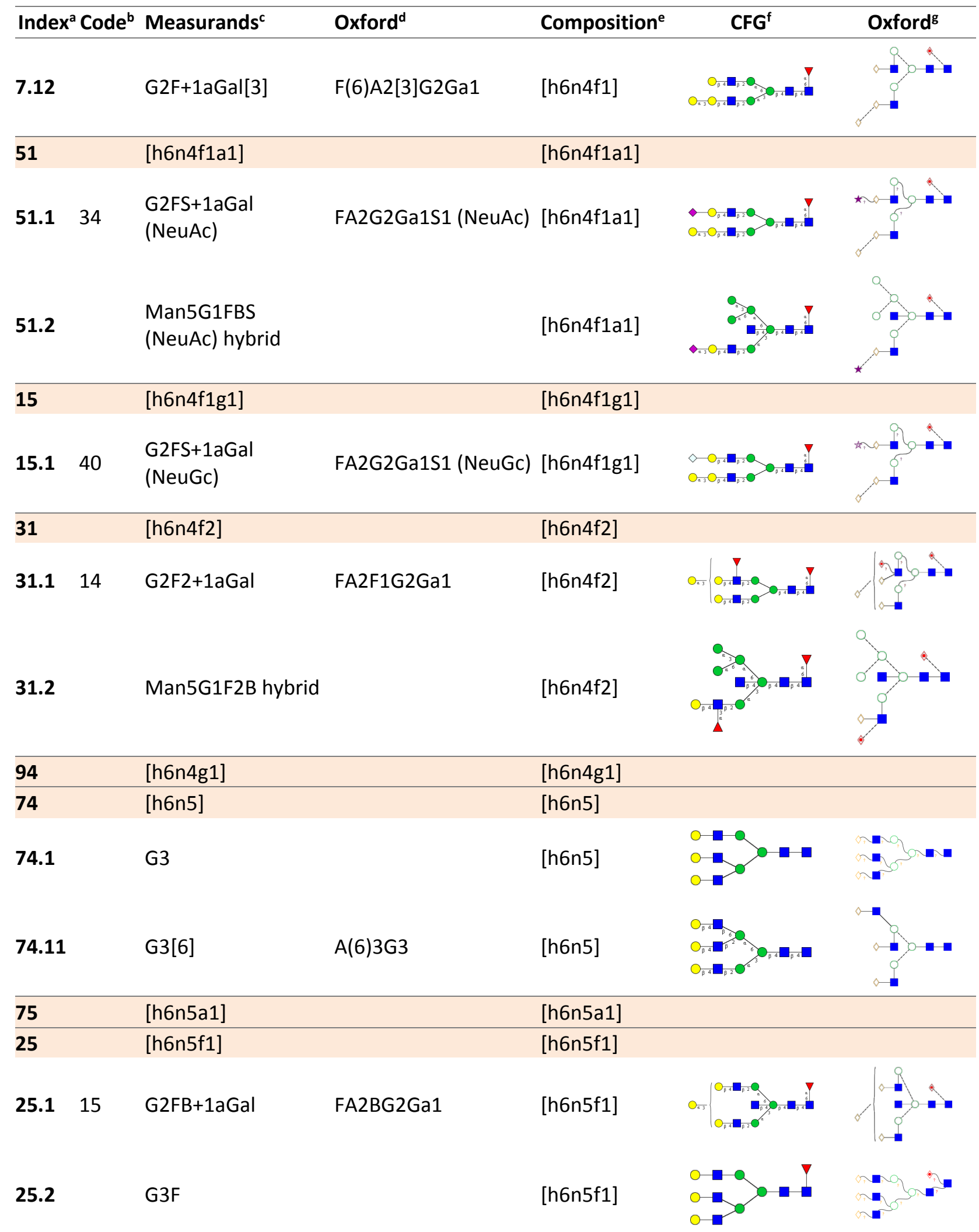




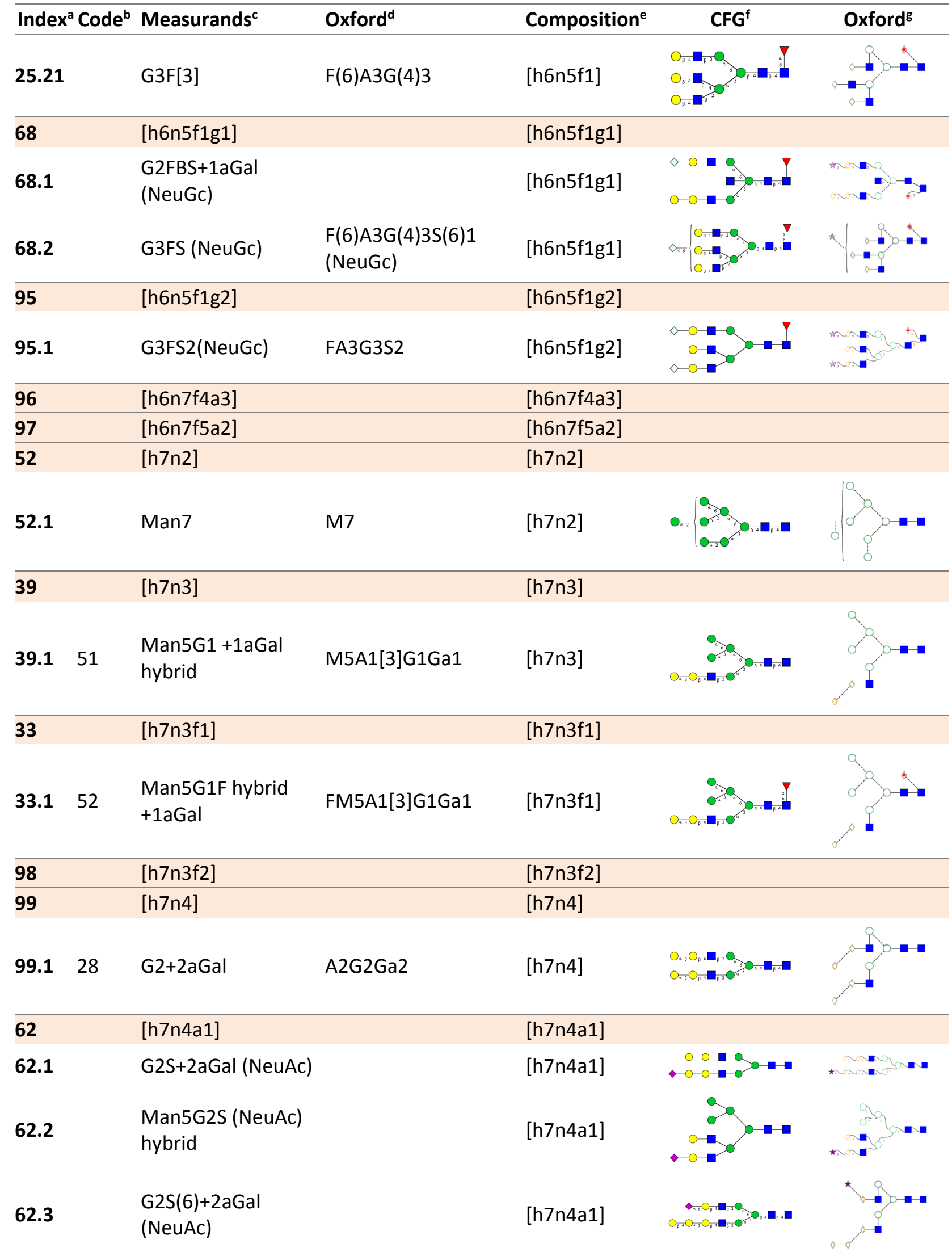




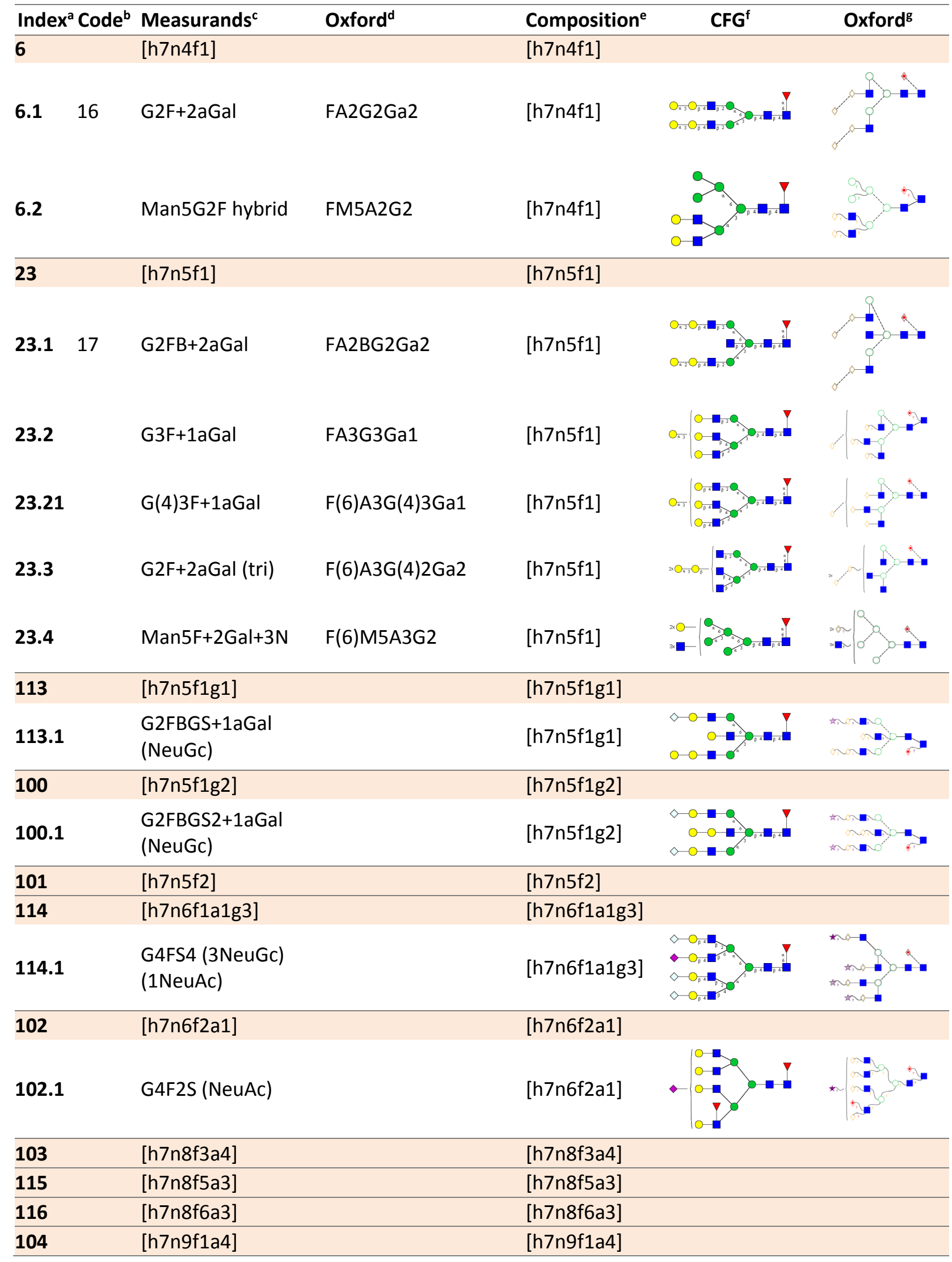




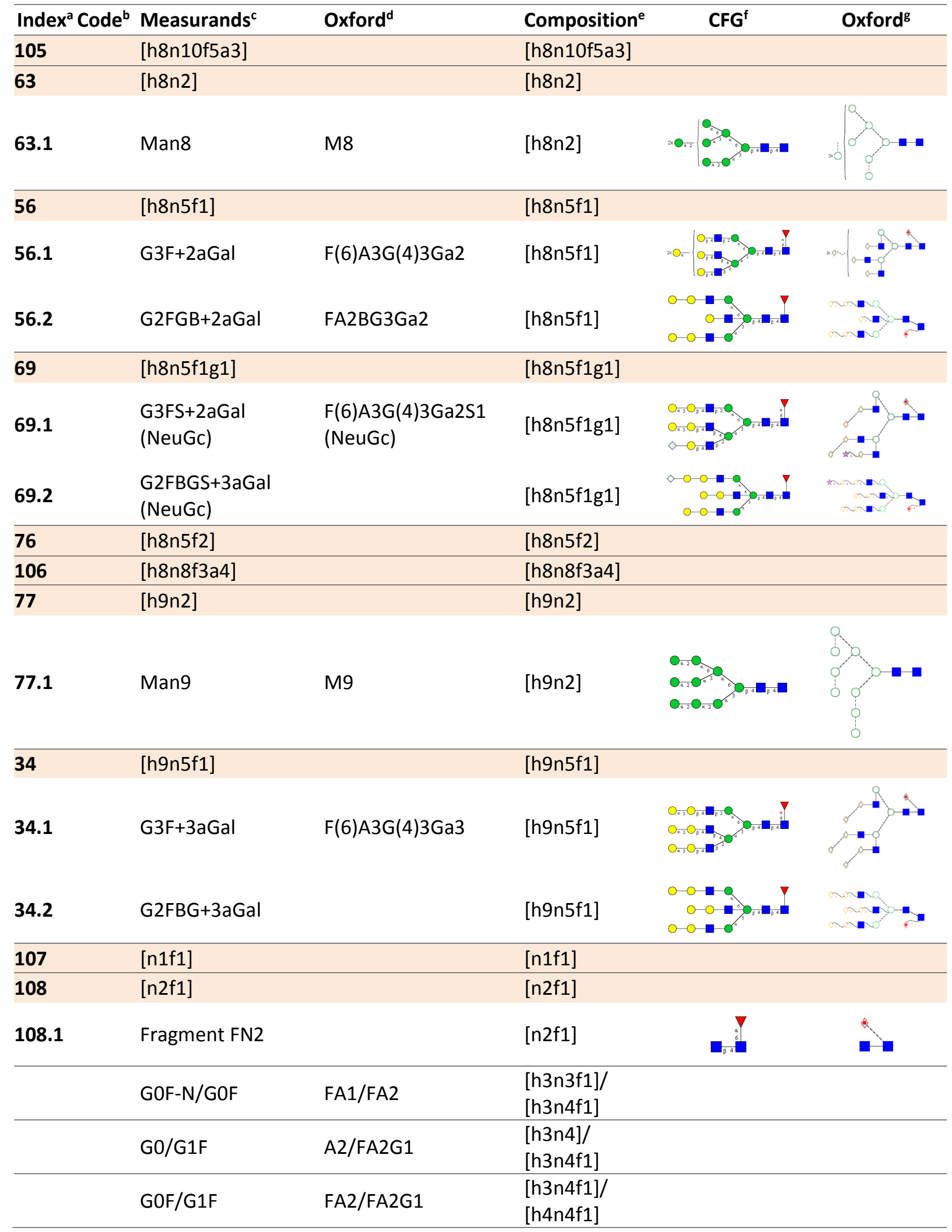




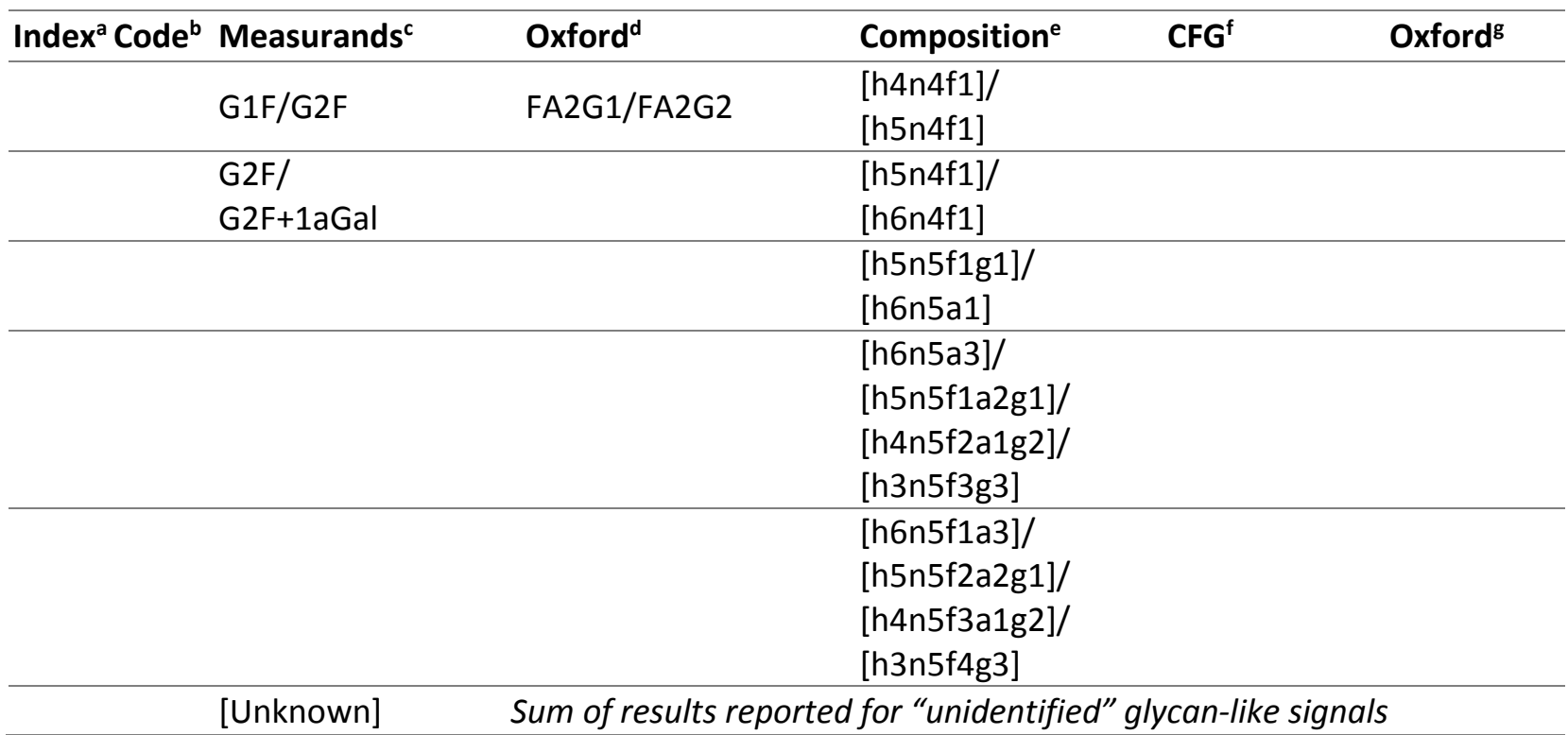

a Index: Each different glycan composition is represented by an integer. Individual glycans are represented by a digit following a decimal point - isomers of these are represented by an additional digit. Indices in bold are glycans with complete structural assignments.

b Code: These correspond to numbers in the data reporting template. Entries with code Other are glycans reported by participants but not in the data reporting template.

c Measurands: text in square brackets correspond to monosaccharide compositions (see Composition). Common names are listed when available.

d Oxford: Oxford naming convention: All N-glycans have two core GlcNAcs; F at the start of the abbreviation indicates a core fucose, (6) after the $F$ indicates that the fucose is $\alpha 1-6$ linked to the inner GlcNAc; Mx, number ( $x$ ) of mannose on core GlcNAcs; $A x$, number of antenna (GlcNAc) on trimannosyl core; $A 2$, biantennary with both GlcNAcs as $\beta 1-2$ linked; $A 3$, triantennary with a GlcNAc linked $\beta 1-2$ to both mannose and the third GlcNAc linked $\beta 1-4$ to the $\alpha 1-3$ linked mannose; $A 3^{\prime}$, triantennary with a GlcNAc linked $\beta 1-2$ to both mannose and the third GlcNAc linked $\beta 1-6$ to the $\alpha 1-6$ linked mannose; $A 4$, GlcNAcs linked as $A 3$ with additional GlcNAc $\beta 1-6$ linked to $\alpha 1-6$ mannose; $B$, bisecting GlcNAc linked $\beta 1-4$ to $\beta 1-3$ mannose; $G x$, number $(x)$ of linked galactose on antenna, (4) or (3) after the $\mathrm{G}$ indicates that the Gal is $\beta 1-4$ or $\beta 1-3$ linked; [3]G1 and [6]G1 indicates that the galactose is on the antenna of the $\alpha 1-3$ or $\alpha 1-6$ mannose; Gax, number $(x)$ of linked alpha galactose on antenna; Sx, number ( $\mathrm{x}$ ) of sialic acids linked to galactose; the numbers 3 or 6 in parentheses after $\mathrm{S}$ indicate whether the sialic acid is in an $\alpha 2-3$ or $\alpha 2-6$ linkage. (Courtesy of Louise Royle, Ludger)

e [Composition] denotes monosaccharide composition. Small letters are used to avoid confusion with elements (hydrogen, nitrogen, fluorine, etc.): $h=h e x o s e, ~ n=N$-acetylhexosamine, $f=$ deoxyhexose (e.g. fucose), $a=N e u A c, g=N e u G c$. Number after the letter denotes the number of residues. For example: [h6n4f1a1] $=6$ hexoses, $4 \mathrm{~N}$-acetylhexosamine, 1 fucose, 1 NeuAc. For sulfonated glycans, $\mathrm{S}=$ sulfur. 
f CFG: Structure using the Consortium for Functional Glycomics (CFG) Notation: Symbol representations of glycans: galactose $=O$, glucose $=O$, mannose $=O, N$-Acetylgalactosamine $=\square$ $\mathrm{N}$-Acetylglucosamine $=\square$ fucose $=\triangle$, xylose $=\underset{k}{\star}, \mathrm{N}$-Acetylneuraminic acid $=\Delta$, $\mathrm{N}$-Glycolylneuraminic acid $=\diamond .[1,2]$

g Oxford: Structure using the Oxford Glycobiology Institute (UOXF) Notation: galactose $=$, glucose $=\square$, mannose $=0, \mathrm{~N}$-Acetylgalactosamine $=\diamond, \mathrm{N}$-Acetylglucosamine $=\square$, fucose $=\ominus$, xylose $=\triangle$, $\mathrm{N}$-Acetylneuraminic acid $=\star, \mathrm{N}$-Glycolylneuraminic Acid $=\Varangle .[2,3]$

\section{References}

[1] Varki A, Cummings RD, Esko JD, Freeze HH, Stanley P, Marth JD, Bertozzi CR, Hart GW, Etzler ME (2009) Symbol nomenclature for glycan representation. Proteomics 9:5398-5399. https://doi.org/10.1002/pmic.200900708.

[2] Ceroni A, Maass K, Geyer H, Geyer R, Dell A, Haslam SM (2008) GlycoWorkbench: a tool for the computer-assisted annotation of mass spectra of glycans. J Proteome Res 7(4):1650-1659. https://doi.org/10.1021/pr7008252.

[3] Harvey DJ, Merry AH, Royle L, Campbell MP, Dwek RA, Rudd PM (2009) Proposal for a standard system for drawing structural diagrams of $\mathrm{N}$ - and O-linked carbohydrates and related compounds. Proteomics 9(15):3796-3801. https://doi.org/10.1002/pmic.200900096. 


\section{All-Lab Report}

The All-Lab Report summarizes results of all laboratories for the two samples. It consists of:

All-Lab Report

\#Pages

Summary of reported and derived values for Samples A and B, and the A/B ratio

9

Legend for the summary 


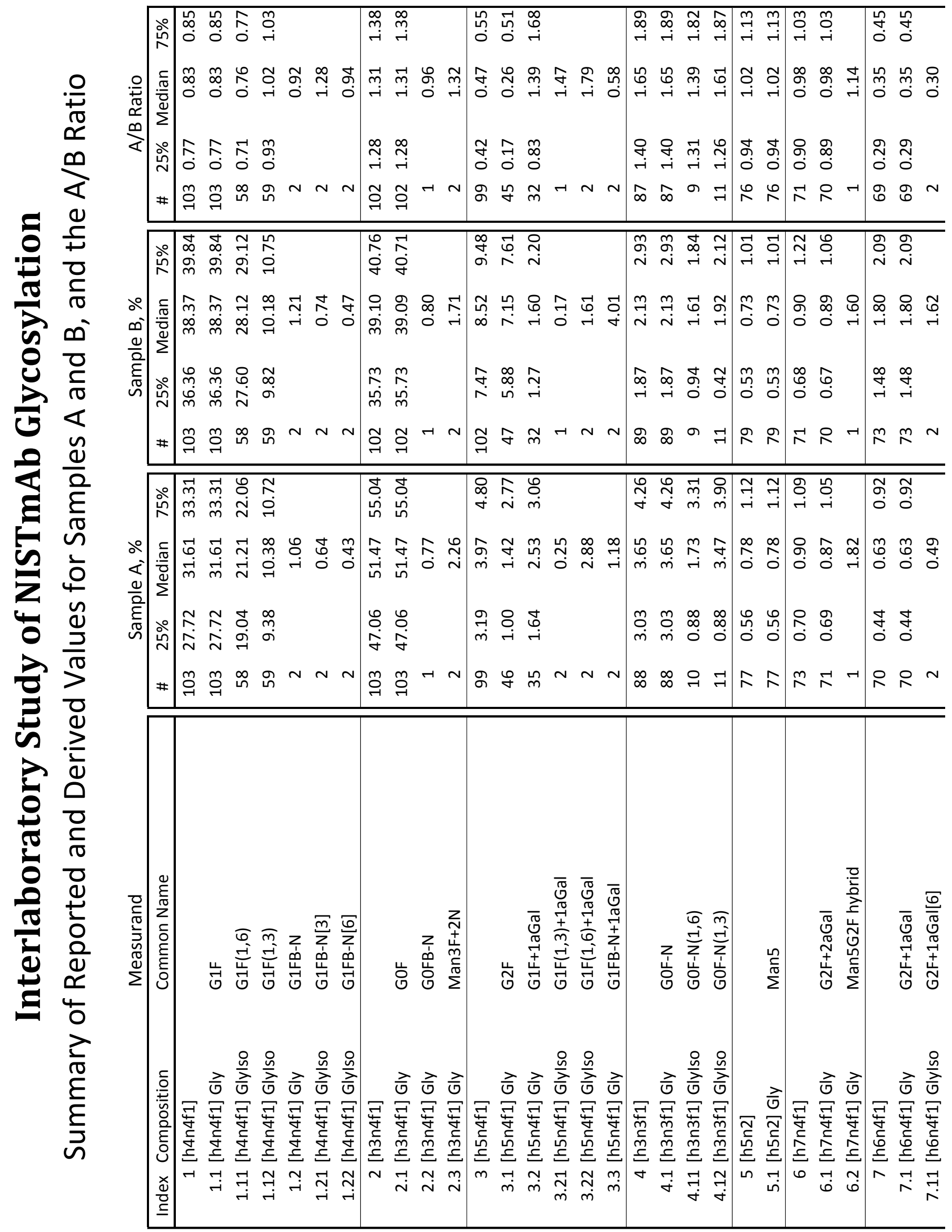




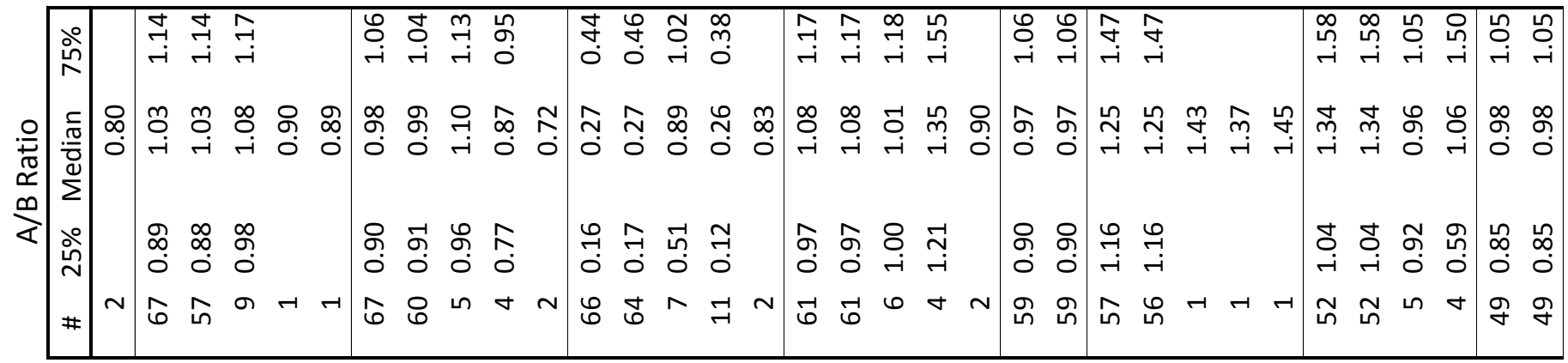

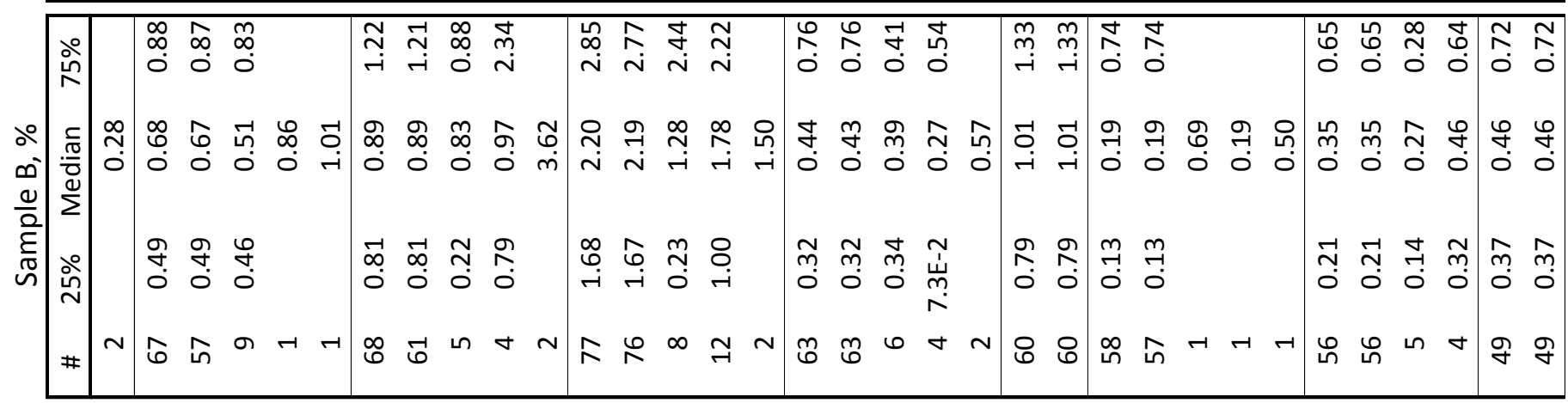

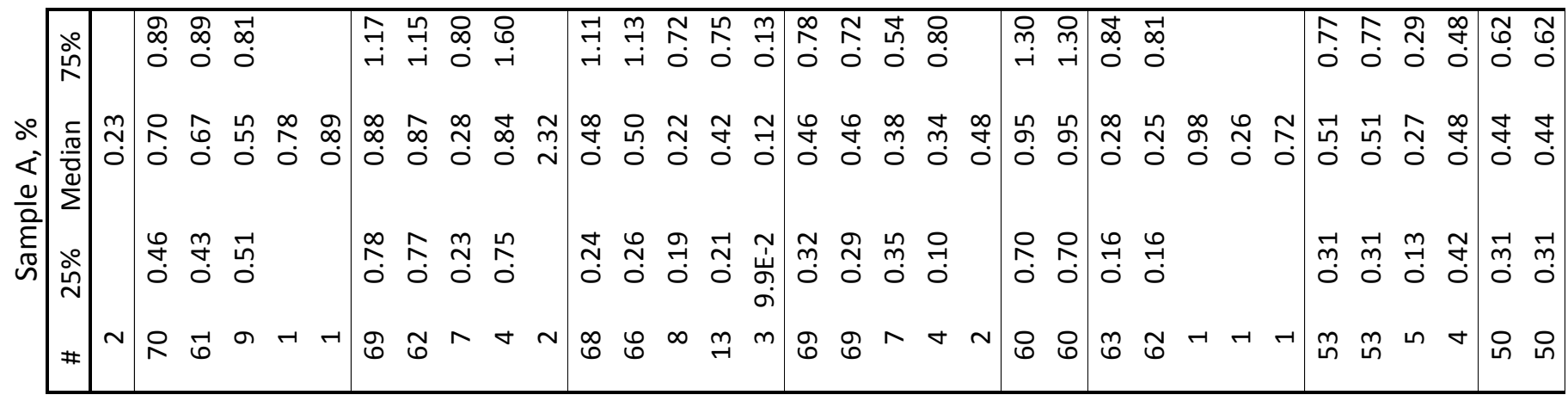

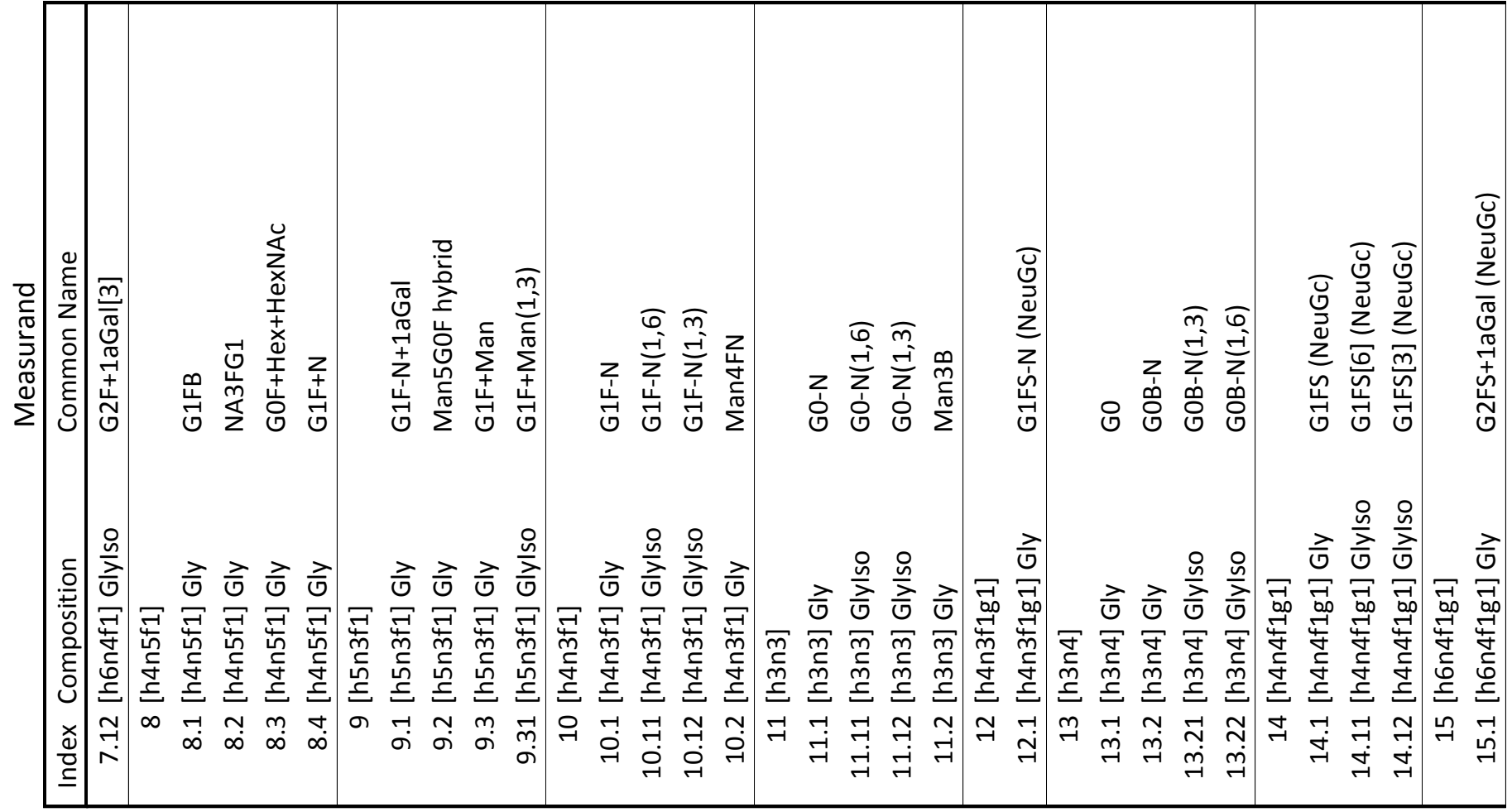




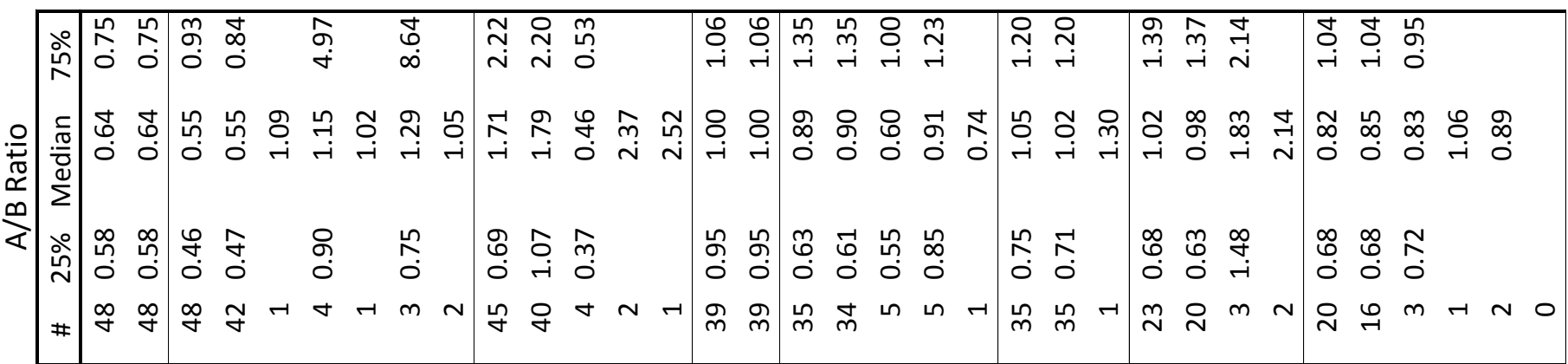

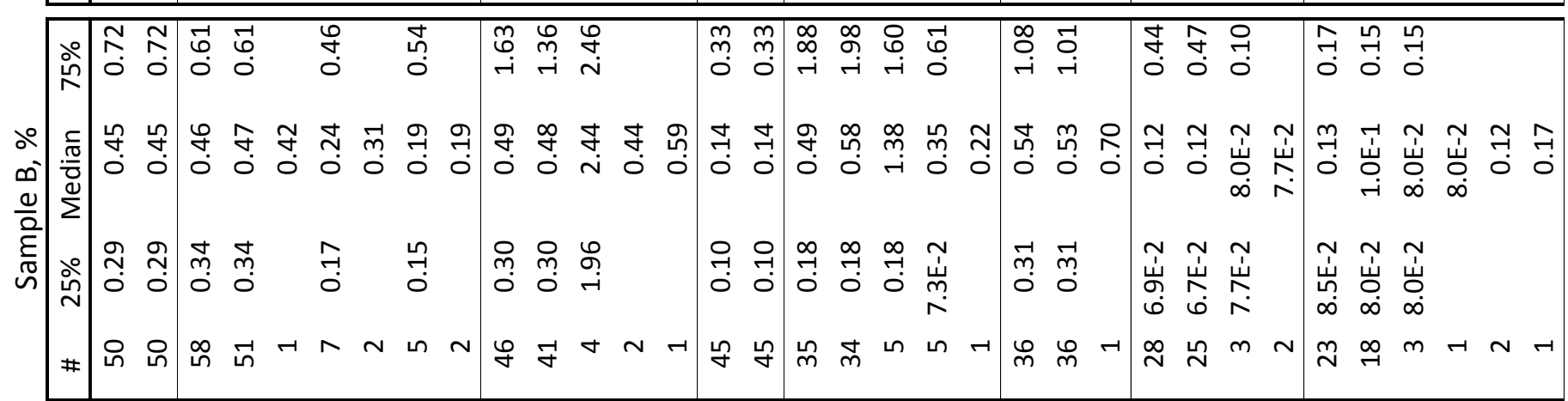

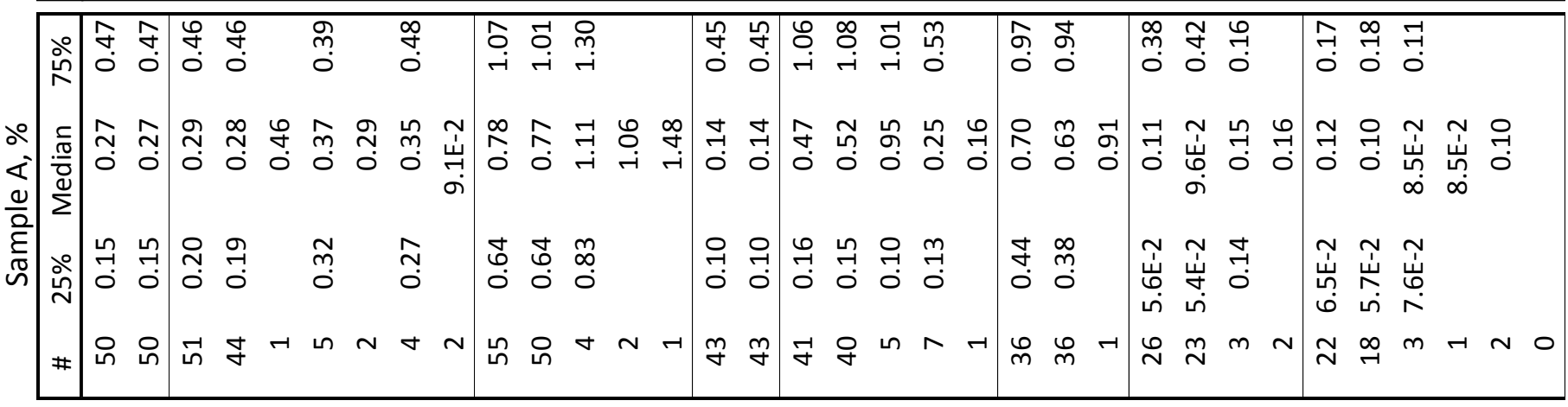

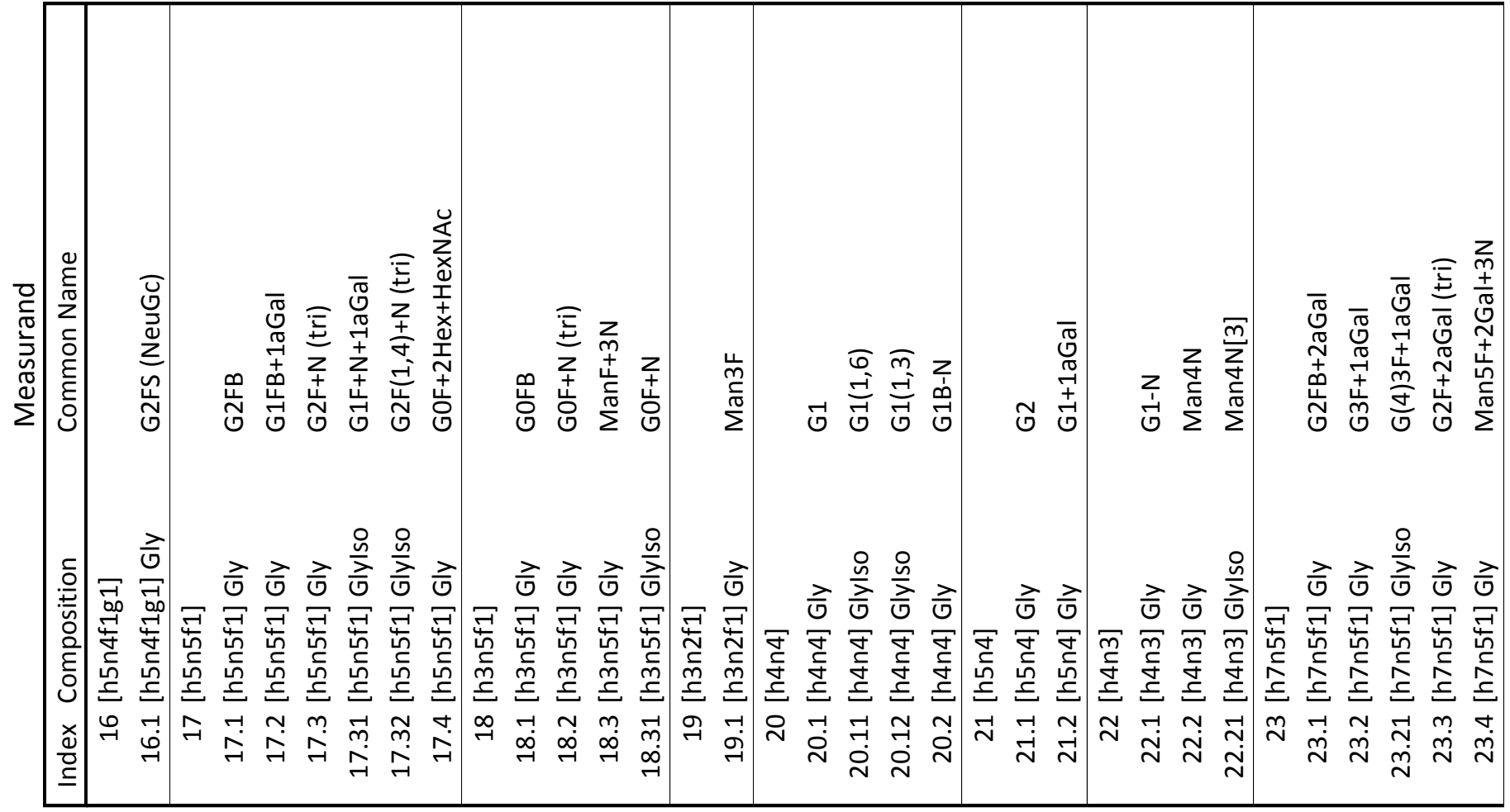




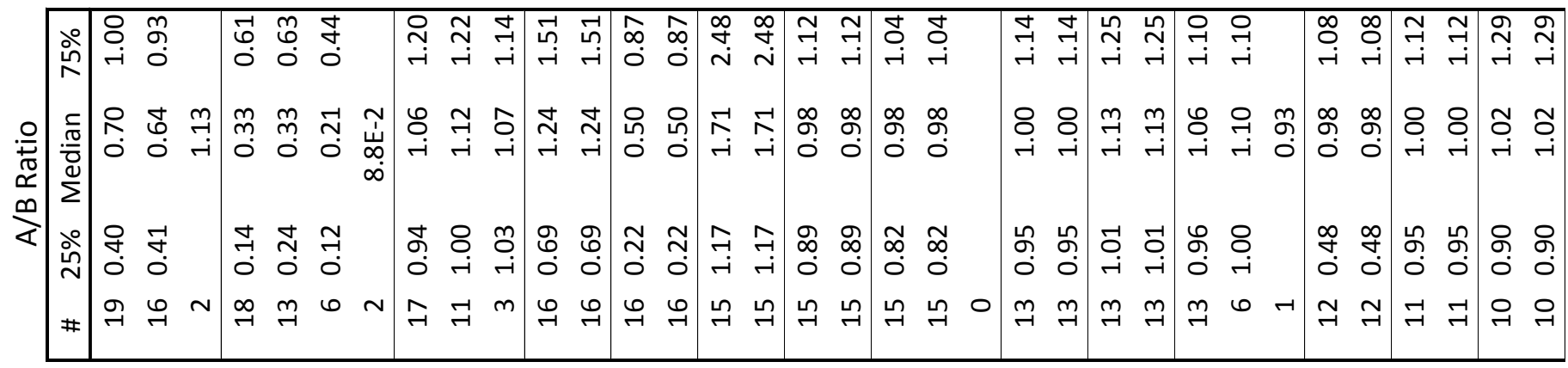

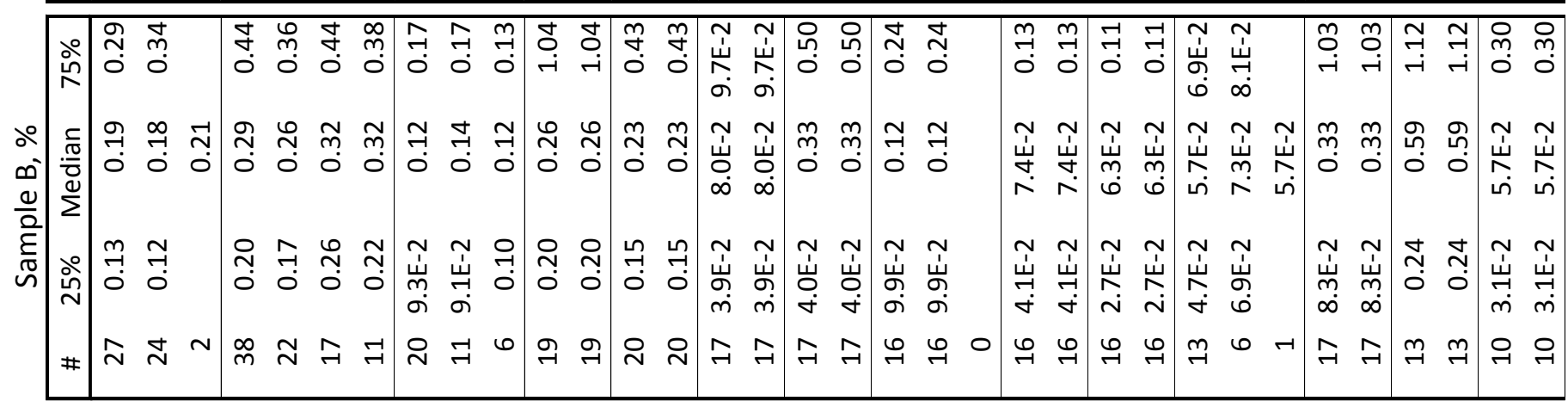

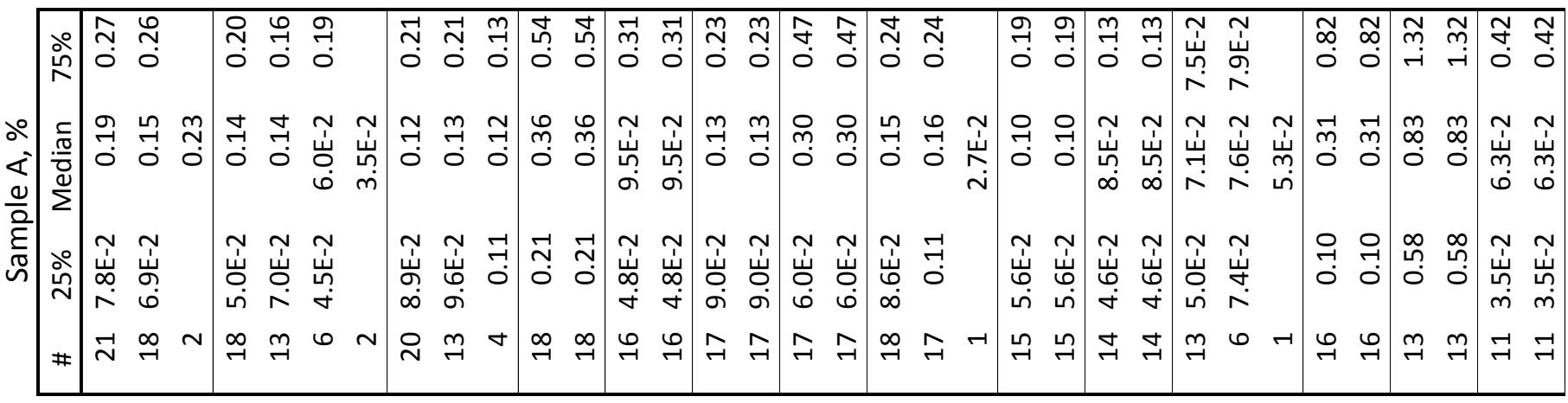

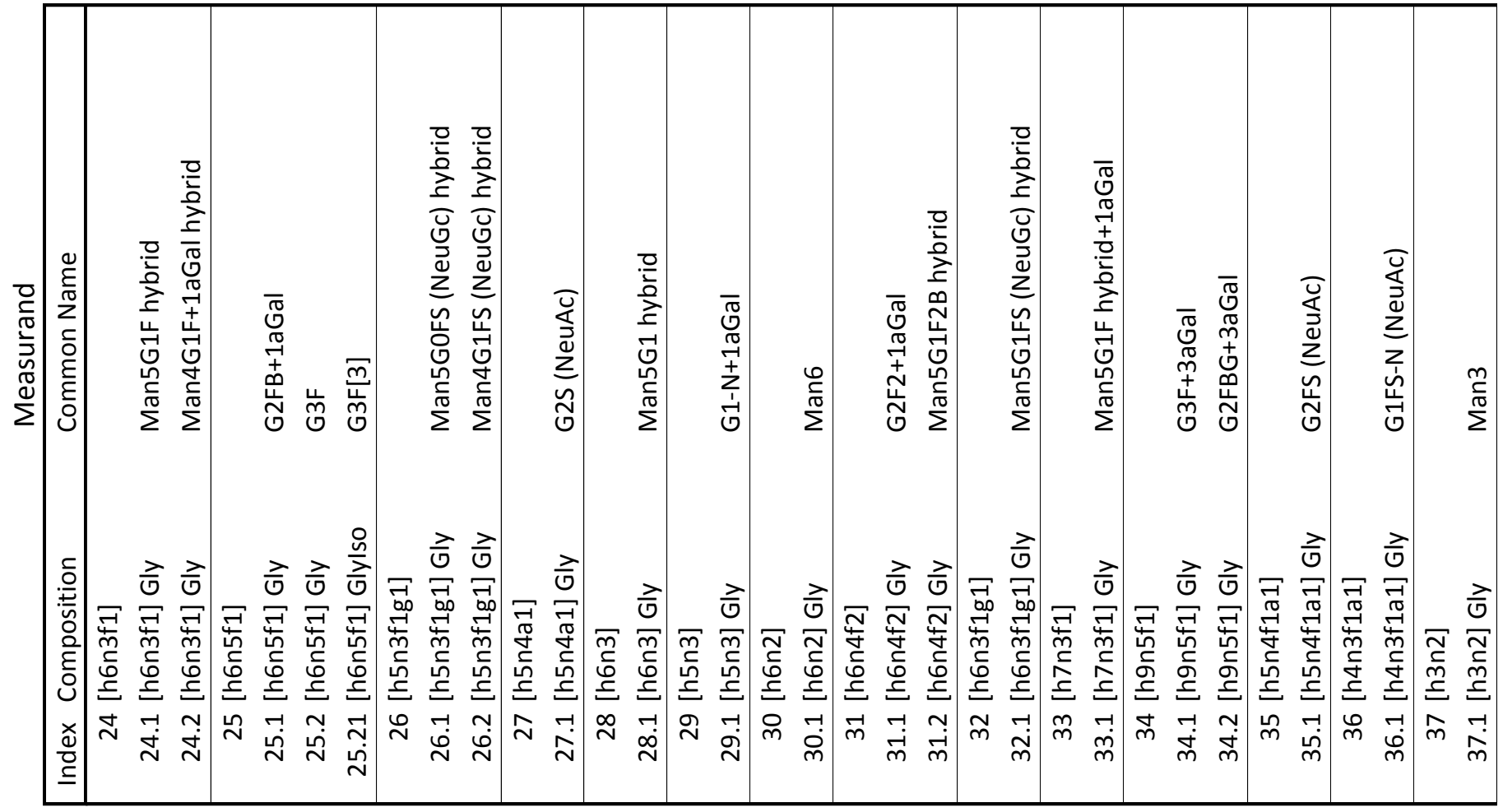




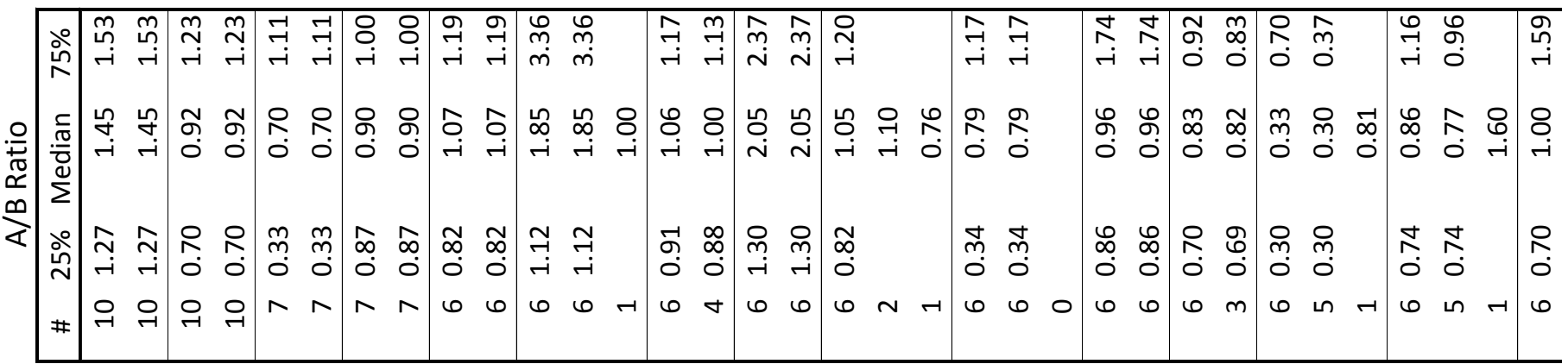

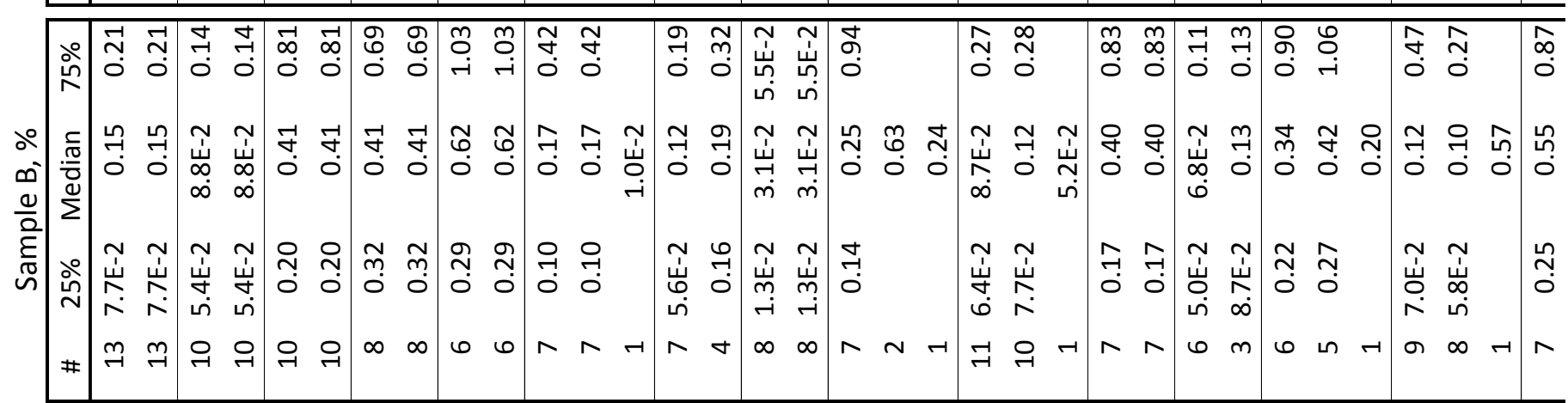

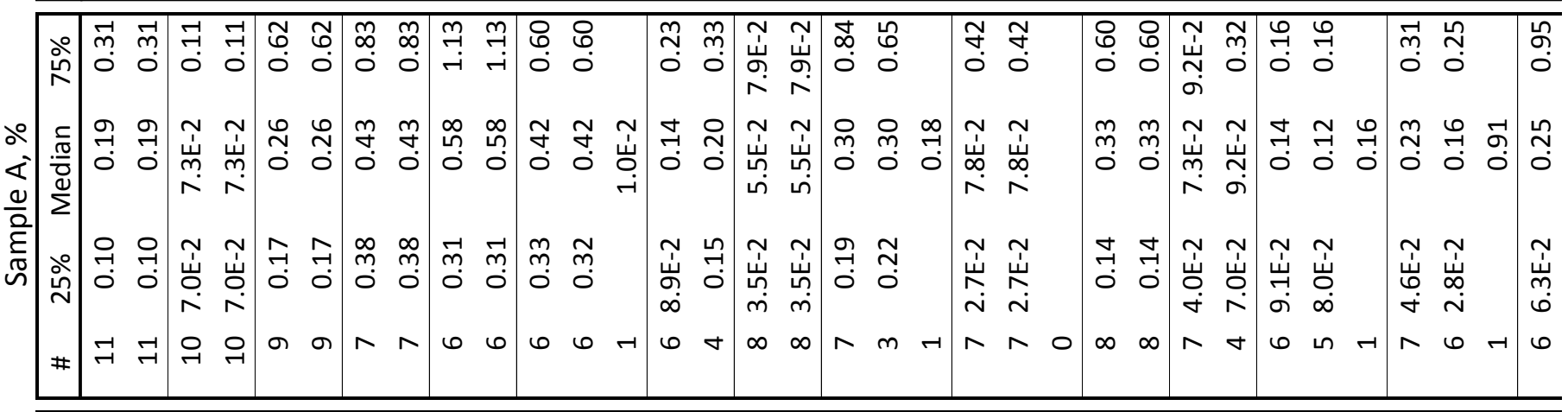

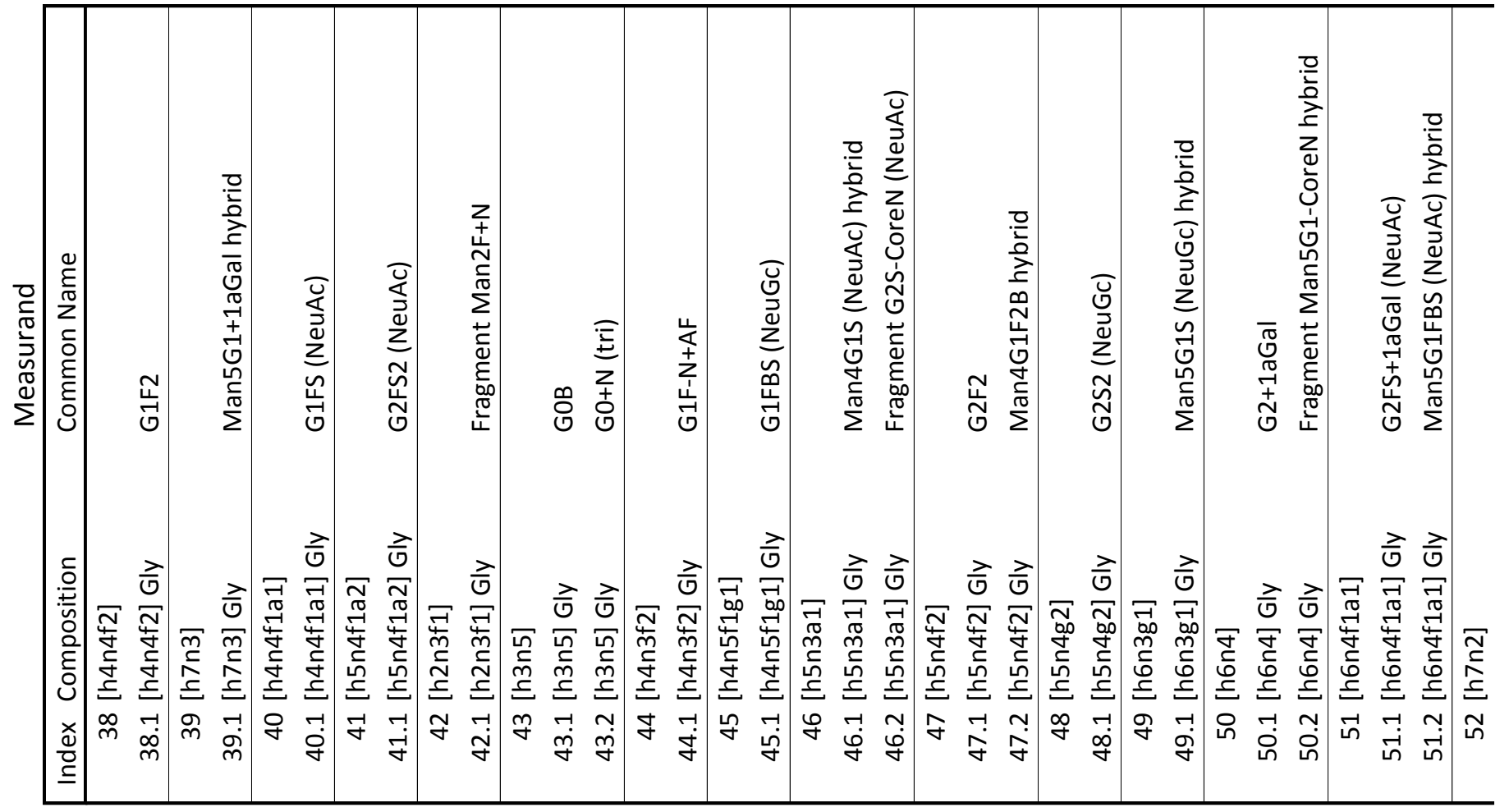




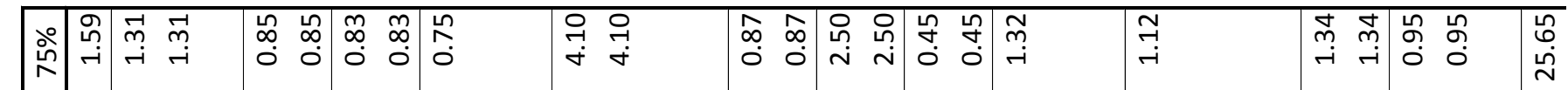

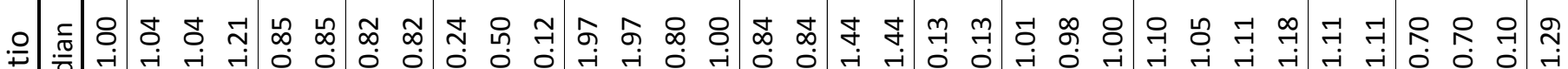

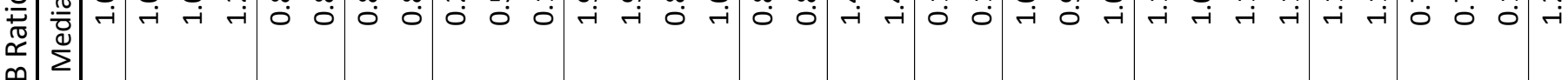

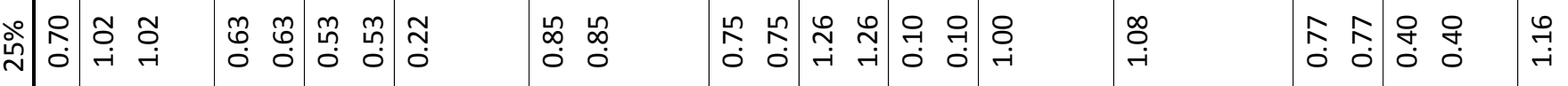

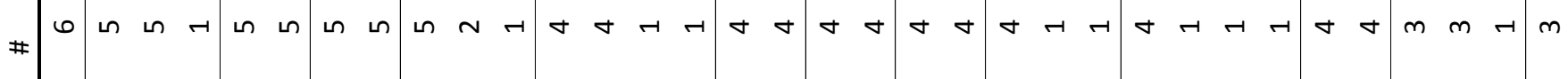

\begin{tabular}{|c|c|c|c|c|c|c|c|c|c|c|c|c|c|c|}
\hline ㅇํㅅ & \begin{tabular}{|l|}
$\infty$ \\
0 \\
0
\end{tabular} & 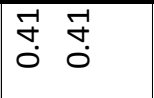 & $\begin{array}{cc}m & m \\
\stackrel{-}{0} & \stackrel{0}{0}\end{array}$ & \begin{tabular}{ll|}
9 & 9 \\
0 & 0 \\
0 & 0
\end{tabular} & 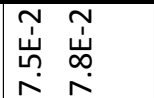 & 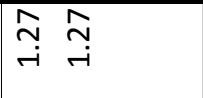 & \begin{tabular}{ll}
\multirow{2}{*}{} & 9 \\
0 & 0 \\
\end{tabular} & \begin{tabular}{ll|}
$\stackrel{\Upsilon}{0}$ & $\stackrel{N}{1}$ \\
0 & 0
\end{tabular} & 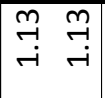 & $\stackrel{\vec{N}}{0}$ & f̊. & $\begin{array}{ll}\text { ㅇํำ } & \text { ํํ } \\
0 & 0\end{array}$ & $\begin{array}{ll}9 & 9 \\
r & 5 \\
r & r\end{array}$ & 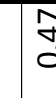 \\
\hline 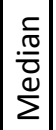 & 占 & 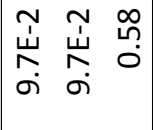 & 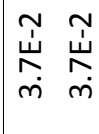 & 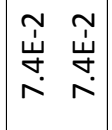 & 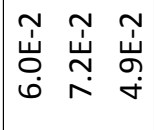 & 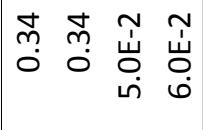 & 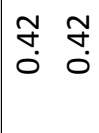 & $\begin{array}{cc}m & m \\
\stackrel{7}{0} & - \\
0 & 0\end{array} \mid$ & $\begin{array}{ll}m & m \\
o & 0 \\
0 & 0\end{array}$ & 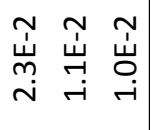 & 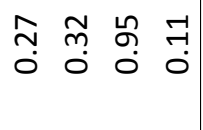 & 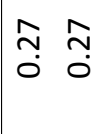 & 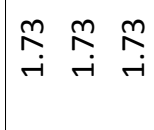 & Si \\
\hline ㅇํํ & $\stackrel{\stackrel{\sim}{n}}{\sim}$ & $\begin{array}{ll}\tilde{u} & \tilde{u} \\
\ddot{m} & \tilde{m} \\
\sigma & \sigma\end{array}$ & $\begin{array}{ll}\stackrel{N}{u} & \stackrel{\sim}{山} \\
m & m \\
m & m\end{array}$ & 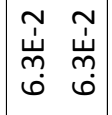 & 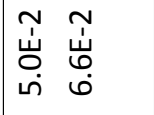 & 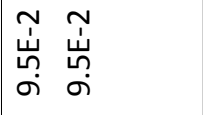 & $\begin{array}{ll}\stackrel{N}{\sim} & \stackrel{\sim}{u} \\
\infty & \infty \\
i & \stackrel{\sim}{N}\end{array}$ & $\begin{array}{cc}m & m \\
\stackrel{7}{0} & \stackrel{1}{0}\end{array}$ & \begin{tabular}{ll}
$N$ & \multirow{0}{0}{} \\
0 & 0
\end{tabular} & 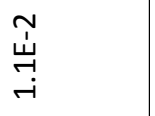 & ণ্ & $\begin{array}{cc}m & m \\
\stackrel{7}{0} & \stackrel{0}{0}\end{array}$ & 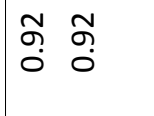 & \\
\hline$\#$ & $r$ & $\wedge \wedge \rightarrow$ & in $\ln$ & in $\ln$ & $a+N$ & $\nabla \triangleleft r-1$ & in $n$ & Ln $\ln$ & $\sigma \quad \sigma$ & $\begin{array}{lll}\sigma & -1 & -1\end{array}$ & $\begin{array}{llll}\nabla & -1 & -1 & -1\end{array}$ & $\theta \quad \theta$ & $m \quad m-1$ & -1 \\
\hline
\end{tabular}

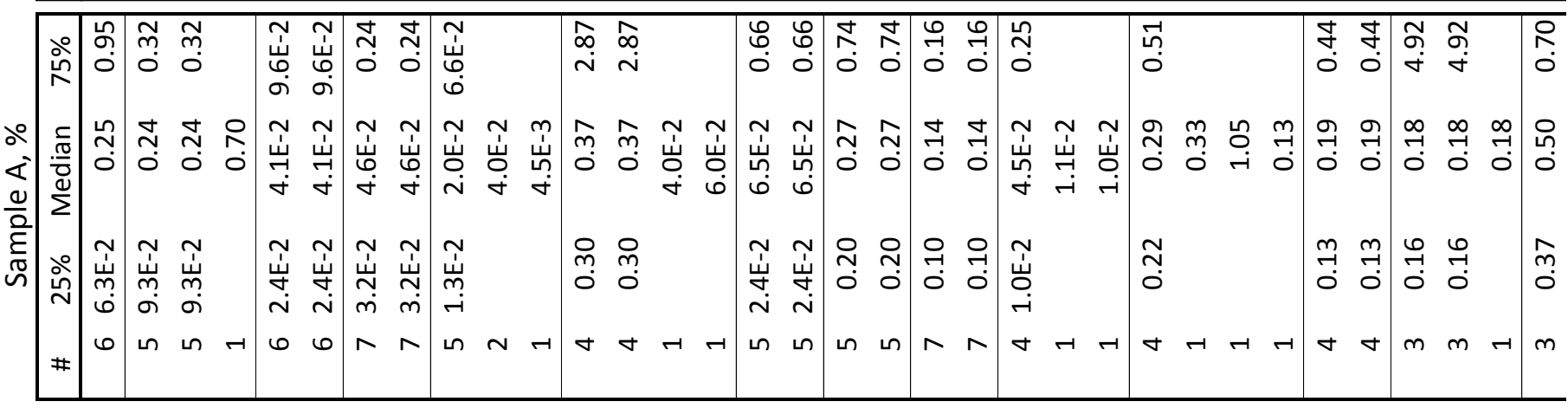

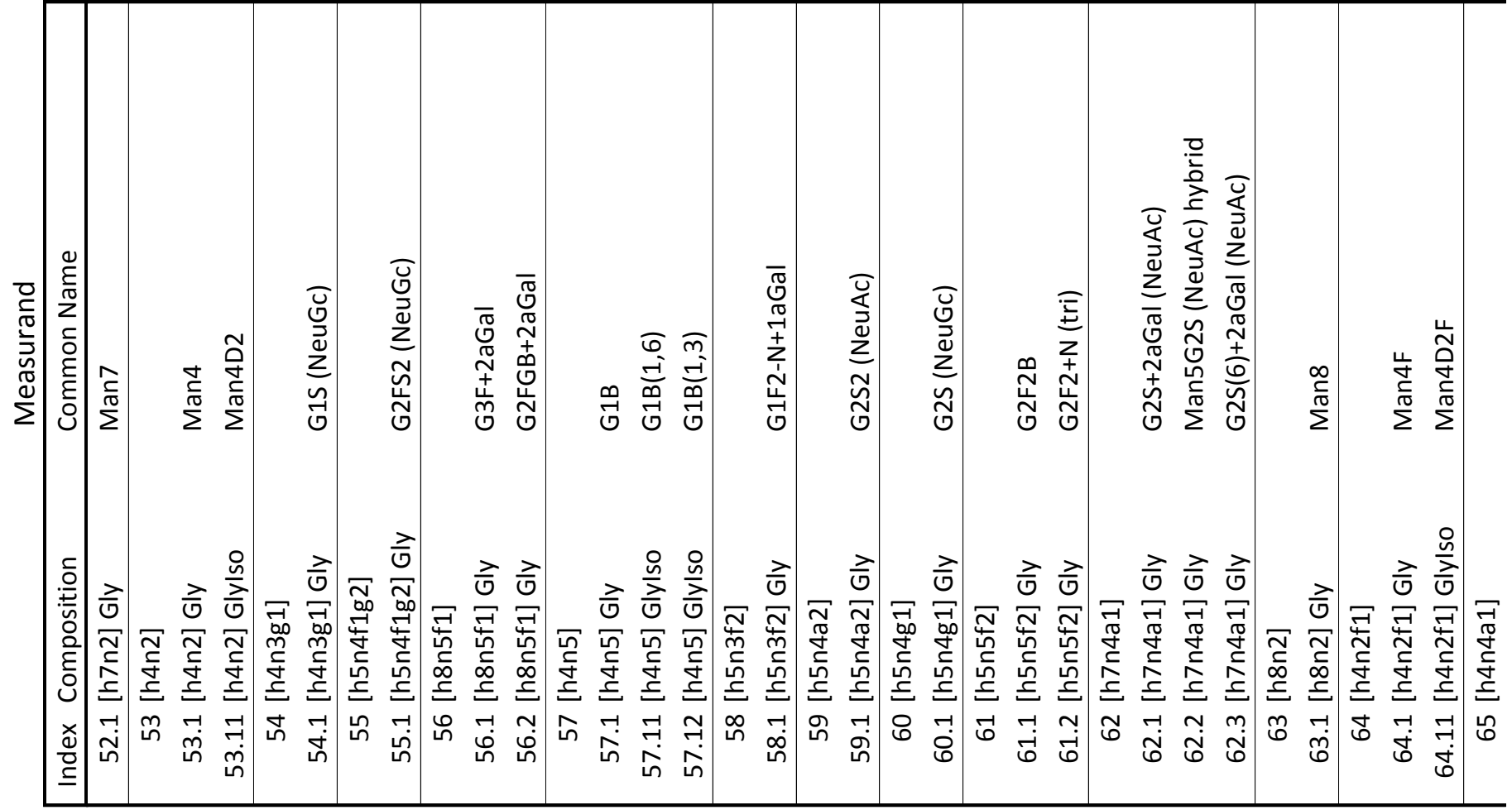




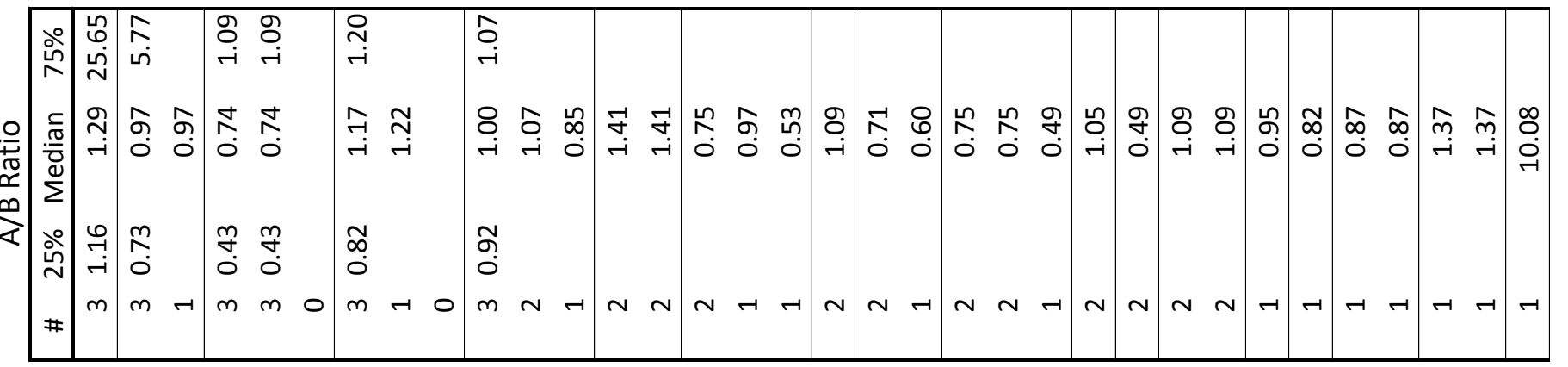

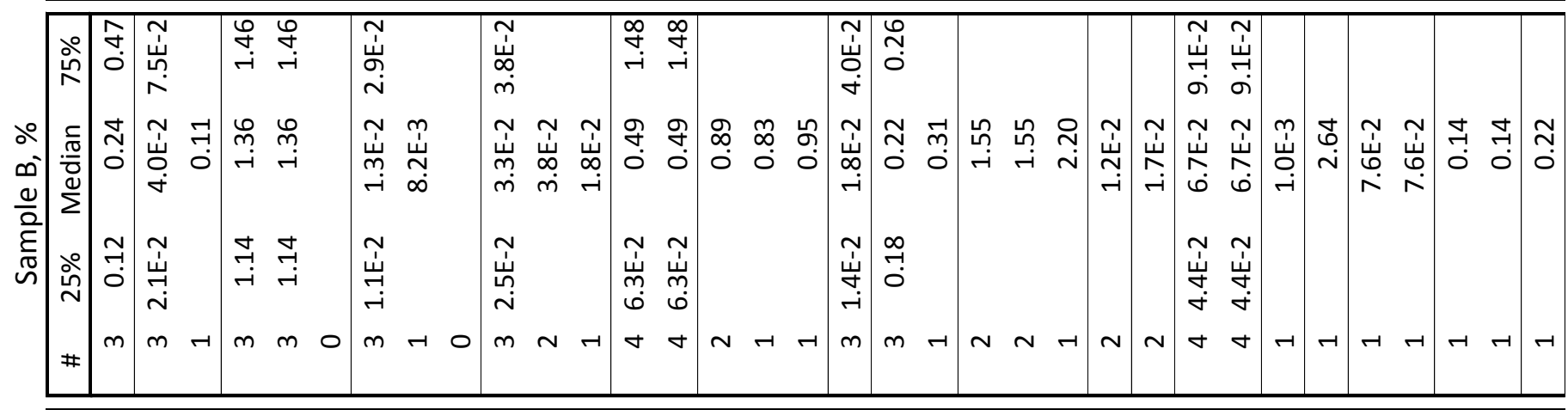

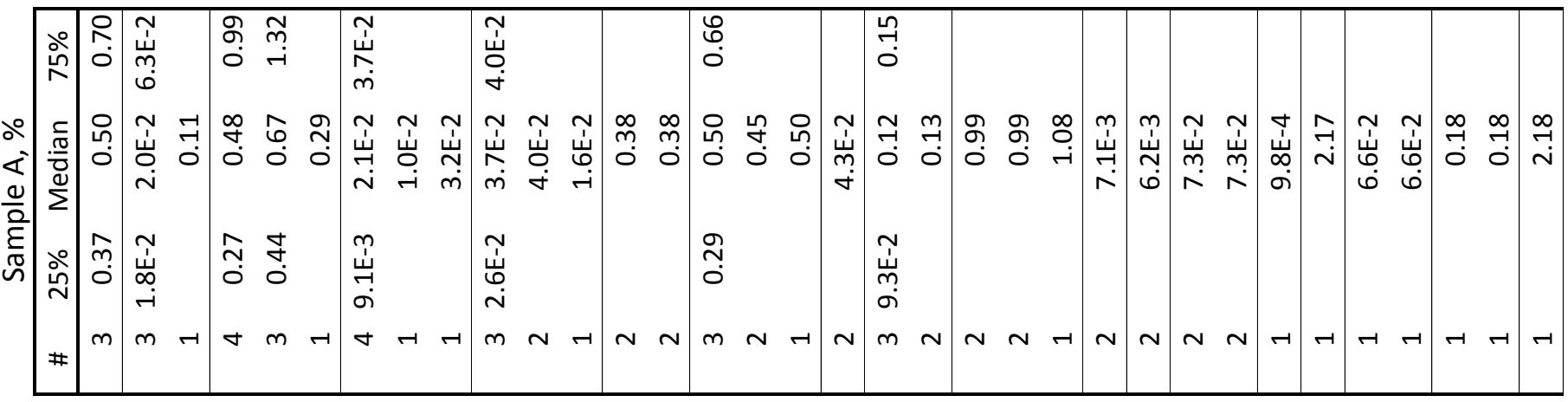

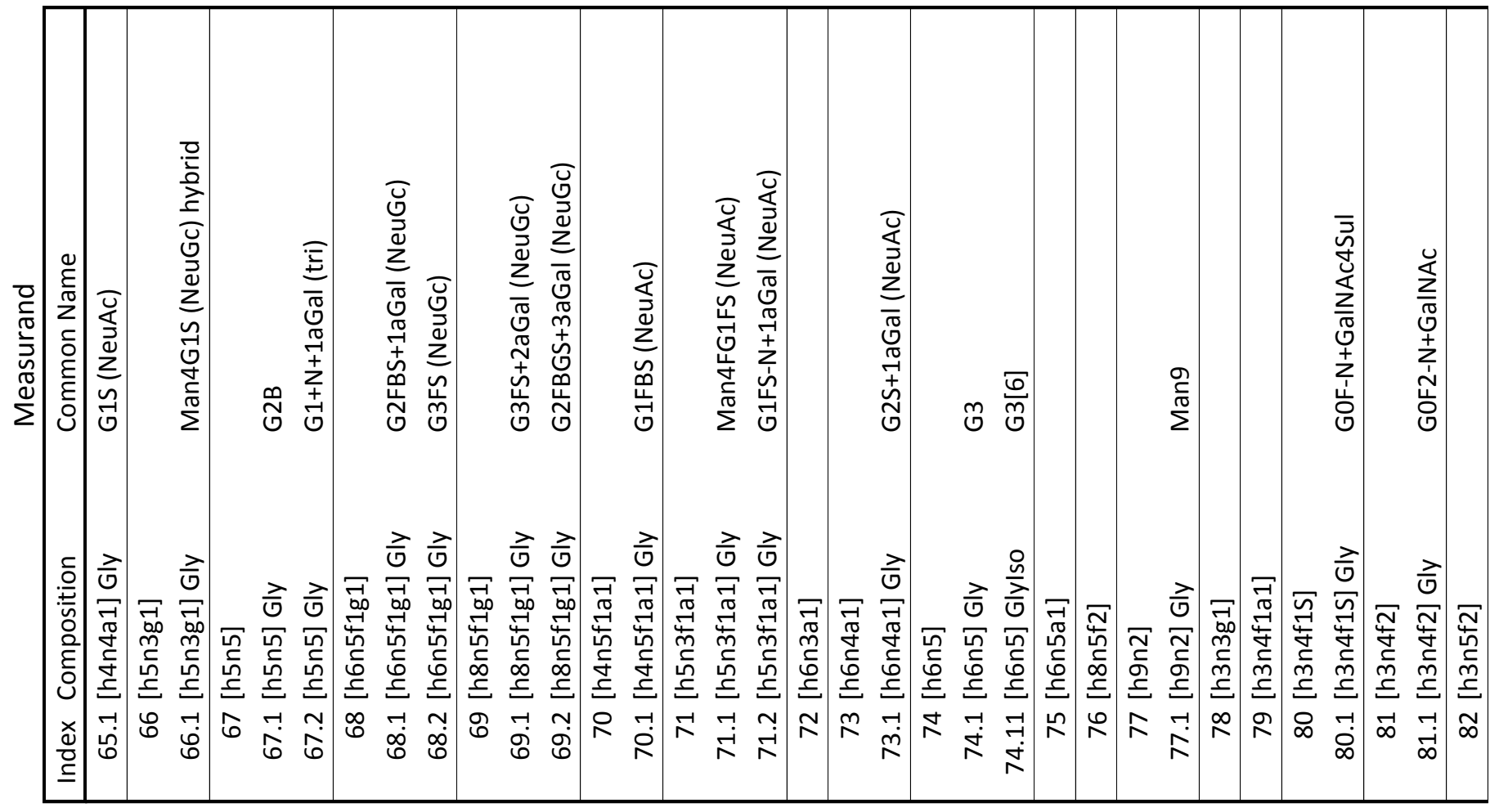



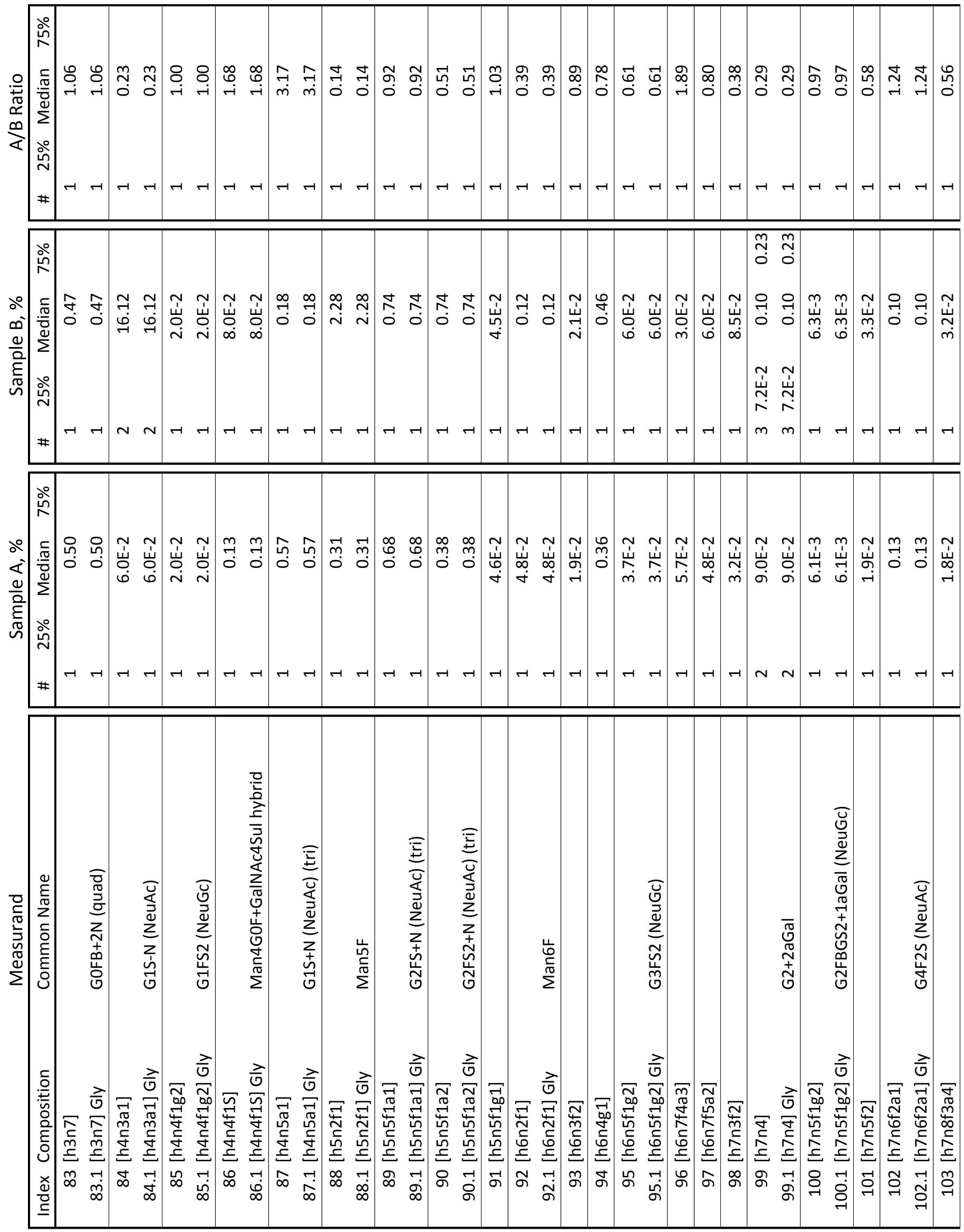

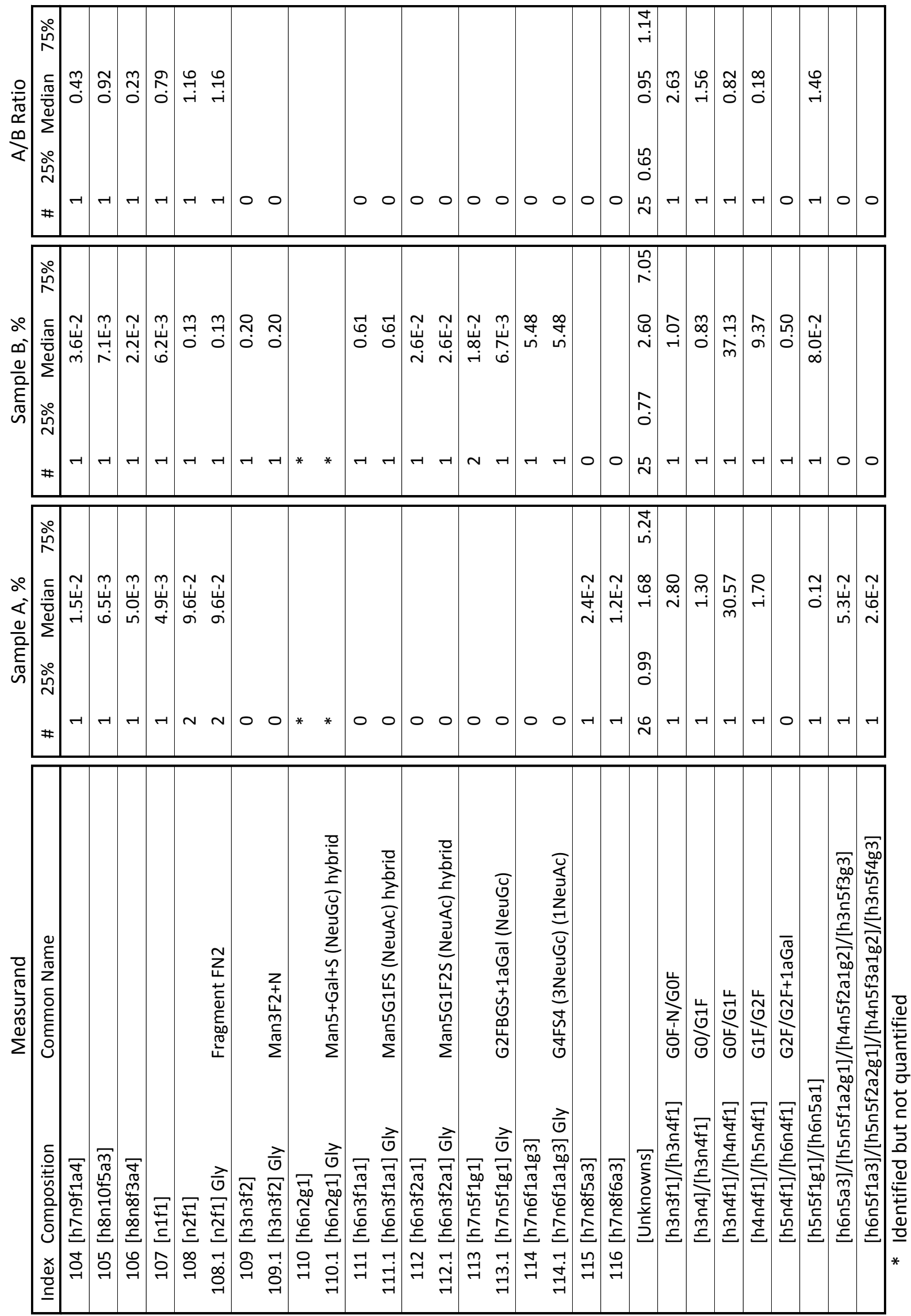


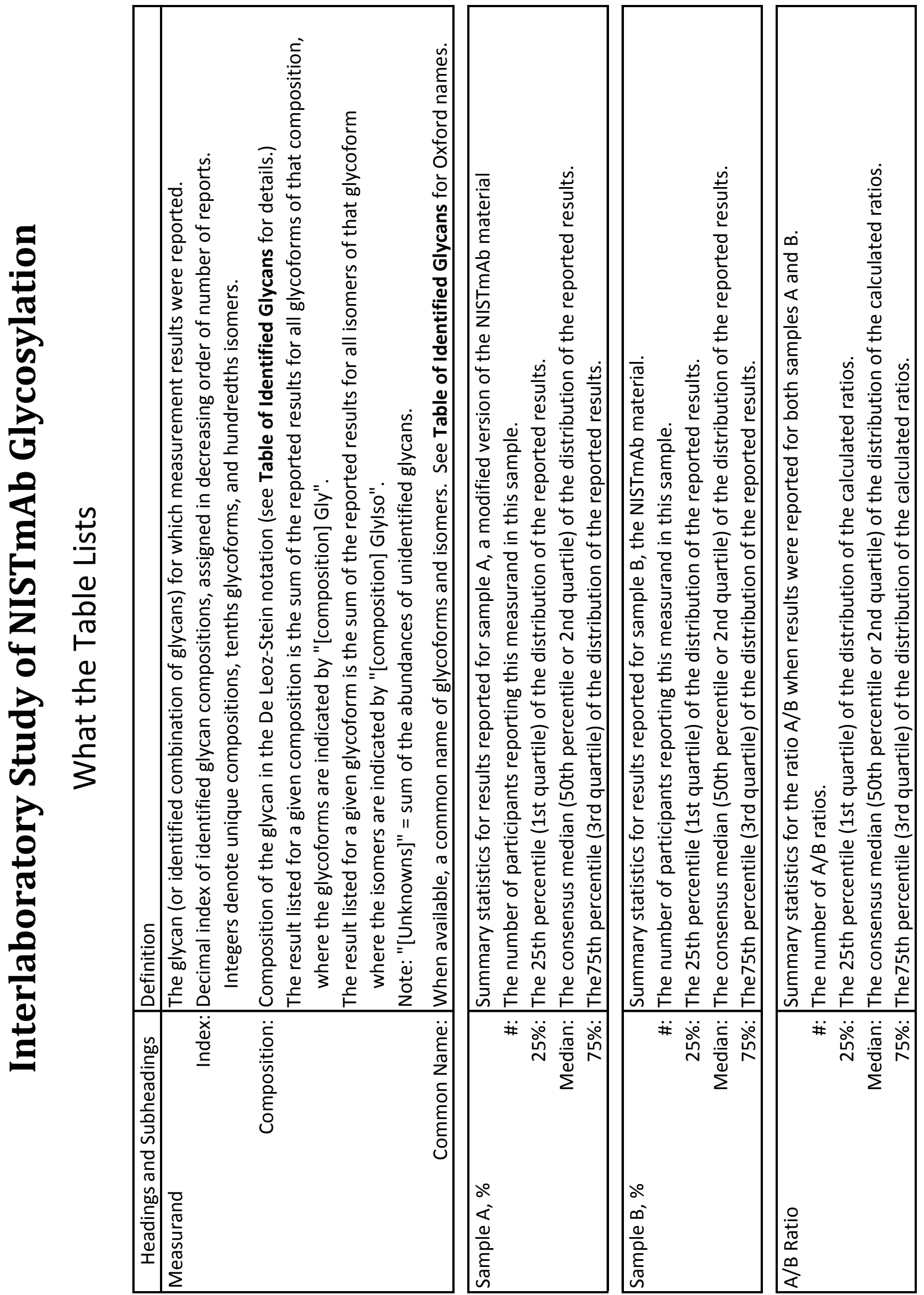




\section{Representative "Individualized Report"}

The Individualized Report contains graphical analyses of the glycan composition results:

\begin{tabular}{lc}
\hline Individualized Report & \#Pages \\
\hline Boxplots of Samples A and B, and the A/B ratio, and targetplot for the A/B ratio & 1 \\
Legend for the boxplots and targetplot & 1 \\
Plots summarizing measurement performance, including glycan composition & 1 \\
counts and sums, repeatability, limits of reporting, minimum reported values, and & \\
consensus & 1 \\
Legend for measurement performance plots & Variable \\
Table of measurement summary & 1 \\
Legend for table of measurement summary & 1 \\
Table of derived glycan attribute quantities & 1 \\
Legend for table of derived glycan attribute quantities & \\
\hline
\end{tabular}




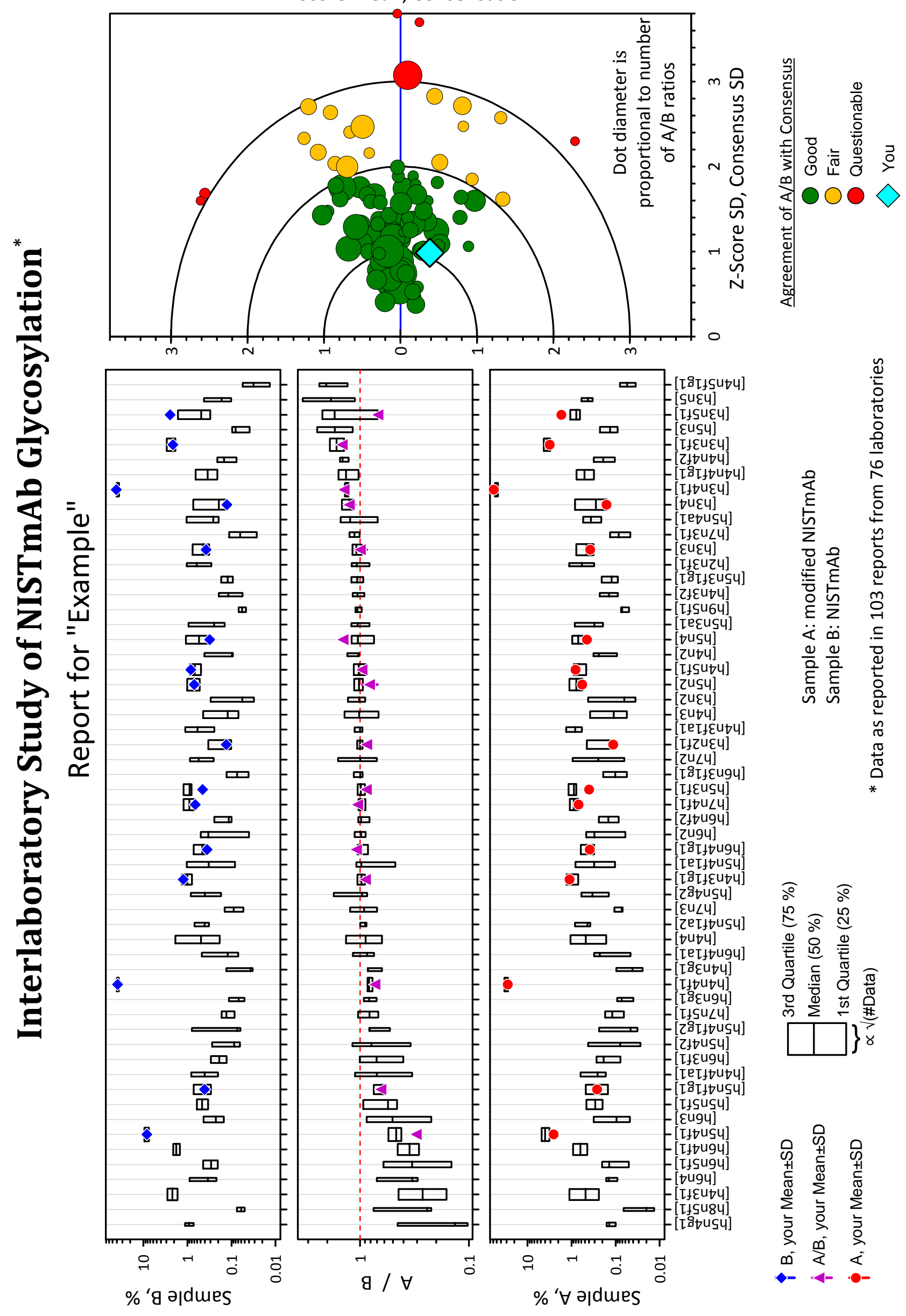


The dots are color-coded by distance from the $\{0,0\}$ origin: dots within two comparability units are colored green, between two and three units are colored yellow, and greater than three units are colored red. These codes roughly indicate "Good", "Moderate", and "Questionable" agreement with the consensus $A / B$ ratio estimates. However, the large differences in the numbers of glycans in the various sets of results renders these distinctions themselves "Questionable."

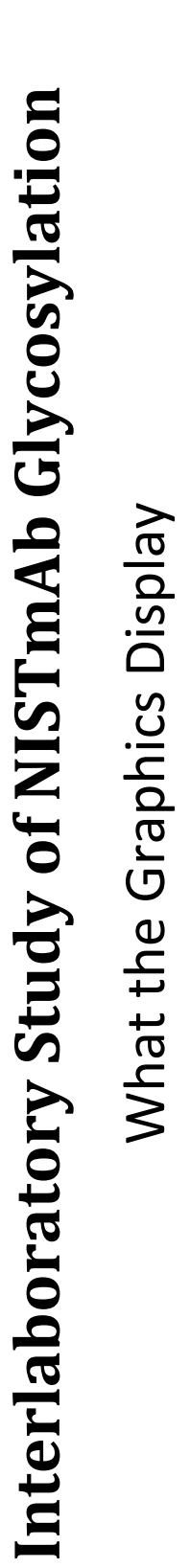

\section{Z-score Mean, Consensus SD}

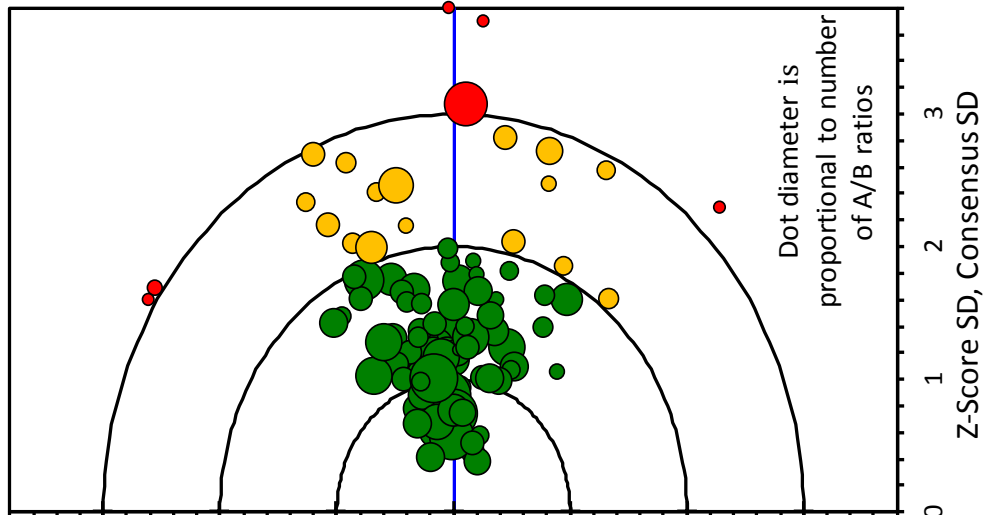

它

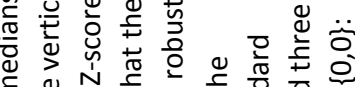

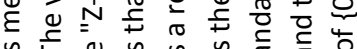

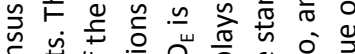

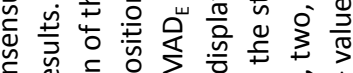

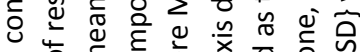

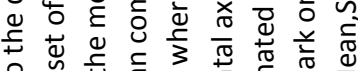

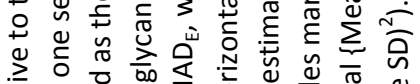

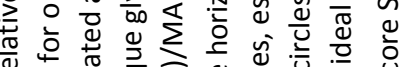

ब

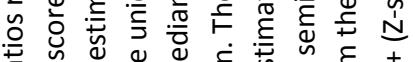

๘

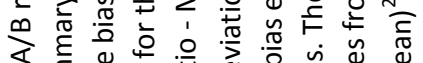

Ч

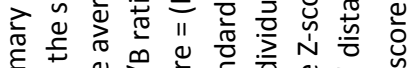

है

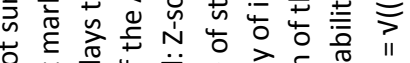

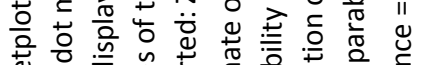

ळ

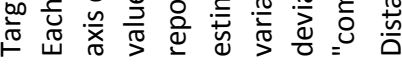

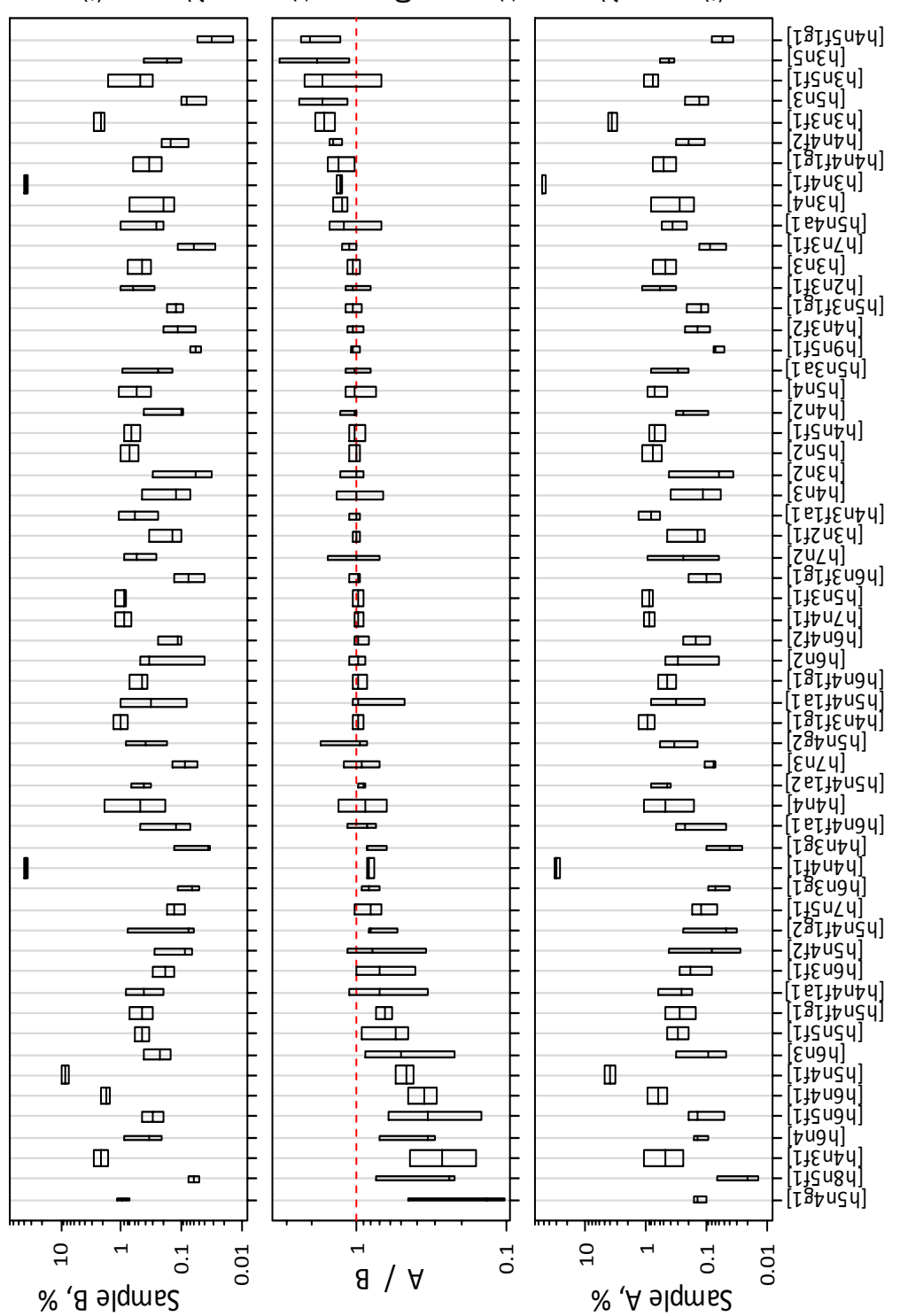

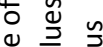

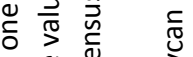

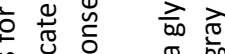

告 0

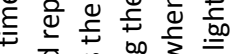

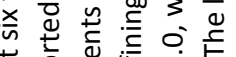

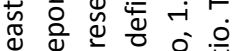

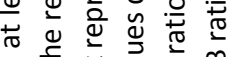

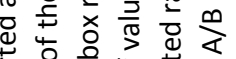

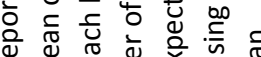

ब

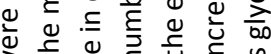

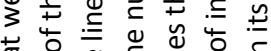

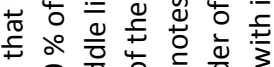

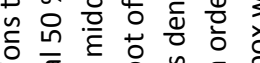

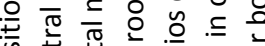

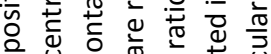

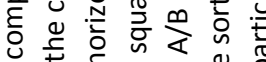

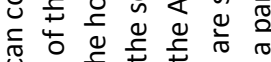

บ다유

का

告

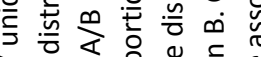

ก \&

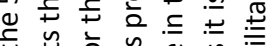

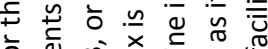

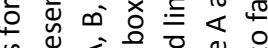

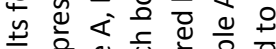

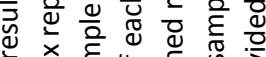

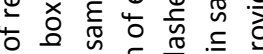

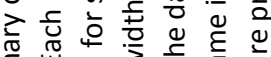

山ै।

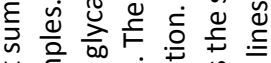

는

员 

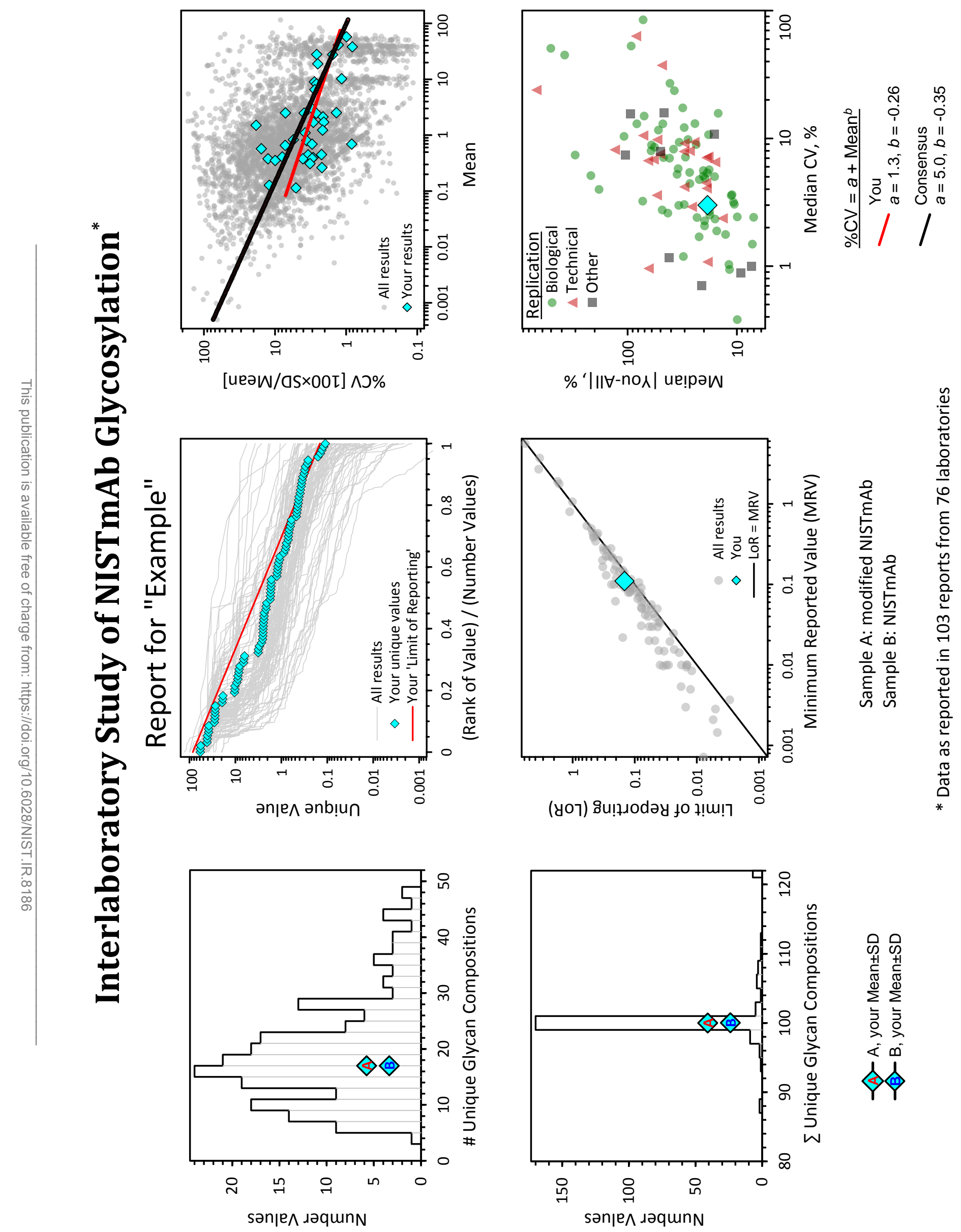

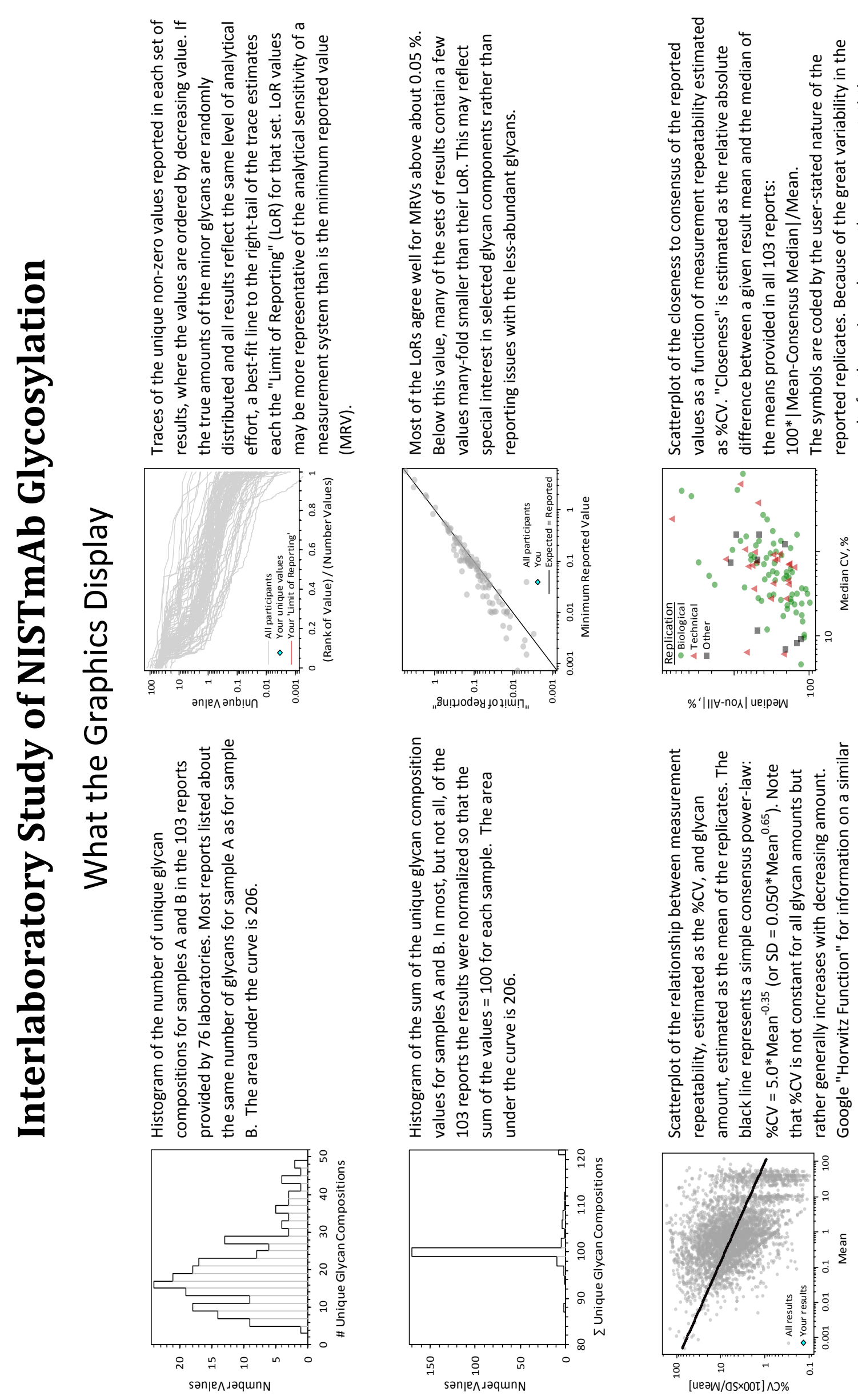

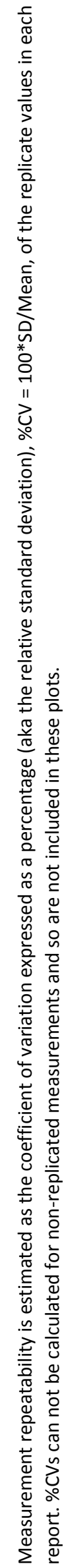

B-37 


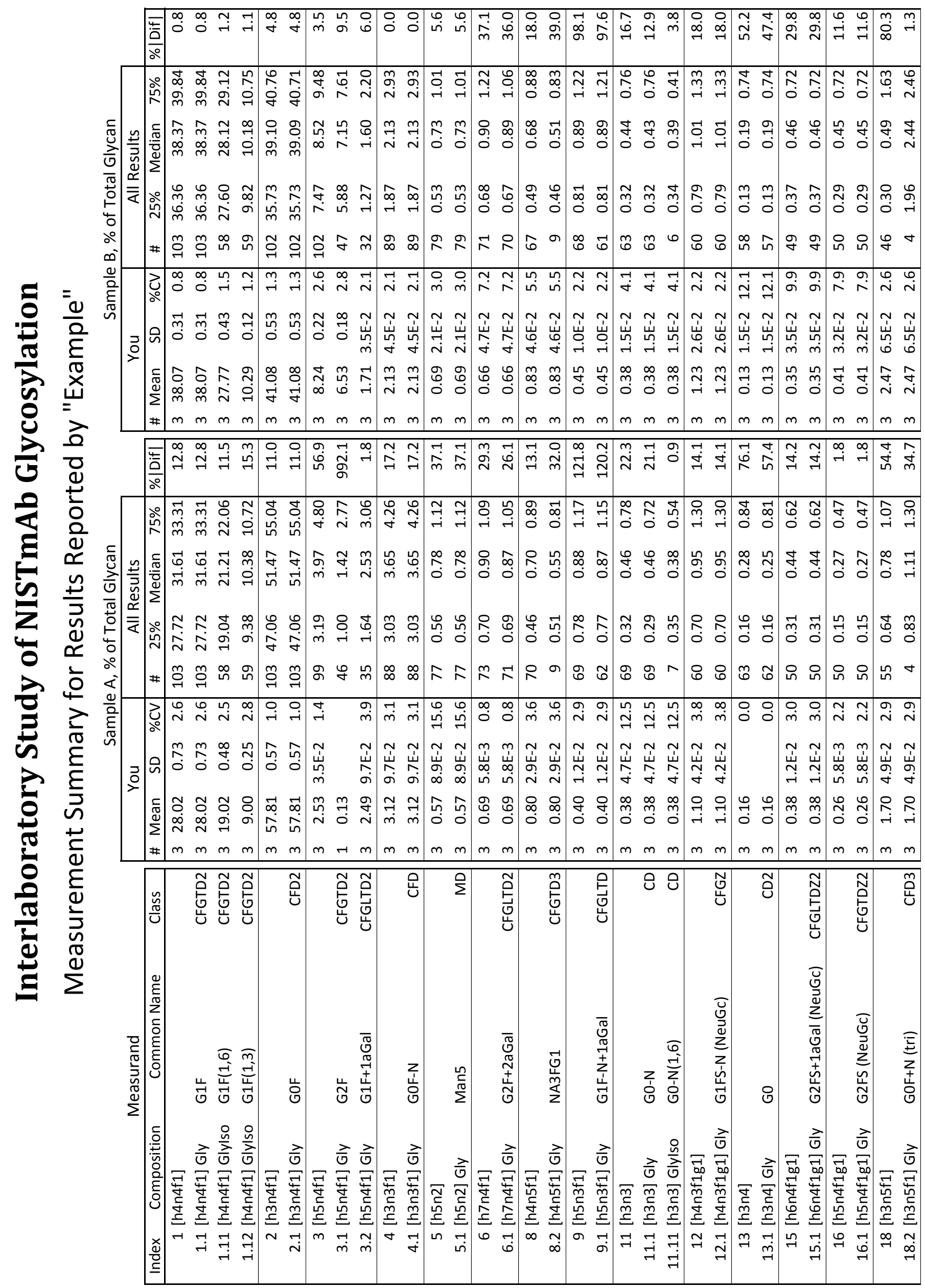



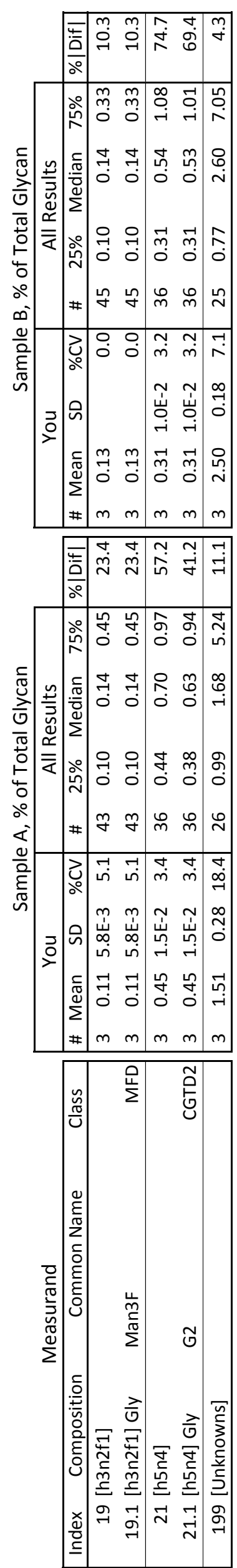


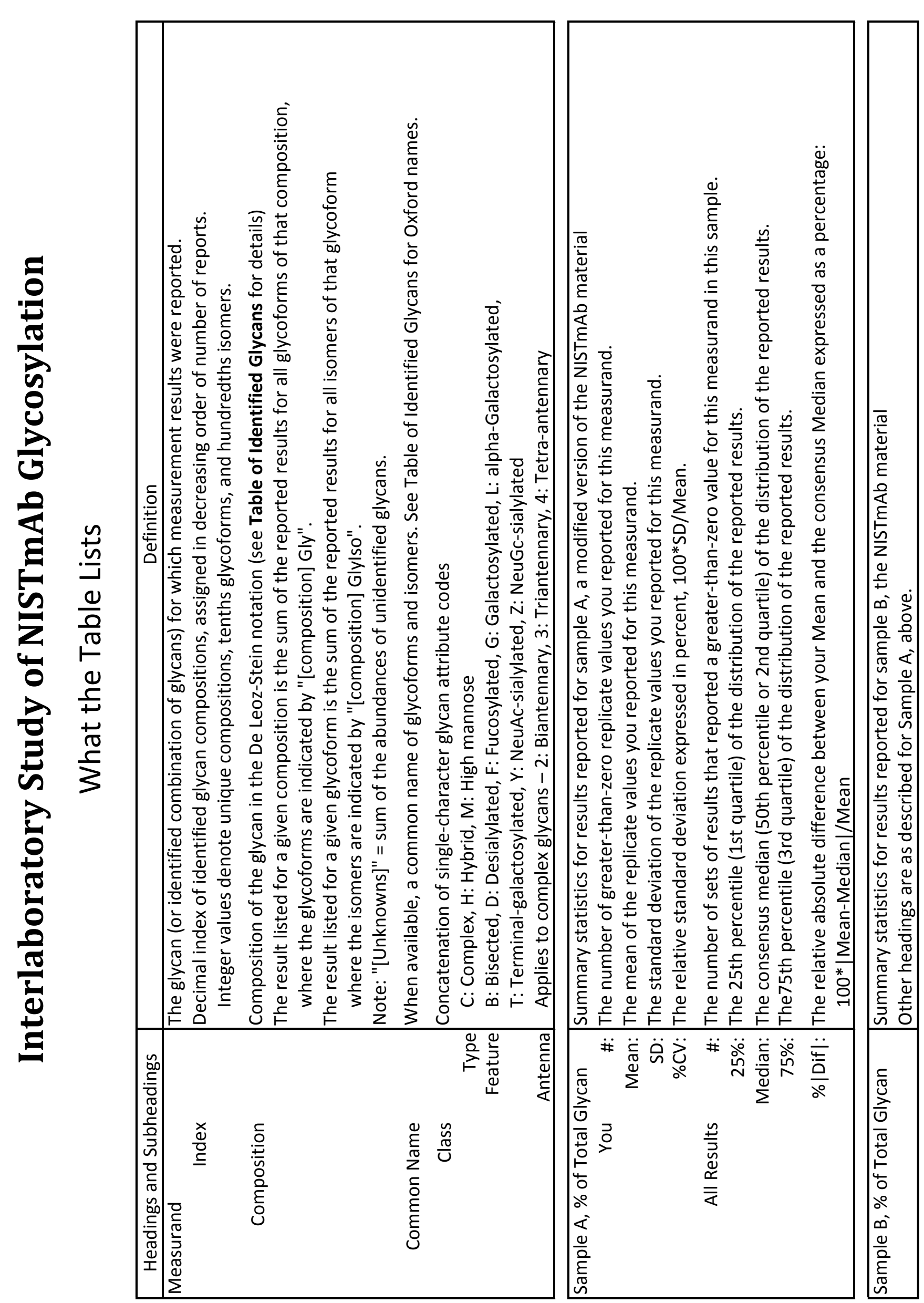




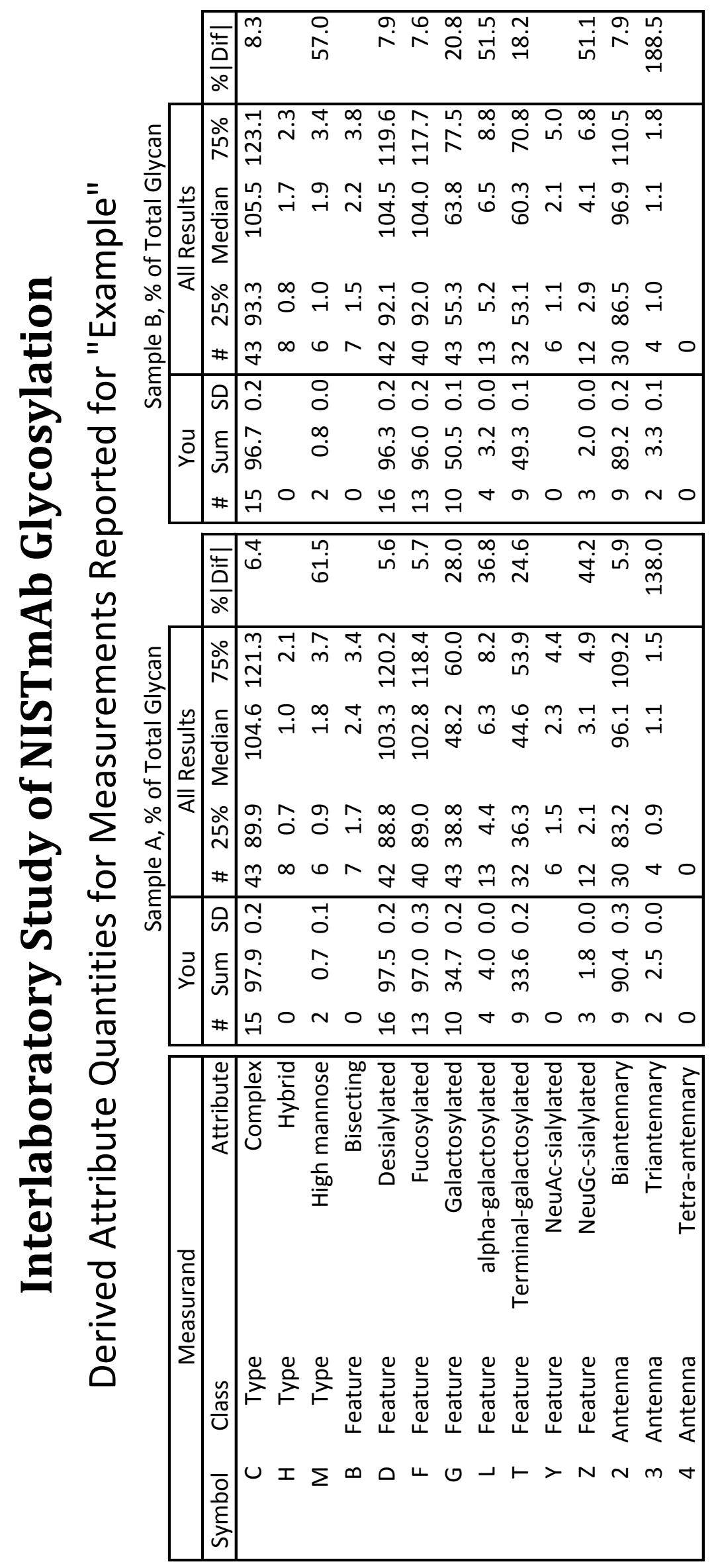



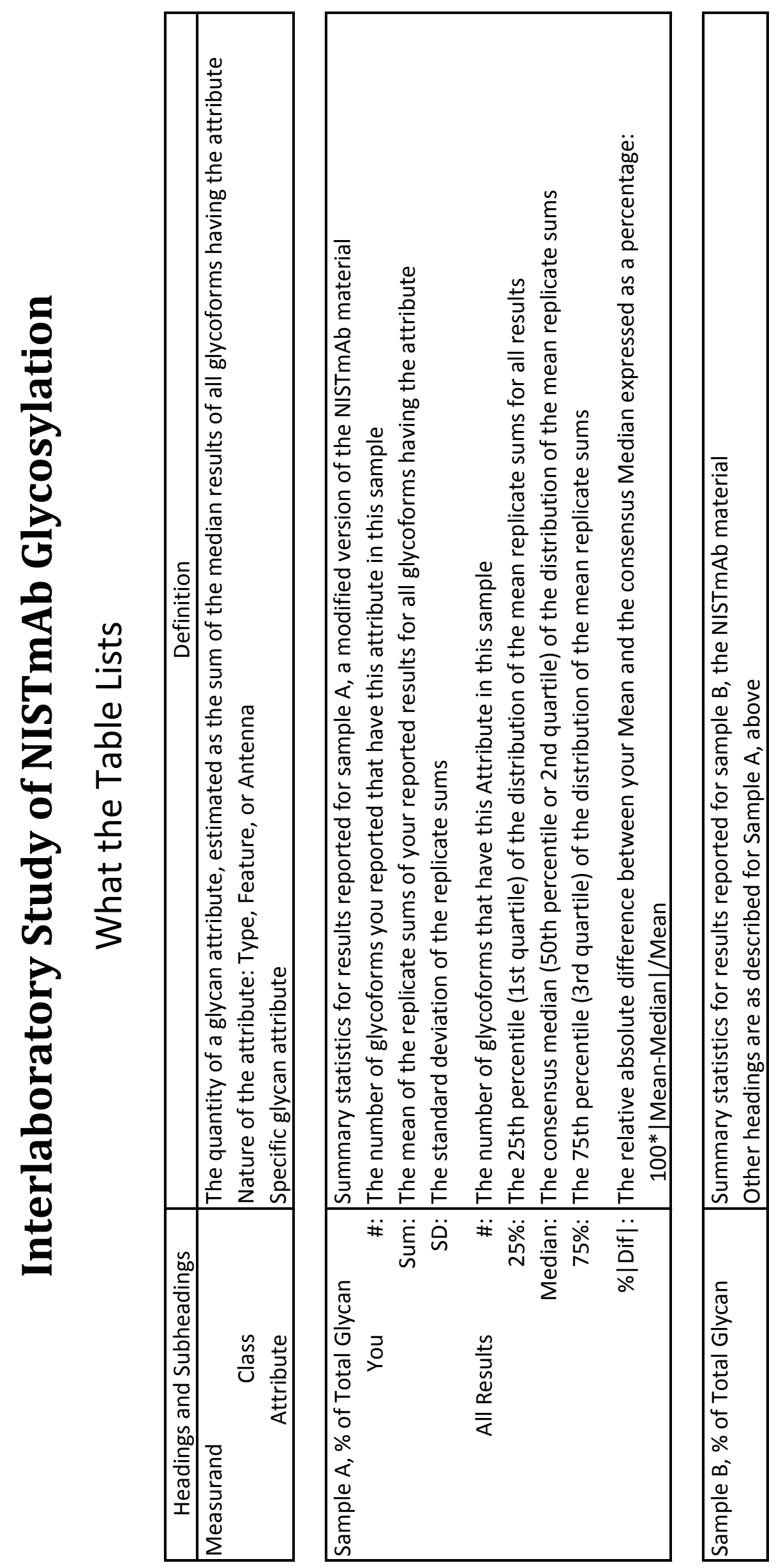